UCRL -53267

DE82 015657

\title{
HOTIGE
}

PQRTIARS OF THSS BEPBRT ARE ULLEIBLE.

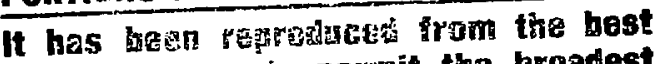
available cony to perinit the broadest possible availatility.

\section{On Geotechnical Studies Relevant to the Containment of Underground Nuclear Explosions at the Nevada Test Site}

\author{
Francois E. Heuze
}

Manuscript date: May 1982

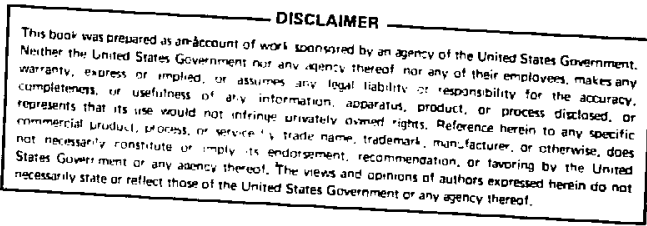

LAWRENCE LIVERMORE LABORATORY University of California $\bullet$ Livermore, California 994550 
Abstract

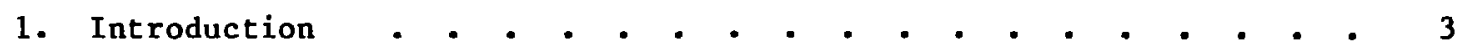

2. Current Geotechnical Practice for Containment Evaluation . . . 6

2.1. Physical Properties • • . • - • • • • • • • • . 6

2.2. Mechanical Properties . . . . . . • . . . . . . 9

2.3. Computer-Based Containment Calculations . - • • • . . 11

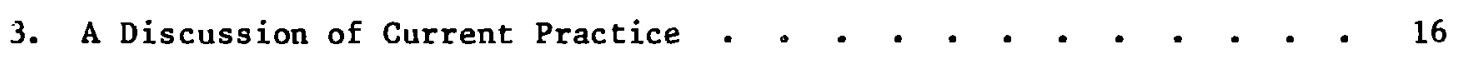

3.1. Conmon Assumptions in the Calculations . . . . • • • 16

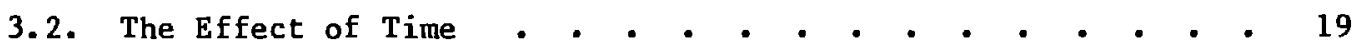

3.3. The Effect of Scale - • - • • • • • • • • • • . 20

3.4. An Outline of Suggested Complementary Studies - • - - • 29

4. Details of the Suggested Geotechnical Studies . - . . . . 33

4.1. In Situ Testing • • • • • • • • • • • • • • • 33

4.1.1. In Situ Stresses . • . • • • • • • • • • 33

4.1.2. In Situ De Lormability - . . . . . . . . . - 35

4.1.3. In Situ Tensile Strength . • • . • . . • • . 36

4.1.4. In Situ Shear Strength . . . . . . . . . . 39

4.1.5. Suppliers and Costs . . . . . . . . . . . 39

4.2. Laboratory Testing . . . . . . . . . . . . . . 40

4.3. Numerical Modeling . . . . . . . . . . . . . . 41

5. Summary • • • • • • • • • • • • • • • • • • • 444

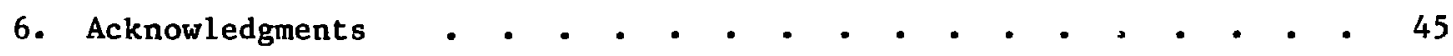

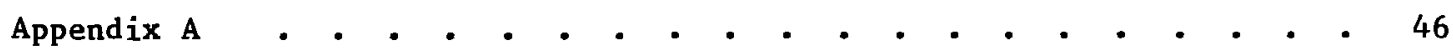

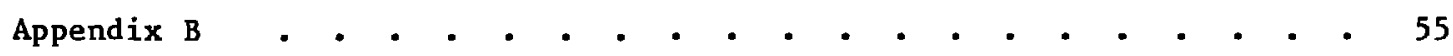

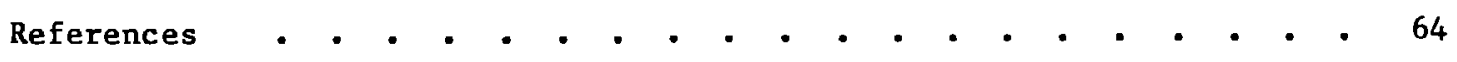


ON CEOTECHNICAL STUDIES RELEVANT TO THE

CONTA INMENT OF UNDERGROUND NUCLEAR EXPLOSIONS

AT THE NEVADA TEST SITE

ABSTRACT

The Department of Energy and the Department of Defense are actively pursuing a program of nuclear weapons testing by underground explosions at the Nevada Test Site (NIS). Over the past 11 years, scores of tests have been conducted and the safety record is very good. In the short run, emphas is is put on preventing the release of radioactive materials into the atmosphere. In the long run, the subsidence and collapse of the ground above the nuclear cavities also are matters of interest.

Currently, estimation of containment is based mostly on empiricism derived from extensive experience and on a combination of physical/mechanical testing and numerical modeling. When measured directly, the mechanical material properties are obtained from short-term laboratory tests on sma11, conventional samples. This practice does not determine the large effects of scale and time on measured stiffnesses and strengths of geological materials. Because of the limited data base of properties and in situ conditions, the input to otherwise fairly sophisticated computer programs is subject to several simplifying assumptions; some of them can have a nonconservative impact on the calculated results. As for the long-term, subsidence and collapse phenomena simply have not been studied to any significant degree.

This report examines the geomechanical aspects of procedures currently used to estimate containment of underground explosions at NTS. Based on this examination, it is concluded that state-of-the-art geological engineering practice in the areas of field testing, large scale laboratory measurements, and numerical modeling can be drawn upon to complement the current approach. Specific discussions are presented with regard to:

- The time and scale effects in the measurement of the mechanical properties of geological materials.

- Measurement of in situ stresses by hydraulic fracturing and borehole-jack fracturing.

- Measurement of in situ deformability by NX-jack tests. 
s Measurement of in situ tensile strength by hydraulic fracturing and borehole-jack fracturing.

- Measurement of in situ shear strength by borehole shear tests.

- Large scale, laboratory triaxial tests.

- Large scale, laboratory direct shear tests.

- Implicit numerical modeling of subsidence and collapse processes using the output from short-term, explicit calculations of early ground response to explosions.

In cases where today's evaluations indicate marginal conditions or in cases where new test areas are contemplated for which there is no benefit of experience, it is reasonable to expect that a refined input to the calculations will provide more realistic containment estimates than does current practice. 


\section{INTRODUCTION}

The U.S. Departments of Energy and Defense are actively pursuing a program of nuclear weapons testing by underground explosions at the Nevada Test Site (NTS). Tests take place mainly in the alluvium and tuffs of Yucca Flat, as well as in the tuffs and other volcanics of Rainier Mesa and Pahute Mesa. The most serious environmental consequence of the underground explosions is the potential atmospheric release of radioactive materials. When release takes place quickly through the geological formation, it is referred to as dynamic venting. ${ }^{1}$ Release also may be due to failure of the stemming in the emplacement hole or tunnel and is then referred to as a leak. 1 The main factors contributing to vents and leaks are summarized in Table 1. The notion of a containment cage alluded to in Table 1 bears some further explanation. This "cage" is a region of high compressive, tangential stresses added to the in situ stresses, located at a distance of between one and two cavity radii from the working point (WP). It is created by the rebound of the material towards the cavity. ${ }^{2}$ Based on calculations with the TENSOR code ${ }^{1,2}$ the time required for the cage to set up goes from about $0.1 \mathrm{~s}$ for a $1 \mathrm{kt}$ yield, to a few seconds for higher yields. As long as the cage fully surrounds the cavity with tangential stresses significantly higher than the cavity gas pressure, there is reason to expect that venting will be prevented because fractures will not propagate from the pressurized cavity.

The tangential stresses may relax with time, however, and in spite of early containment, the ground above the cavity may yield and bring about a surface collapse. Such subsidence is poorly understood and has not been modeled successfully. ${ }^{2}$ Collapse may take from a few minutes to several years to occur. The possibility that an early collapse may allow some harmful release cannot be excluded. Thus, it appears that the behavior of the ground beyond the first few seconds after the explosion also is of some interest.

Currently, estimation of containment for nuclear events at NTS is based mostly on experience and on a combination of physical testing and numerical modeling. There is an important empirical data base which consists of the information on several hundred past events. Data include yield, depth of burial (DOB), cavity radius, density of the overburden materials, and density of the WP region. A standard suite of physical and geophysical tests usually is performed in the emplacement hole and/or adjacent exploration hole(s). 
Table 1. Possible factors in atmospheric releases.

Geologic failure/dynamic venting

- Too shallow burial of the device. The tensile rarefaction wave comes back from the surface before the containment cage is established.

- Burial too close to a hard interface below the working point, WP. ${ }^{a}$ The reflected compressive wave hampers the locking effect of the rebound.

Burial too close to a fault. High pressure gases can move along the fault and crack overlying formations above the containment cage.

\section{Stemming failure/leaks}

- Leaks through open line-of-sight pipes or tunnels.

- Leaks caused by stemming falls or improper stemming.

- Seepage through stemming.

- Cable leaks.

a WP is the location of the de ice.

References 3 to 9 have been selected as representative of this work, during the past 10 years.

Depth of burial has been the object of particular attention, and criteria based on experience have been proposed for minimum DOB. ${ }^{1}$ However, in areas where the geology is complex or in new test areas, calculations are performed for additional guidance. They are based on finite-difference wave-propagation programs. Predicting the mecinanical response of the ground to explosions requires an input of its deformability and strength properties. Up to now, this information has been obtained during short-term tests on cores a few inches in diameter. This practice does not determine the effects of scale or strain rate on measurement of rock mass stiffness and strength. ${ }^{10-14}$ The strength measured on standard laboratory samples, 5 to $10 \mathrm{~cm}$ diam, can be several times higher than the strength of larger volumes in the prototypes. The overestimation of material strength can lead to selecting a more shallow DOB than would be warranted with lower strength values, thus reducing the intended margin of safety. No attempt has been made to determine what volumes 
of rocks and soils must be tested as representative of the conditions in situ. Current data acquisition does not include either the long-term strength properties, which play a role in surface subsidence and collapse, or the strength properties undez very high strain rates, as experienced under explosive loading.

This report is an attempt to evaluate the geomechanical aspects of procedures used to estimate the likelihood of containment for underground explosions at NTS. Chapter 2 summarizes the current geotechnical practice for containment evaluation at Lawrence Livermore National Laboratory (LLNL). Chapter 3 discusses the current practice in terms of the assumptions made and in terms of the time and scale effects involved. We then present elements of an approach to incorporate current geological engineering methods in the containment evaluation process. Chapter 4 provides the details of the suggested geotechnical studies in this approach. In cases where today's evaluations indicate marginal conditions or in cases where new test areas are contemplated for which there is no benefit of experience, it is reasonable to expect that refined procedures will provide more realistic containment estimates than does current practice. The main conclusions and recommendations from this study are summarized in Chapter 5. 


\section{CURRENT GEOTECHNICAL PRACTICE FOR CONTAINMENT EVALUATION}

\subsection{PHYSICAL PROPERTIES}

For each new event, site specific geological and geotechnical data are gathered in a document called the Preliminary Site Characteristics Summary (PSCS). The PSCS is part of the containment prospectus submitted to the Containment Evaluation Panel of the Department of Energy. This information is in addition to the knowledge of physical properties already gained in the various test areas, as illustrated in Figs. 1 to 3 from Ref. 4. The PSCS information relevant to our discussion typically consists of:

- Vertical geologic cross section(s) through the working point.

- A surface effects map illustrating the subsidence effects of past events in the vicinity, the surface expressions of faults, etc.

- A history of hole drilling documenting any anomalies encountered. Typically, only Hunt sidewall scrapings are recovered from the holes after the rotary drilling has been completed. Few cores are taken.

- A summary of rock and soil physical properties at the working point, and in the overburden. The properties include bulk density, grain density, water content, and $\mathrm{CO}_{2}$ content. Also, note is made of zones where the proportion of swelling clay is more than $20 \%$ by weight. Other properties are calculated from the first three: total porosity, water saturation, and gas porosity.

- A summary of the borehole geophysical logs, including velocity data from the dry hole acoustic log (DHAL) method and the vibroseis method. - A comparison of tha above values with values obtained for other holes in similar material (e.g., alluvium, unsaturated tuff, etc...) at NTS.

Representative data are presented in Appendix A, Figs. A-1 to A-14. They are excerpted from two recent summaries 8,9 corresponding to one event in alluvium (TILCI - hole U4ak) and one event in unsaturated tuff (AKAVI - hole U2es). As shown in the surface effe-ts maps, the event areas may be quite new and untested (see Fig. A-2) or they may be extensively fractured by prior events (see Fig. A-9). Regarding geotechnical properties, it is worth noting that the two methods used for sonic velocity measurements may on occasion give quite different results (see Fig. A-11). This is because the DHAL technique works over intervals of a few feet, whereas the Vibroseis method provides average values from the surface to receivers which can be several hundred 
Sverburden density veriation $\left(\mathrm{Mg} / \mathrm{m}^{3}\right)$

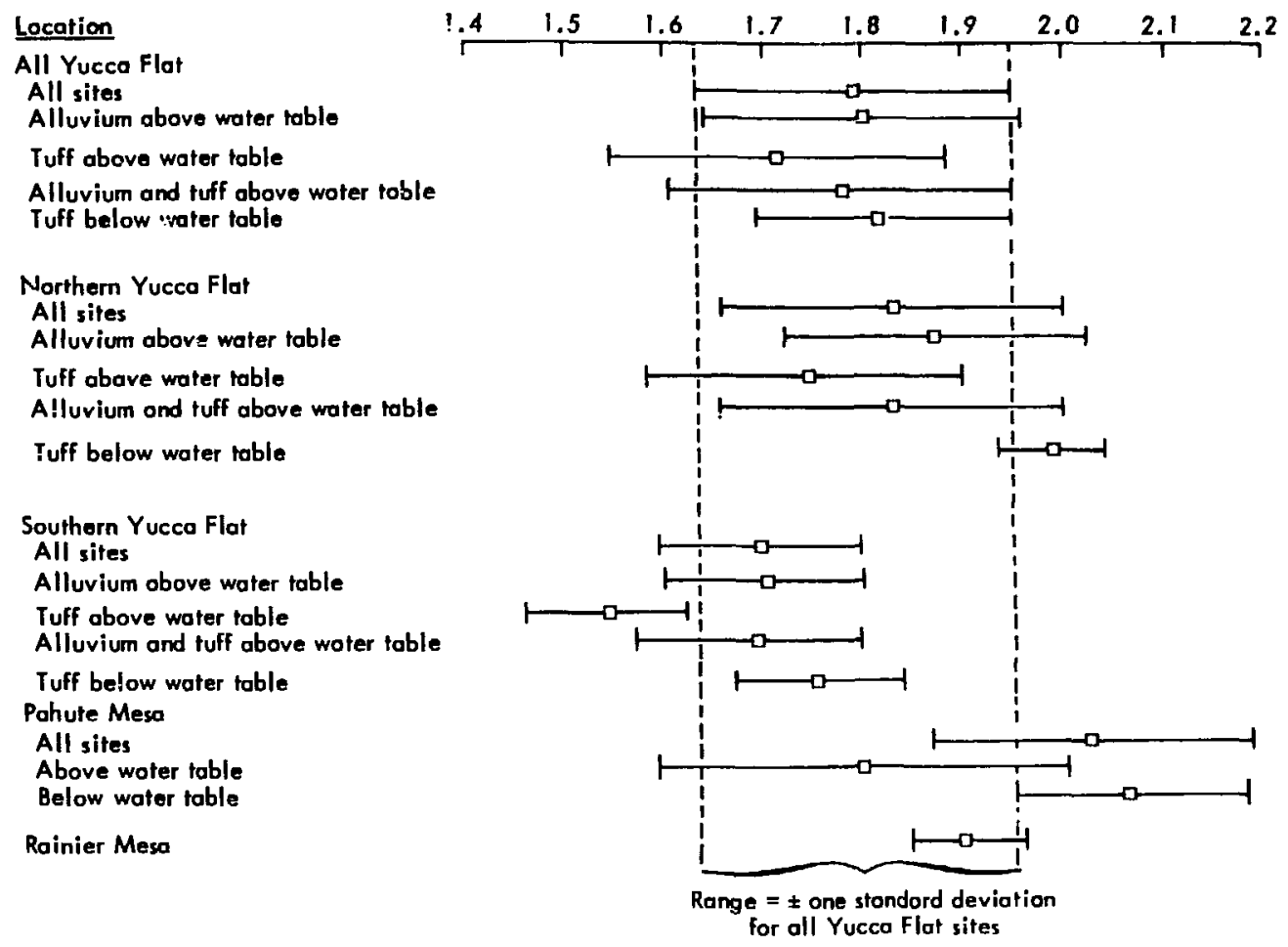

Figure 1. (After Ref. 4.)

Location

All Yucca Flat

All sites

Alluvium above water table

Tuff above water table

Alluyium and fuff above water able Tuff below water tr.ble

Northern Yucca Flat

All sites

Alluvium above water toble

Tuff above water table

Alluvium and tuff above water table Tuff below woter table

Southern Yucca Flat All sites

Alluvium above water table

Tuff above water table

Alluvium and tuff above water table Tuff below woter toble

Pahute Mesa

Belaw water table

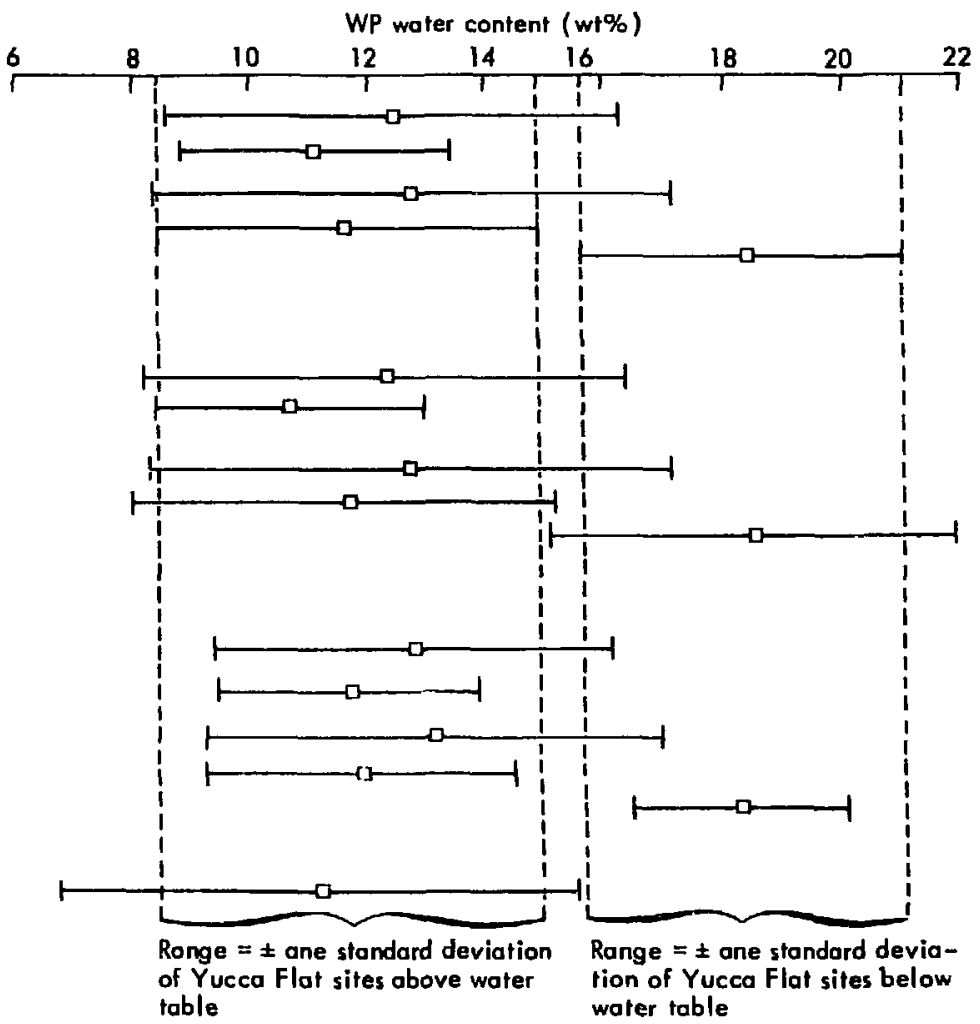

Figure 2. (After Ref. 4.) 
Locotion

All Yucco Flat

All sites

Alluvium above water table

Tuff above water table

Alluvium and tuff above woter table

Tuff below woter table

Northern Yucco Flat

All sires

Alluvium obove water toble

Tuff obove woter toble

Alluvium and tuff above water toble

Tuff below water table

Southern Yucca Flat

All sites

Alluvium above water table

Tuff above water table

Alluvium and tuff above woter table

Tuff below water table

Pahure Meso

All sites

Below water table

Rainier Mesa

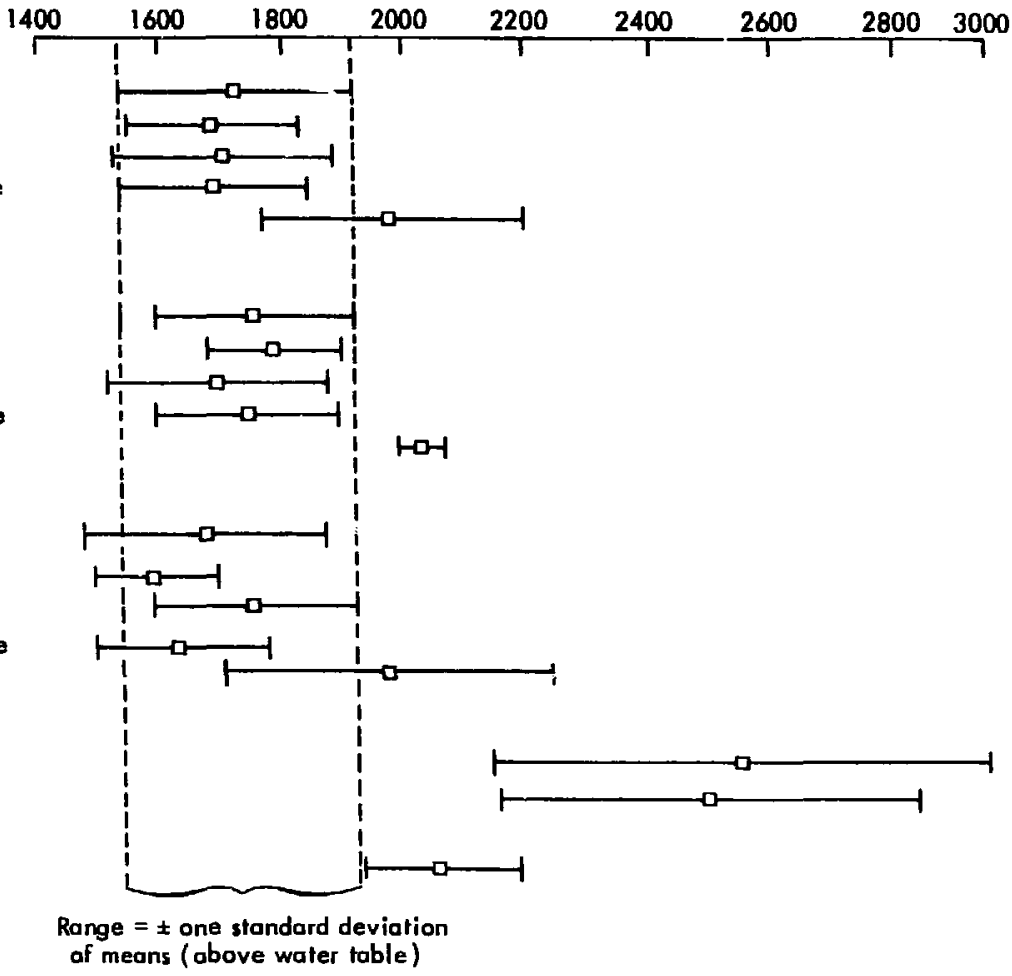

Location

All Yucca Flar

All siles

Alluvium above water table

Tulf above waler table

Allurium and luff above woter toble

Tuff below wath table

Northern Yucca Flal

All sites

Allurium above water fobla

Tuff above water tablo

Alluvium and luff above wuler table

Tuff below waler table

Southarn Yucea Flat

All viles

Alluvium obove woler foble

Tuff cbove water roble

Alluivium and tuff above water table

Tuff below woler toble

Pahute Mesa

Bolow water toble

WP-lo-gurfoce velocily $(\mathrm{m} / \mathrm{s})$

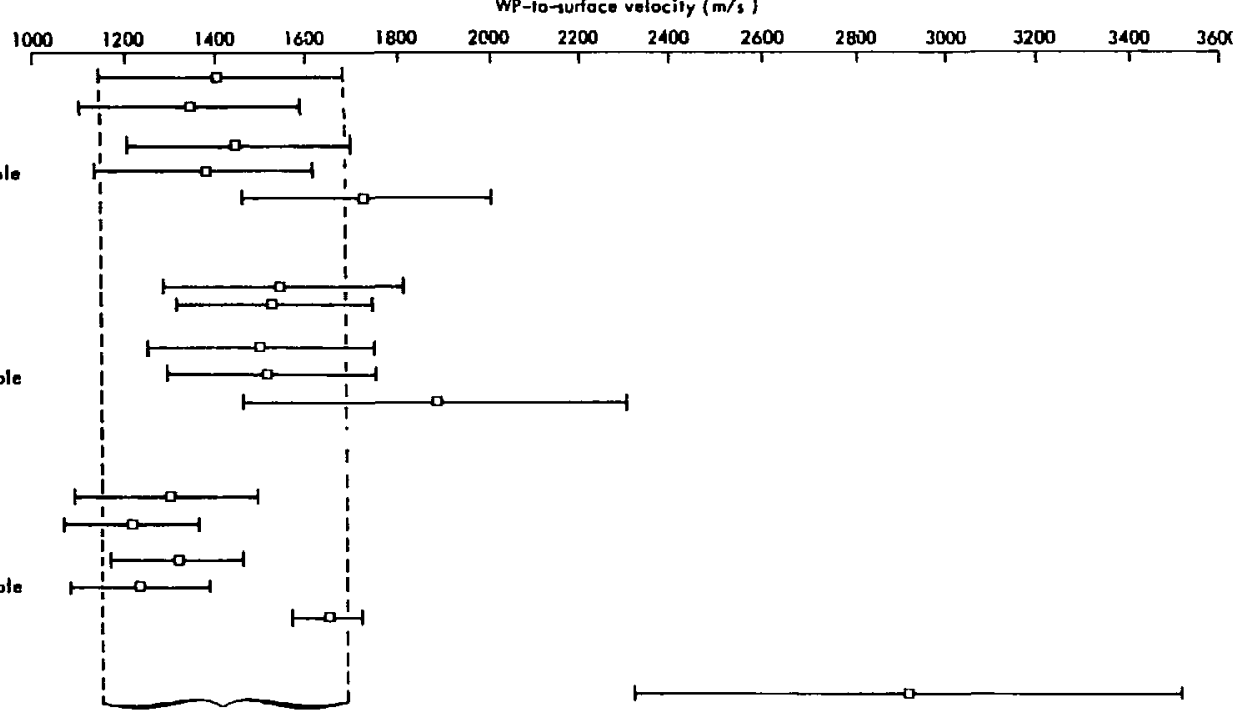

Range $= \pm$ ane stondard deviation of all Yucca F lat sites

Figure 3. (After Ref. 4.) 
metres away, down the hole. So, in the case of a layered geology with marked velocity contrasts, one would be tempted to use the DHAL results that are obtained over shorter intervals. On the other hand, these measurements are taken along the wall of the holes where drilling and the intrusion of the drilling fluids can disturb the in situ material and mask their true properties.

\section{2. MECHANICAL PROPERTIES}

As illustrated above, the typical site summaries usually do not contain data on mechanical properties of the geological materials. However, some mechanical data may be inferred from the geophysical tests. For example, the bulk modulus up to a so called "elastic limit" usually is calculated from the measured compressional wave velocity and material density, after assuming some value for the Poisson's ratio. In turn, the shear modulus can be calculated. Geological engineering experience ${ }^{15-18}$ has shown that the modulus values calculated from various tests (e.g., static loading, dynamic cyclic loading, and seismic wave loading) vary because of the differences in stress levels and strain rates in those tests. For example, a recent series of tests on zuffs 18 gave the following results:

average $E$ seismic/average $E$ static $=5.4$, average $E$ dynamic-cyclic/average $E$ static $=1.5$.

Hence, the type of test must be tailored to the level and duration of the loading in the prototype.

LLNL and its contractors also have obtained mechanical properties data for NTS rocks and soils. Pressure-volume relations and shear strength have been measured directly in triaxial compression, uniaxial compression, and Brazilian tensile tests on cores. ${ }^{19-34}$ Whereas there is a substantial number of results for material deformability, the strength data base is quite limited. All results found in this study are reported in Appendix 3, Figs. B-1 to B-13, for the two main test media: alluvium and tuff. The tuff coverage includes samples from NTS areas $2,8,12$, and 16 , as well as from Mt. Helen, 70 miles NW of Mercury, NTS. The locations of the various areas are shown on the NTS map of Fig. 4. Data from areas 2 and 8 are very scarce. The paucity is even more acute when it comes to alluvium. All the published alluvium strength results found in this work are summarized in Figs. B-12 and B-13 and relate to areas 3 and 4 . As it is, the LLNL experimental program is still far more extensive than the one at LANL. 35 


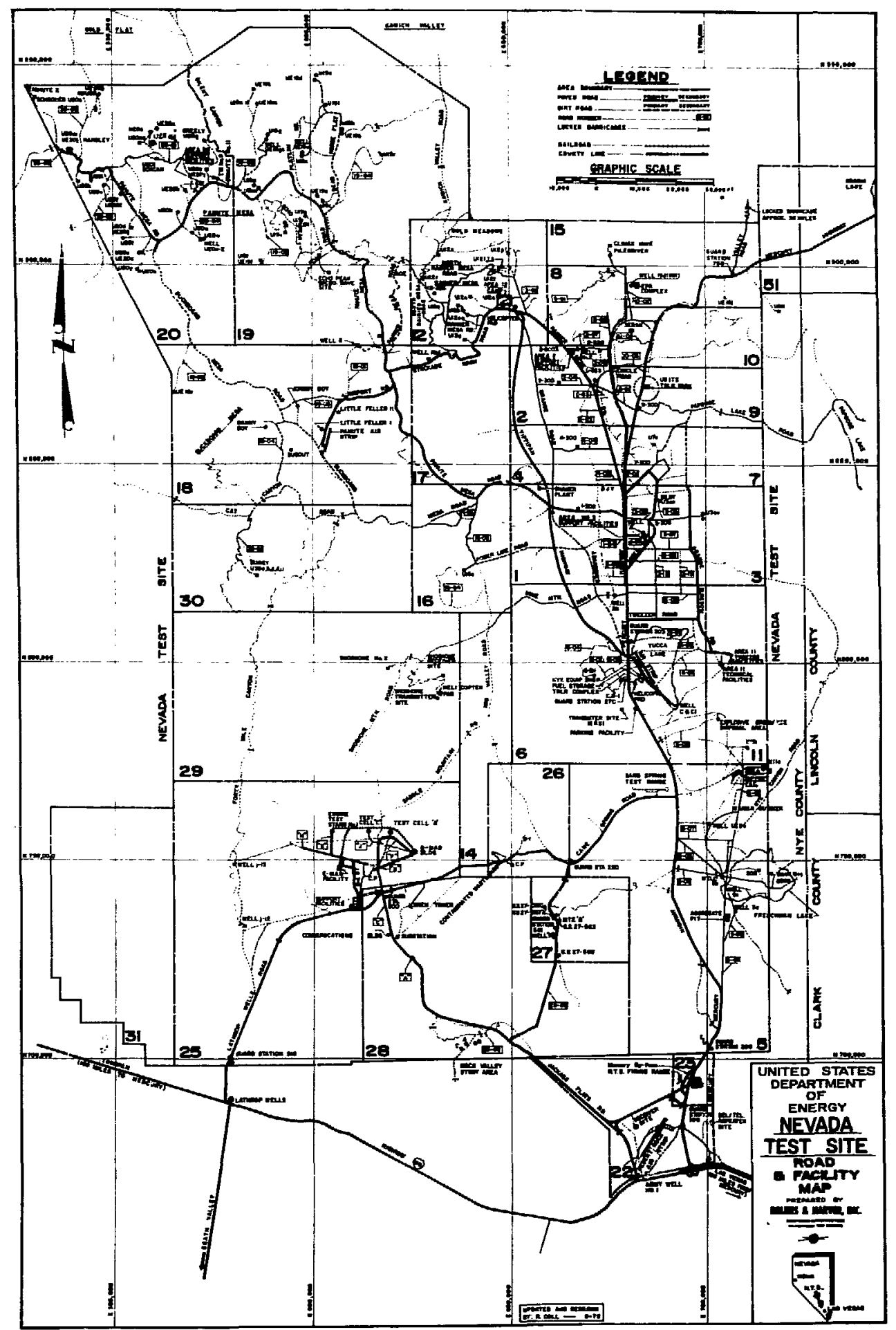

Figure 4. Map of the Nevada Test Site. 
The lack of strength data is critical, considering that:

- The magnitude of the stress within the containment cage region and the distance the cage extends from the cavity surface are very sensitive to the strength of the rock surrounding the cavity. 1

- The time required for the containment cage to form depends on the rebound time which is controlled by the shear strength. 1

- High shear strength may be adverse to containment. 1

- The extent of the spall zone is controlled by tensile strength.

\subsection{COMPUTER-BASED CONTAINMENT CALCULATIONS}

The Department of Energy, the Department of Defense, and their contractors have strived to develop models to predict the effects of nuclear and highexplosive events in geological media. References 36 to 48 have been selecteä as representative of work in this area over the past several years; most models are computer based. The computer codes usually operate on finite difference approximations of wave propagation equations; their material models are directed at the dynamic response of soils and rocks. ${ }^{49-58}$ The two codes used at LLNL are the one-dimensional $\operatorname{soc}^{39}$ and the two-dimensional TENSOR. $47,48,57$ At LANL, SOC also is available, as is the two-dimensional TOODY code. 37 Because SOC is one-dimensional, it can only model the development of the containment cage in simple geologies. At LLNL, SOC also is used in sensitivity analyses to adjust the parameters of the TENSOR models. Two-dimensional codes themselves have their drawbacks: slant planar interfaces are modeled as conical surfaces, and in situ stresse - cannot be given independent values in all three principal directions. These limitations could be removed by using three-dimensional models, but the high cost and time involved in the application of such codes have precluded their use in containment calculations, so far.

Because of the short-term nonlinear dynamics involved in explosion-related ground motion phenomena, the computations typically are performed with explicit schemes. Figure 5 illustrates the steps of a single calculational cycle with TENSOR. The inelastic constitutive models for deformability and strength that are incorporated in TENSOR are depicted in Figs. 6 and 7. They accommodate loading and unloading of materials from an intact condition to a completely crushed condition and accommodate shear failure in the brittle and ductile 


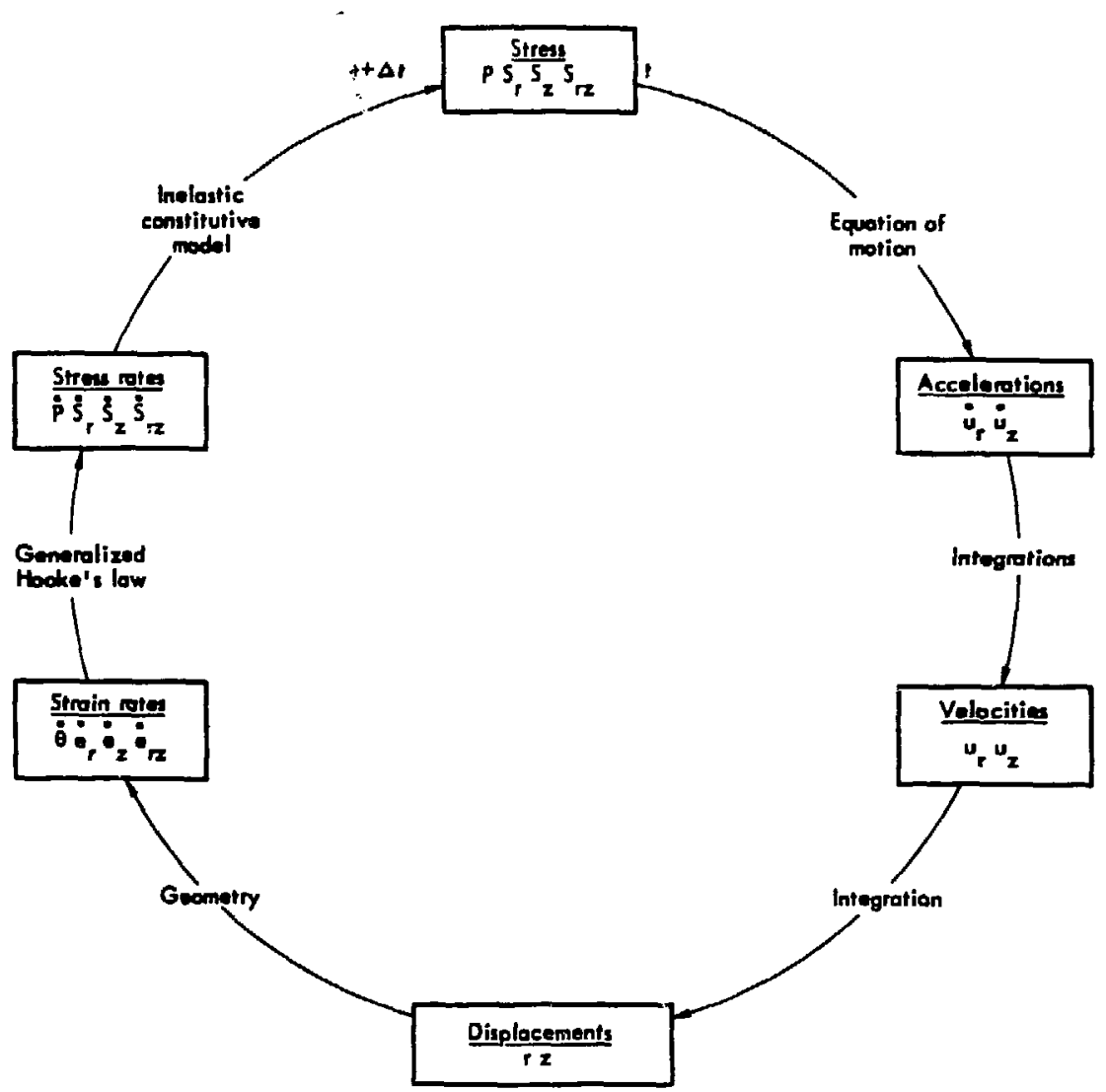

Figure 5. Calculational cycle in TENSOR. 57

ranges. Opening and closing of tension induced fractures also can be accommodated. 58

The phenomena of greatest interest in containment evaluation are the short-term events; i.e., the initial extent of the cavity, the extent of the region where tensile fracture occurs, and the development of the containment cage. Less critical is the long-term creep behavior of the overburden during which the cage may relax and the cavity may grow and create surface collapse. As an example of short-term calculations, the BURZET results ${ }^{59}$ predict the existence of a spall region (see Fig. 8) and the development of a strong containment cage (see Fig. 9), in spite of the proximity of the Paleozoic surface which was actually modeled closer than it was later determined to be (see Fig. 10). In this case, there was no further evidence of potentially unsafe conditions and it was concluded that "the calculational results satisfy a11 the criteria for containment." 59 


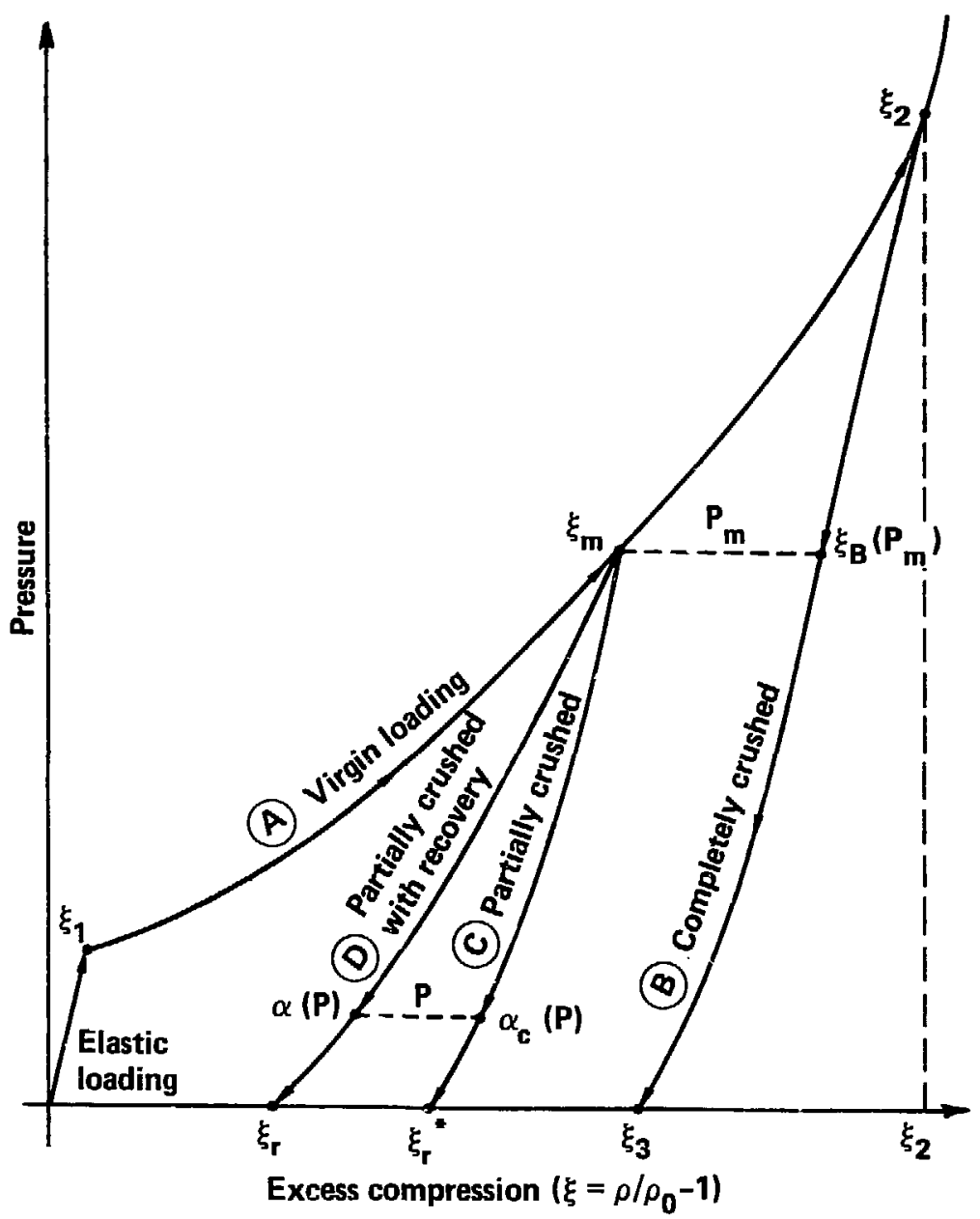

Figure 6. Pressure-volume model in TENSOR code. 57

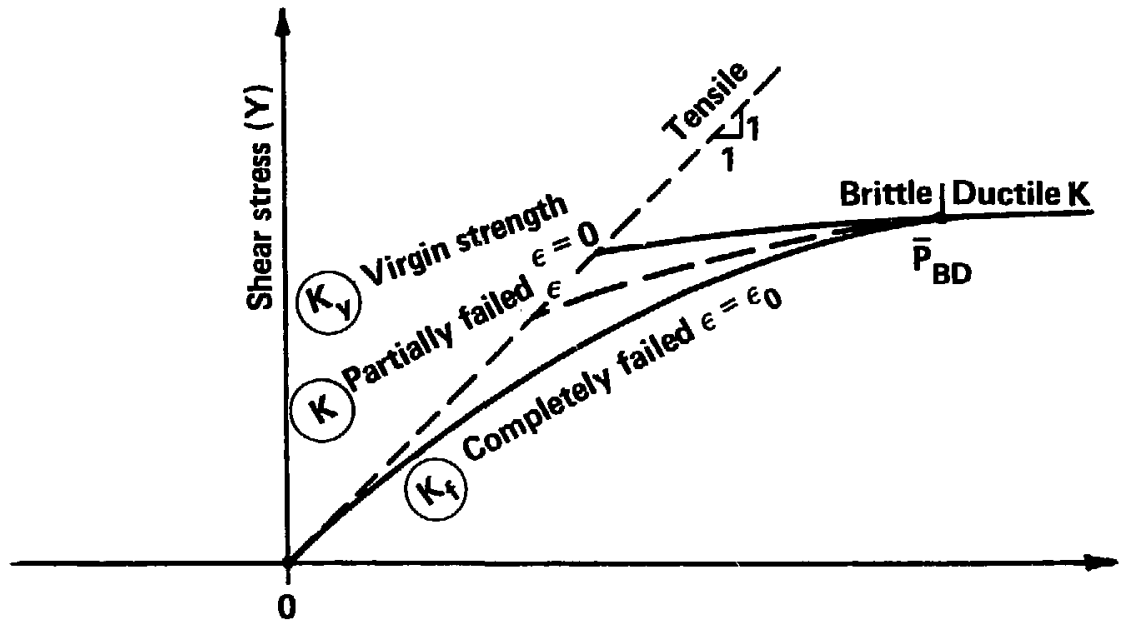

Mean normal stress $(\overline{\mathrm{P}})$

Figure 7. Shear envelopes in TENSOR code. 57 


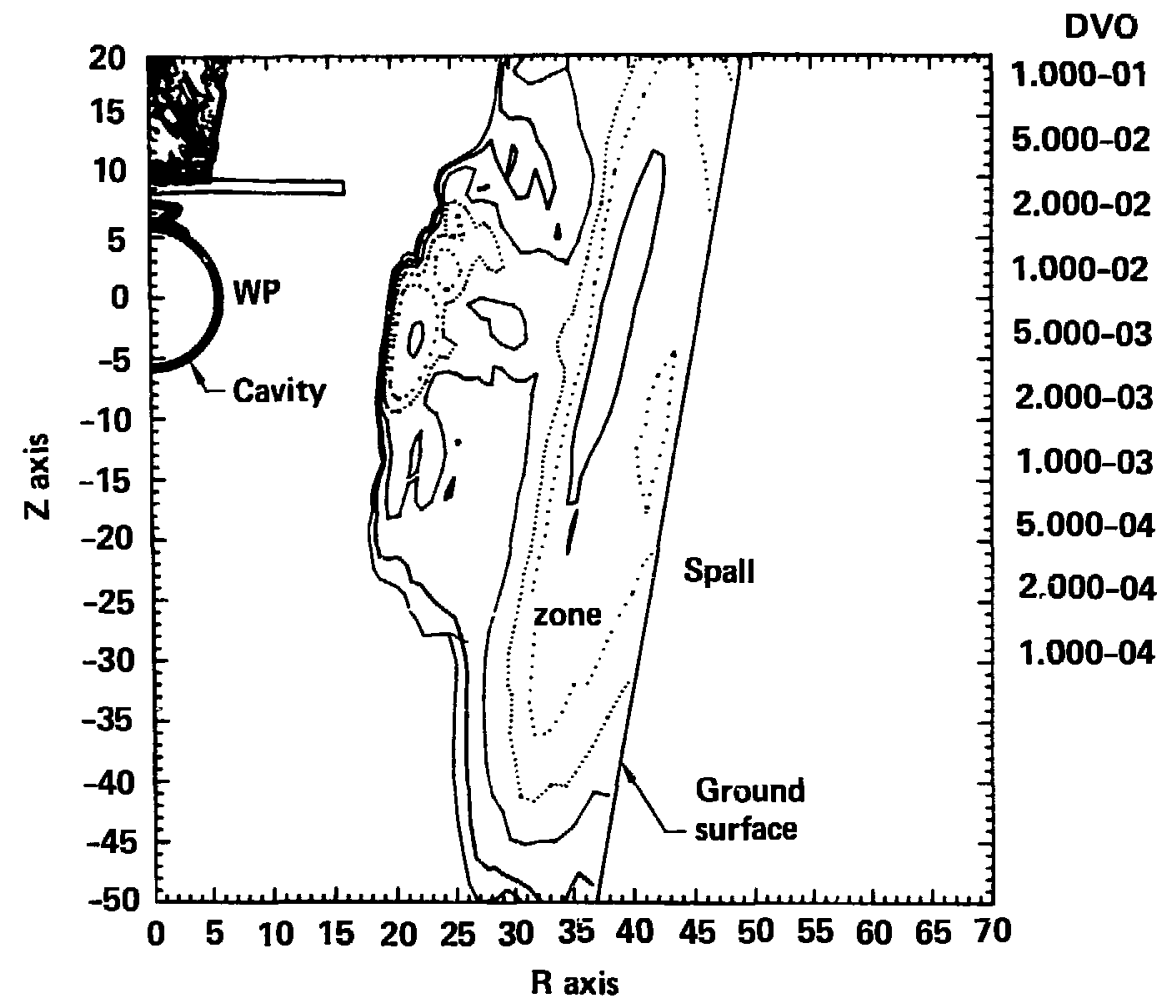

Figure 8. Region of tensile spalling in BURZET calculations. 59

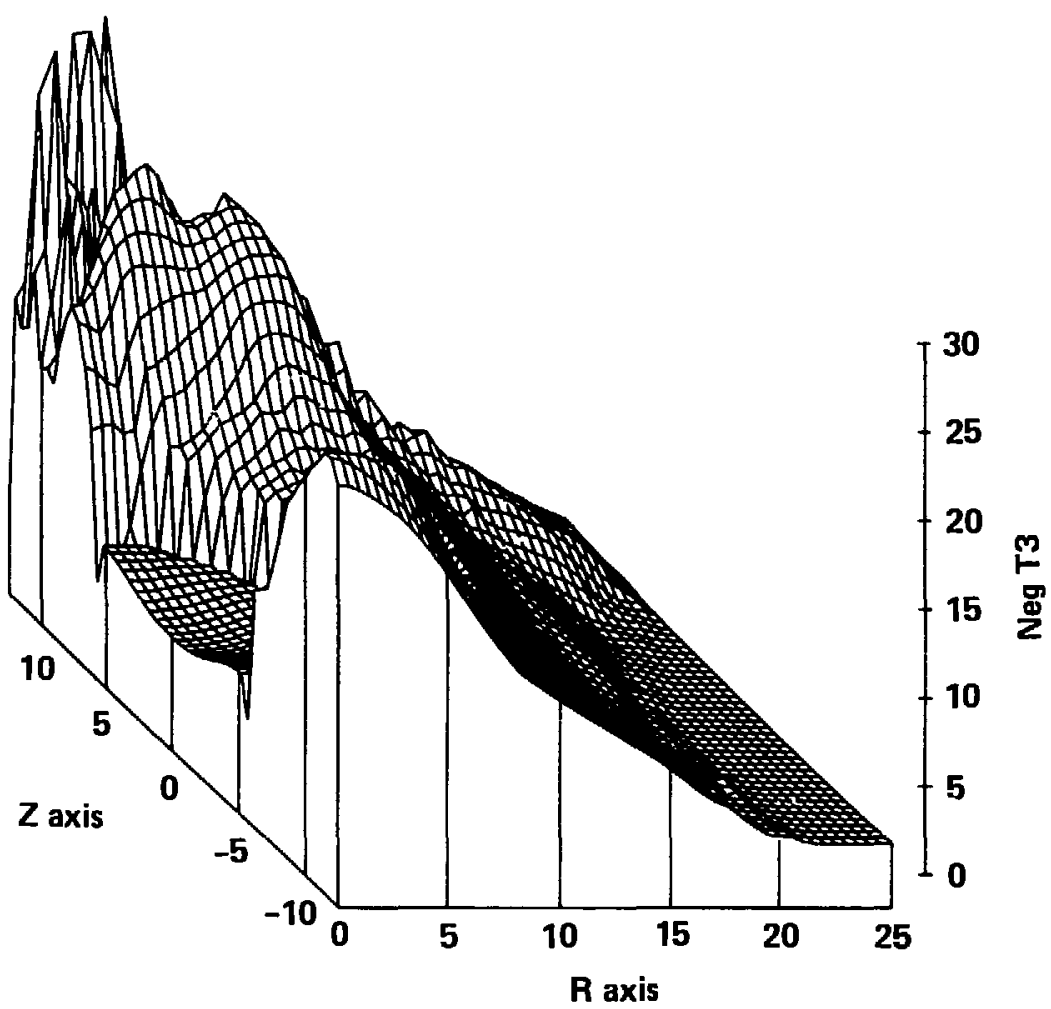

Figure 9. Containment cage calculated for BURZET. 59 


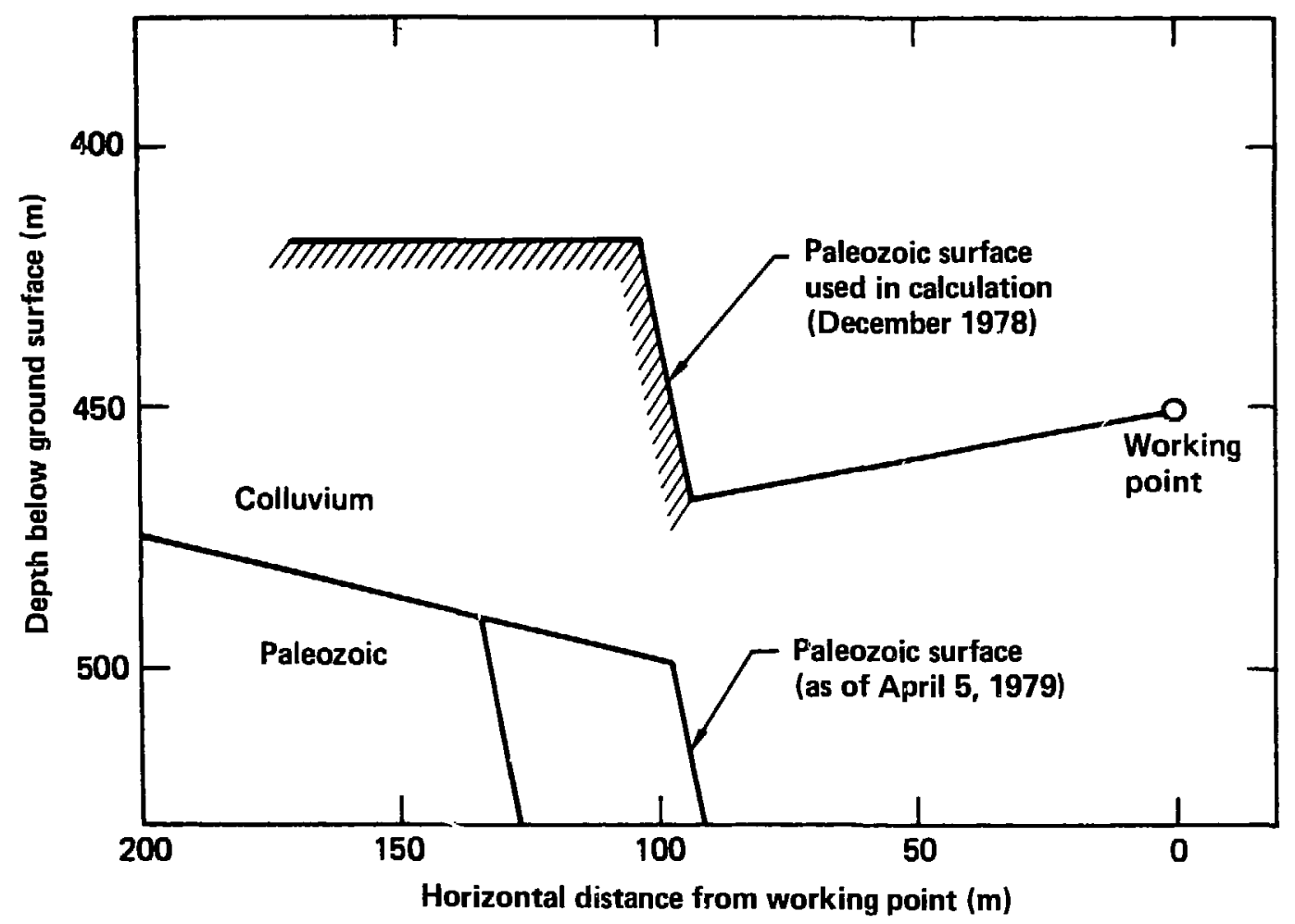

Figure 10. Cross section showing fault and scarp for BURZET model as assumed, and as it was later determined to be. 59 


\section{A DISCUSSION OF CURRENT PRACTICE}

\subsection{COMMON ASSUMPTIONS IN THE CALCULATIONS}

Several characteristics of containment calculations performed at LLNL since 1973 are summarized in rable 2. The calculation names do not imply that there was an event correspording to each calculation because some named events eventually did not take place. Conversely, the calculations did not address all events which have taken place at NTS during that time. Many events never were calculated. The salient features revealed by the compilation of Table 2 are:

- About $40 \%$ of the calculations are two-dimensional.

- All event calculations assume hydrostatic stresses.

- When the geological materials are given some tensile strength, it is an assumed value, typically 1 to 2 bars. Occasionally the Paleozoic rocks are assigned a 5-bar tensile strength. No measurements have been made of tensile strength, in situ or in the laboratory, for alluvium or tuffs.

- The bulk modulus, $\mathrm{K}$, generally is calculatid from seismic compressional velocity, $v_{p}$.

- Poisson's ratio, $v$; generally is assumed to be in the range of 0.15 to 0.3 .

Also, within a given geologic formation, the shear strength of soils and rocks commonly is assumed to be independent of depth. The choice of a single shear strength value may be based upon an approximation of some laboratory test data. In other cases, it may be based on an empirical relation developed between a shear index and the radius of the explosion-produced cavity. 60 This index is in fact an average shear strength which, when input in TENSOR calculations, tends to result in cavity radii close to observed radii. Conversely, when cavity radii are known, the back-calculation of the event with TENSOR yields an estimate of the average shear strength for the vicinity of the cavity.

Results from such back-calculations are shown in Fig. 11 for events in NTS areas $2,3,4,8,9,10,11$, and 12 . The plots do not seem to predict a correlation between depth of burial and shear strength. In fact, the 
Table 2. Some characteristics of containment calculations at LLNL for the period 1973-1981 (courtesy of J. T. Rambo, LLNL).

\begin{tabular}{|c|c|c|c|c|c|c|}
\hline $\begin{array}{l}\text { Calculation } \\
\text { name }\end{array}$ & NTS area & $\begin{array}{l}\text { One or two } \\
\text { dimensions }\end{array}$ & $\underset{\substack{\text { horiz } \\
\sigma_{\text {vert }}}}{\sigma_{\text {ner }}}=$ & $\begin{array}{c}\text { Tensile } \\
\text { strength }=0\end{array}$ & $\begin{array}{c}\text { K from } \\
V_{p}\end{array}$ & $\begin{array}{c}\text { Measured } \\
v\end{array}$ \\
\hline Asiago & 2 & $1 \mathrm{D}$ & Yes & Yes & Yes & No \\
\hline Azul & 10 & $1 D-2 D$ & Yes & Yes & Yes & No \\
\hline Baneberry & 8 & $1 D-2 D$ & Yes & Yes & Yes & Yes ${ }^{a}$ \\
\hline Banon & 2 & $1 \mathrm{D}$ & Yes & Yes & Yes & No \\
\hline Burzet & 4 & $1 D-2 D$ & Yes & Yes & Yes & No \\
\hline Caboc & 2 & $1 D-2 D$ & Yes & Yes & Yes & No \\
\hline Camembert & 19 & 1D & Yes & $?$ & Yes & No \\
\hline Cheshire & 20 & $1 \mathrm{D}$ & Yes & Yes & Yes & No \\
\hline Chevre & 10 & $1 D-2 D$ & Yes & Yes & Yes & No \\
\hline Coulommiers & 8 & $1 D-2 D$ & Yes & Yes & Yes & No \\
\hline Dauph in & 9 & $1 D-2 D$ & Yes & Yes & Yes & No \\
\hline Edam & 21 & $1 D-2 D$ & Yes & No & Yes & No \\
\hline Fallon & 2 & $1 \mathrm{D}$ & Yes & Yes & Yes & No \\
\hline Farallones & 2 & $1 D-2 \bar{D}$ & Yes & Yes & Yes & No \\
\hline Flax & 2 & $1 \mathrm{D}$ & Yes & Yes & Yes & No \\
\hline Fontina & 20 & $1 \mathrm{D}$ & Yes & No & Yes & No \\
\hline Handley & 20 & $1 D$ & Yes & Yes & Yes & No \\
\hline Harzer & 19 & $1 D-2 D$ & Yes & No & Yes & No \\
\hline Islay & 2 & ID & Yes & No & Yes & No \\
\hline Kasser $\mathrm{i}$ & 20 & $1 \mathrm{D}$ & Yes & No & Yes & No \\
\hline Leyden & 9 & $1 D$ & Yes & Yes & Yes & No \\
\hline Mast & 19 & ID & Yes & Yes & Yes & No \\
\hline Molbo & 20 & $1 D-2 D$ & Yes & No & Yes & No \\
\hline Muenster & 19 & $1 \mathrm{D}$ & Yes & Yes & Yes & No \\
\hline Panir & 19 & $1 D$ & Yes & Yes & Yes. & No \\
\hline Pepato & 20 & 1D & Yes & No & Yes & No \\
\hline Portmanteau & 2 & $1 D-2 D$ & Yes & Yes & Yes & No \\
\hline Portulaca & 2 & $1 D$ & Yes & No & Yes & No \\
\hline Scant 1 ing & 4 & $1 D$ & Yes & Yes & Yes & No \\
\hline Scotch & 19 & $1 \mathrm{D}$ & Yes & Yes & Yes & No \\
\hline Serpa & 19 & $1 D$ & Yes & $?$ & Yes & No \\
\hline Stantan & 2 & $1 D$ & Yes & Yes & Yes & No \\
\hline Stanyan & 8 & $1 D-2 D$ & Yes & Yes & Yes & No \\
\hline Starwart & 2 & $1 D-2 D$ & Yes & $?$ & Yes & No \\
\hline Stilton & 20 & $1 D$ & Yes & Yes & Yes & No \\
\hline Tybo & 20 & $1 D-2 D$ & Yes & Yes & Yes & No \\
\hline Wichita & 9 & $1 D-2 D$ & Yes & $?$ & Yes & No \\
\hline Zaza & 4 & $1 D$ & Yes & Yes & Yes & No \\
\hline
\end{tabular}

a Poisson's ratio measured on laboratory samples. 

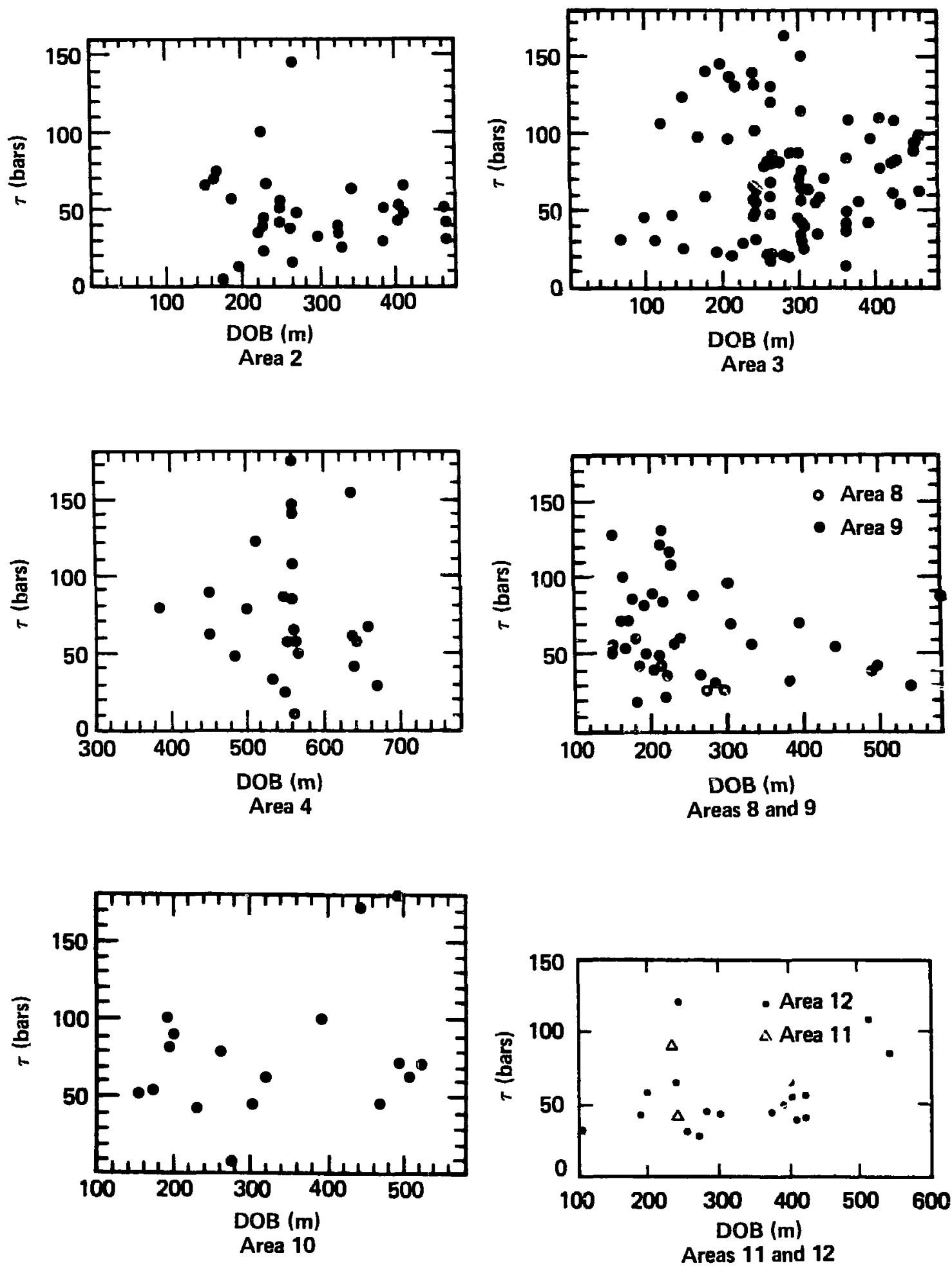

Figure 11. Average material shear strength back-calculated with TENSOR from known cavity radii, for various areas at the NTS. 60 
materials in these areas are frictional materials which have been consolidated; i.e., there are no excess pore pressures prior to loading. Under dynamic loading, there is no time for drainage; the properties to be used are those obtained in consolidated-undrained (C-U) tests. 50 In such tests, the shear strength is independent of pressure during the test but depends upon the preconsolidation stress. On the contrary, in drained tests the shear strength is pressure dependent. This is very clearly shown, particularly below a 1 kbar mean pressure, in the figures of Appendix B. The assumption of constant shear strength, regardless of overburden (preconsolidation) stress and test pressure, corresponds to an unconsolidated-undrained ( $U-U$ ) condition, which prevails if no excess pore-pressure dissipation is permitted either before or during loading. This is not the case in the containment problem at hand. In spite of the common assumption of constant shear strength, TENSOR does offer the option of including pressure-dependent strength. On the other hand, TENSOR does not offer yet the capability to model pore-pressure dissipation, but work has started to couple a fluid flow model to the continuum mechanics computations.

Yet another procedure which is used in preliminary calculations, such as with SOC, consists in letting a pressure-dependent shear envelope be generated by the code from stored average properties of NTS materials. 52 In this case, the user need only specify the bulk density, grain density of the solid matrix, weight fraction of water, and bulk modulus. The author of this procedure clearly points out that it is not intended to replace a rock property measurement program. 52

\subsection{THE EFFECT OF TIME}

The calculations usually are carried out from a few tenths of seconds to a few seconds, depending upon the yield, until the velocity field is close to zero and a pattern of stresses has emerged which reveals the presence or absence of a satisfactory containment cage. The long-term behavior of the overburden is not investigated to estimate future collapse. The SOC and TENSOR codes were not intended to handle creep and progressive failure. Long-term strength and creep properties are not being obtained on the geological materials. However, with respect to this last point, it should be noted that some existing triaxial test data could be reanalyzed to give 
indication of long-term strength level. According to published theory, 61 the volumetric behavior of brittle materials in triaxial compression can permit a recognition of the stress levels at which stable and unstable fracture propagations will occur. The threshold between the two types of fracture propagation is thought to be the ultimate strength for long-term loading. On volumetric plots, this level is marked by a reversal of the sign of the increments of volumetric strain. The only published volumetric strain plot found in this work is that for the Diamond Mine tuff of area 16,24 shown in Fig. 12. Undoubtedly, more such plots could be generated from past triaxial tests, where longitudinal and radial strains were recorded. On Fig. 12, the stress level of point $A$ would be the long-term strength of the tuff on the scale of a few cubic inches; it appears to be about $75 \%$ of the ultimate short-term strength. A corollary idea proposed for the long-term predictions is that the total strain at failure under a stress exceeding level A will be that which can be read from a complete stress-strain curve in triaxial conpression. 62,63 Turning to the one-dimensionel representation of Fig. 13, this means that if a stress level $\sigma_{B}$ is maintained on the material, it is predicted that failure will take place when the total accumulated strain is $\varepsilon_{c}$. The path $B C$ is supposed to be traveled in a steady-state creep mode. The steady-state creep rate for the material can be determined in appropriate creep tests so that the total time for failure at strain $\varepsilon_{c}$ would be predictable.

At the other end of the strain-rate spectrum, the very short-term, dynamic properties of the geologic materials are not being obtained either. There is substantial evidence that both the stiffness and strength vaiues increase when the strain rate increases. 11,12 For example, results obtained on tuff are summarized in Fig. 14 and Table 3 . Unlike in the case of long-term strength, one may argue that ignoring the dynamic effects provides conservative results. However, using static strength values which can be too low by a factor of 2 or more may lead to a deeper burial of the device, at unnecessary additional cost.

\subsection{THE EFFECT OF SCALE}

The concepts and test procedures discussed above apply only as long as the volumes of materials which are tested are representative of the in situ material conditions. Today, there is not a clear indication of what the 


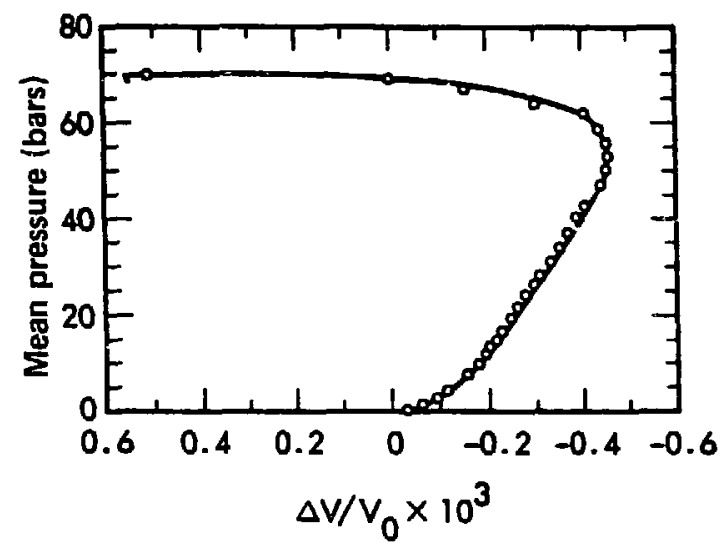

Figure 12. Pressure-volumetric strain relation for Diamond Mine tuff in uniaxial compression. 24

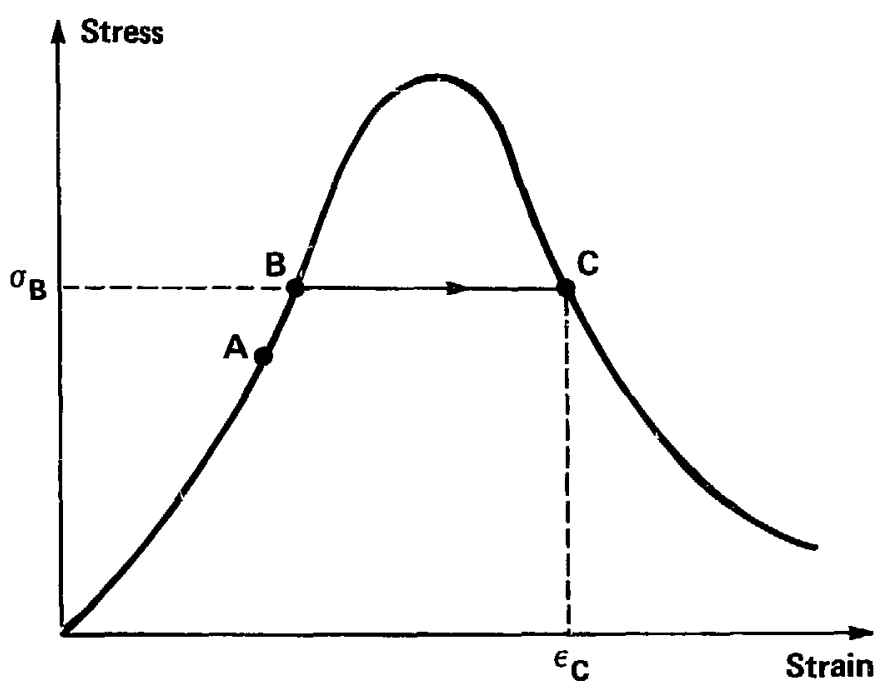

Figure 13. Concept for long-term strength of rocks. ${ }^{62}$ 


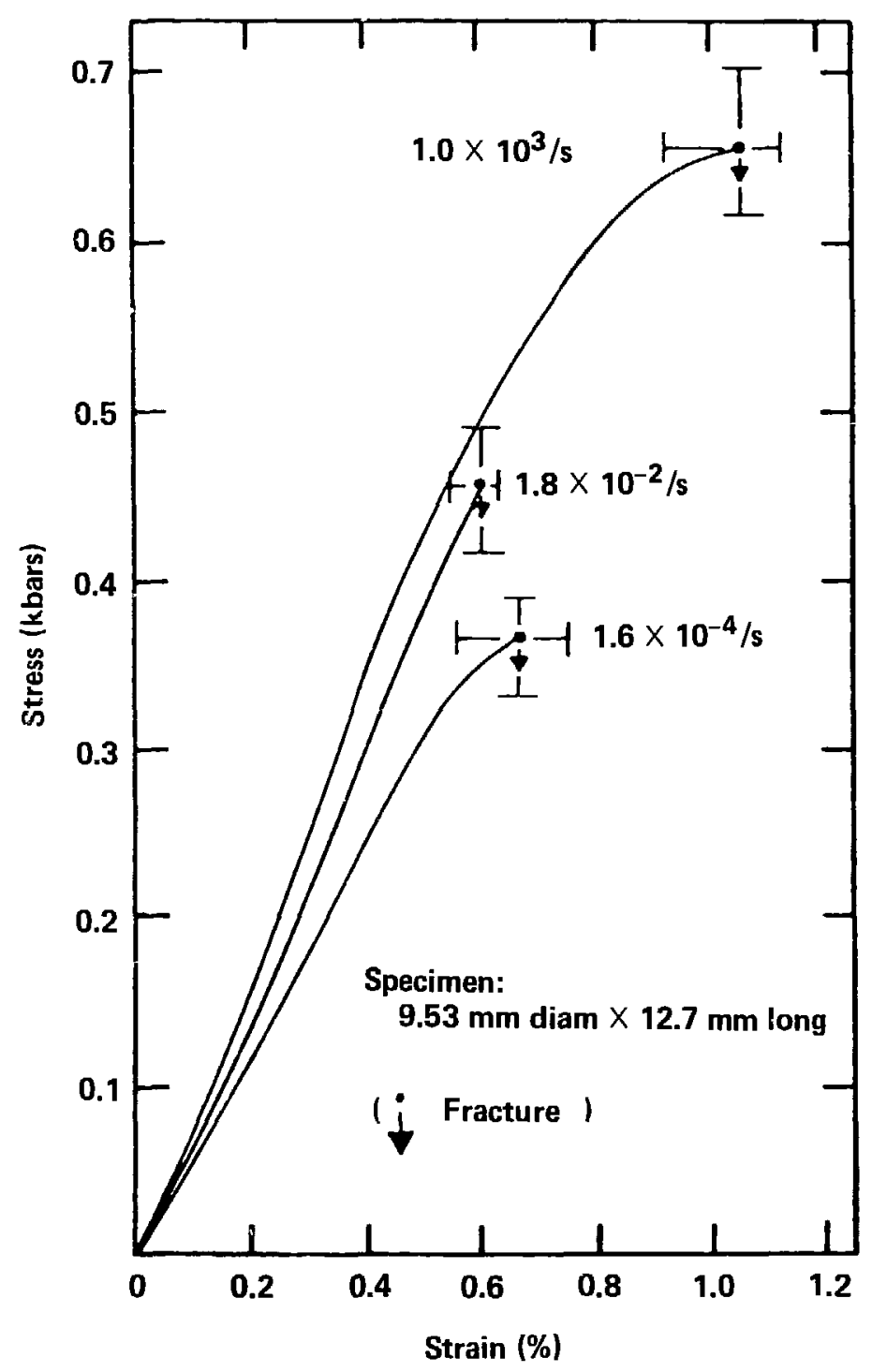

Figure 14. Stress-strain behavior of dry volcanic tuff for various strain rates at room temperature and atmospheric pressure. 12 
Table 3. Results of unconfined compression tests on NTS tuff under various loading rates. 11

\begin{tabular}{ccccc}
\hline $\begin{array}{c}\text { Ultimate } \\
\text { rate } \\
(\mathrm{psi} / \mathrm{s})\end{array}$ & $\begin{array}{c}\text { compressive } \\
\text { strength } \\
(\mathrm{psi})\end{array}$ & $\begin{array}{c}\text { Modulus of } \\
\text { elasticity } \\
\left(10^{6} \mathrm{Fsi}\right)\end{array}$ & $\begin{array}{c}\text { Poisson's } \\
\text { ratio }\end{array}$ & $\begin{array}{c}\text { No. of } \\
\text { specimens }\end{array}$ \\
\hline 50 & 1,640 & 0.54 & 0.19 & 3 \\
$1.68 \times 10^{5}$ & 1,850 & 0.33 & 0.42 & 1 \\
$3.11 \times 10^{5}$ & 2,490 & 0.41 & 0.49 & 1 \\
\hline $.46 \times 10^{5}$ & 4,230 & 0.91 & 0.36 & 1 \\
\hline
\end{tabular}

minimum representative volumes are for NTS materials. Undoubtedly; this knowledge should be developed with a high priority to overcome the scale effects which plague the application of laboratory test results to field situations.

It is expected that, because of the smaller particle sizes, the minimum volume for alluvium should be significantly smaller than the one for jointed rocks. Some useful guidance can be found in large laboratory triaxial tests performed on rockfill materials by the Geotechnical Engineering Division of U.C. Berkeley, at the Richmond Field Station, ${ }^{64,65}$ and by others. ${ }^{66-68}$ Table 4 summarizes strength results for several rockfills at confinement of 350 psi ( $2.4 \mathrm{MPa}) ; \phi$ is the drained friction angle, $\epsilon_{1 \mathrm{f}}$ is the axial strain at failure, $\varepsilon_{v f}$ is the volumetric strain at failure, and $\sigma_{3 f}$ critical is the minimum value of confinement to restrain volumetric dilation before failure. Figure 15 shows the variation of the friction angle with confining pressure. The effect of scale can be studied in Figs. 16 and 17 for the dredger tailings from Oroville Dam, California, and the crushed basalt of a San Francisco rockfill. In these tests, the specimen diameter was kept at six times the maximum particle size. The figures show that for intermediate confining pressures (140 and 650 psi) the sample size has no significant effect on the test results. From this, it seems reasonable to infer that the ratio of 6 for specimen diameter over maximum particle size is adequate; however, there is no evidence as to whether a smaller ratio also would be 
Table 4. Strength and deformation properties of selected large rockfill specimens. 65

\begin{tabular}{|c|c|c|c|c|c|c|c|c|}
\hline Symbol & Dam or Place & Material & Gradacion & $\begin{array}{l}\text { Parcicle } \\
\text { shape }\end{array}$ & $\phi\left(0^{*}\right)$ & $\begin{array}{l}E_{1} f \\
(x)\end{array}$ & $\begin{array}{l}E_{v}^{E} \\
(z)\end{array}$ & $\begin{array}{c}\sigma_{3}^{f} \\
\text { critical } \\
\text { P5 }\end{array}$ \\
\hline$\Delta$ & Oroville & Dredger cailings & $\begin{array}{l}\text { Well graded } \\
\text { 6" to fines }\end{array}$ & Rounded & 40 & 6.5 & 1.5 & 120 \\
\hline$\nabla$ & Pinzandaran & $\begin{array}{l}\text { Sand and gravel } \\
\text { (dry) }\end{array}$ & $\begin{array}{l}\text { Well graded } \\
\text { B" co fines }\end{array}$ & Rounded & 39 & 8 & 4.7 & 60 \\
\hline$\Phi$ & San Francisco & Basalt & $\begin{array}{l}\text { Well graded } \\
\text { g" to } 1 / 4^{\prime \prime}\end{array}$ & Anguler & 39 & 15 & 6 & 60 \\
\hline 口 & San Francisco & Basale & $\begin{array}{l}\text { Well graded } \\
3 " \text { co } 1 / 4^{\prime \prime}\end{array}$ & Angular & 38 & & & \\
\hline$\bullet$ & San Francisco & Resalt & $\begin{array}{l}\text { Poorly graded } \\
\text { 6" to Eines }\end{array}$ & Angular & 37 & 20 & 6.5 & 40 \\
\hline$\bullet$ & Mal paso & Conglowerate & $\begin{array}{l}\text { Well graded } \\
\text { g" to fines }\end{array}$ & Angular & 37 & 13 & 4.5 & 20 \\
\hline 0 & El Infiernillo & $\begin{array}{l}\text { Silicified } \\
\text { conglomerate (dry) }\end{array}$ & $\begin{array}{l}\text { Poorly graded } \\
\text { 8" to fines }\end{array}$ & Angular & 36.5 & 14 & 5.5 & 30 \\
\hline - & Pyramid & Argillice & $\begin{array}{l}\text { Poorly graded } \\
\text { 6" to fines }\end{array}$ & Angular & 36.5 & 20 & 5.5 & 25 \\
\hline 0 & El Infiernillo & Diorite (dry) & $\begin{array}{l}\text { Poorly graded } \\
8^{\prime \prime} \text { lo fines }\end{array}$ & Angular & 35 & 15 & 10 & 25 \\
\hline$\nabla$ & El Granero & $\operatorname{Shal} \mathrm{e}^{a}$ & $\begin{array}{l}\text { Hell graded } \\
\text { B" to } 1 / 4 "\end{array}$ & Angular & 35 & 314 & $>10$ & 10 \\
\hline$\star$ & El Granero & Shale $\mathrm{e}^{\mathrm{a}}$ & $\begin{array}{l}\text { Poor ly graded } \\
{\text { 8" co } 1 / 4^{\prime \prime}}^{\prime}\end{array}$ & Angular & 33 & $>14$ & $>10$ & 5 \\
\hline ๒ & Mica & Granitic Greiss & $\begin{array}{l}\text { Well graded } \\
\text { B" to fines }\end{array}$ & AnguIar & 32 & 314 & 6 & 20 \\
\hline $\begin{array}{l}\text { Hot } \\
\text { shown }\end{array}$ & Hica & Granitic Gneigs & $\begin{array}{l}\text { Well graded } \\
8^{\prime \prime} \text { ro I } 1 / 3^{\prime \prime}\end{array}$ & Angular & 25 & 314 & 6 & 20 \\
\hline
\end{tabular}

a Test not continued to failure.

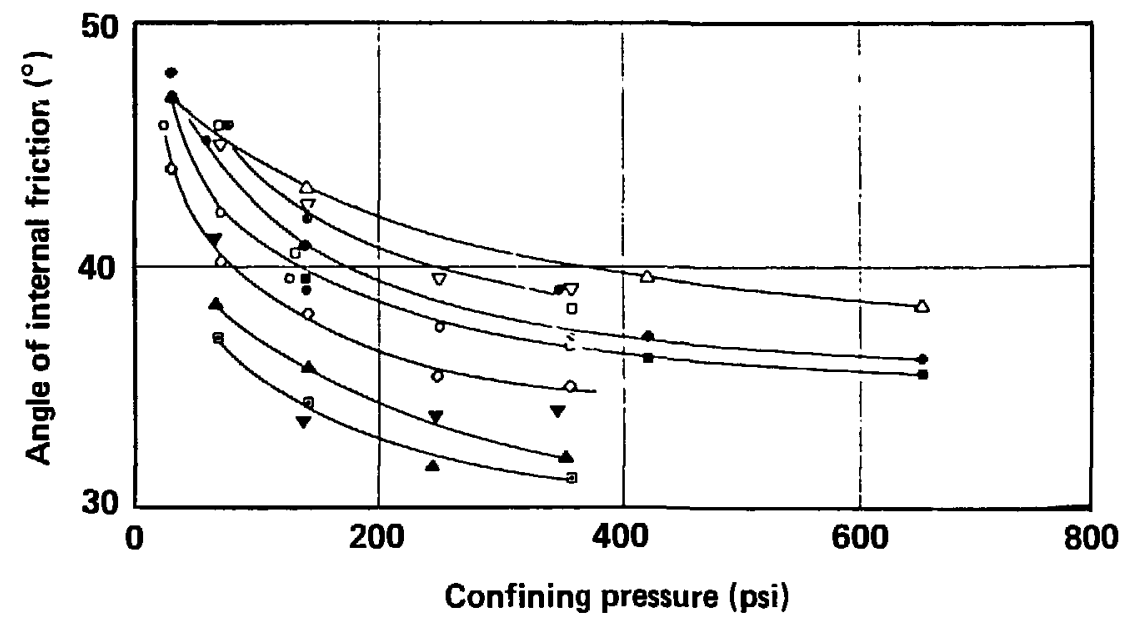

Figure 15. Angle of friction vs confining pressure for large rockfill specimens. 65 

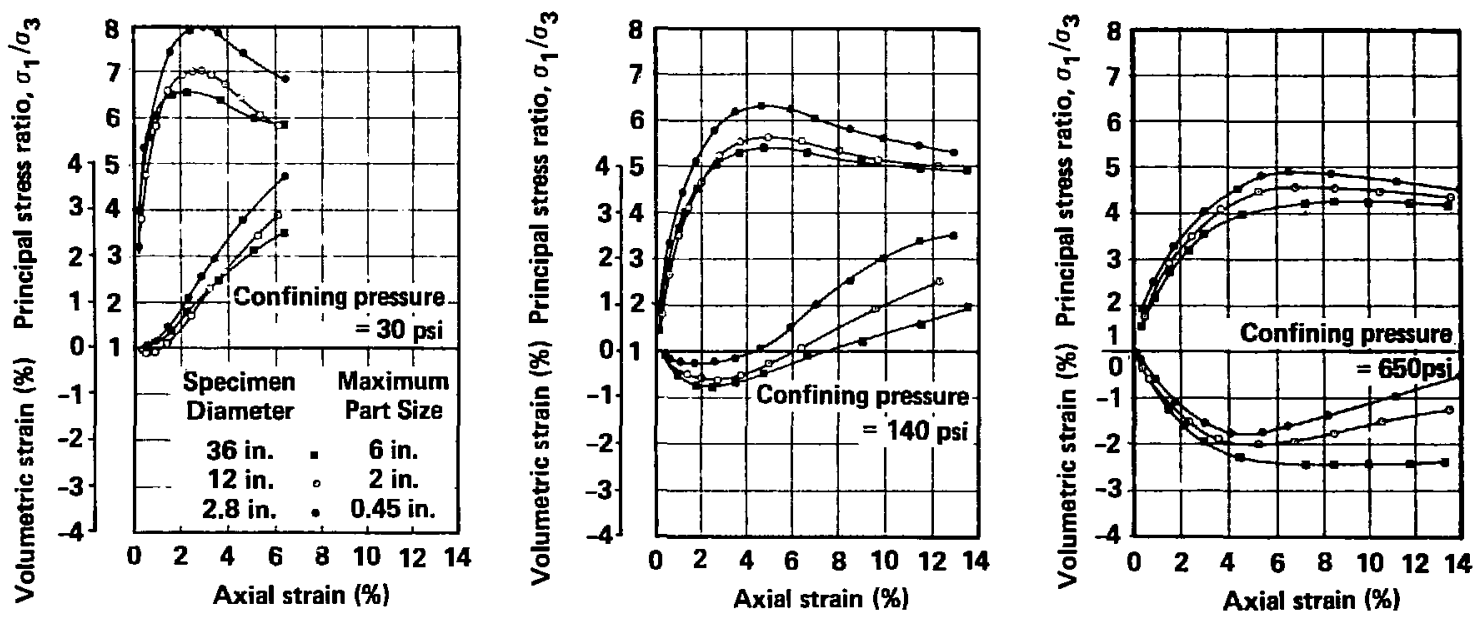

Figure 16. Strength and deformability properties of Oroville Dam rockfill materiai for various sample sizes in triaxial compression. 65
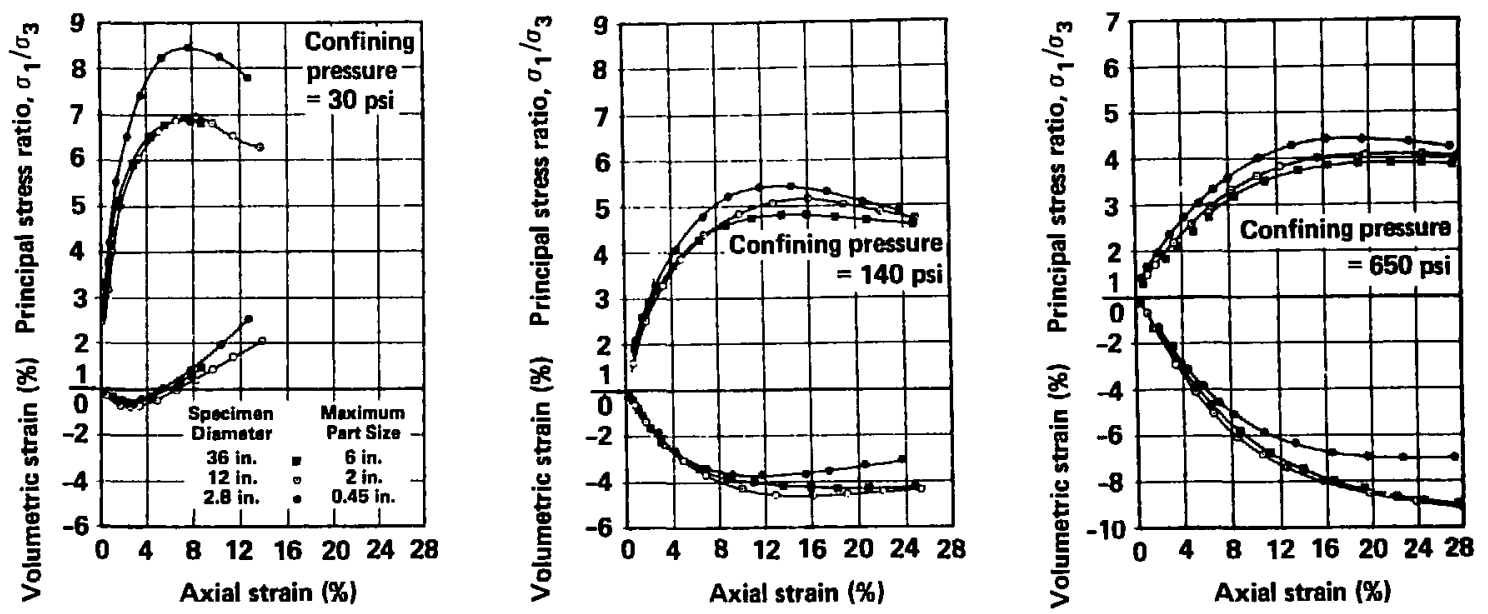

Figure 17. Strength and deformability properties of crushed basalt for various sample sizes in triaxial compression. 65 
acceptable. An alternate method to triaxial testing, for determining friction, is the use of a large size direct shear machine such as used by the Rock Mechanics Laboratory at U.C. Berkeley for granular materials and weak rocks. ${ }^{69}$ The large triaxial cell and the large shear box of U.C. Berkeley are shown on Figs. 18 and 19 respectively. Consideration could be given to making use of this equipment on an ad hoc basis in cooperation with U.C. Berkeley .

As for the rock materials with joints and fractures, the effect of scale on mechanical and fluid flow properties is well recognized. $10,13,14,70-76$ Significant information exists regarding the ratio of field-measured rock mass deformability, $E_{F}$ to laboratory-measured rock material modulus, $E_{\ell}$ - Based on surveys by the author and one of his colleagues, ${ }^{13,76}$ involving 37 large rock projects worldwide, the mean of $103 \mathrm{E}_{F} / \mathrm{E}_{\ell}$ ratios was about 0.40 . The numbers obtained on small cores were on the average 2.5 times higher than deformability values measured in place. Data are much scarcer regarding scale effects on the compressive or shear strength of large rock volumes. Figure 20 shows a typical variation of compressive strength versus size of sample for a hard rock. 70 The striking features are the precipitous decrease in strength, when the size exceeds that of conventional laboratory samples (15 to $20 \mathrm{~cm}$ diameter), and the large scatter of results at the laboratory scale, when compared to the field scale. Today, one can only speculate as to what the corresponding strength/size relations for tuff and other volcanics may look like. Regarding the shear strength of joints, it has been suggested that the minimum test size should be that of a natural block bounded by the existing joints and fractures. 14

The in situ tensile strength of rocks also is poorly documented, although a measurement procedure based on hydraulic fracturing tests in boreholes has been suggested. 63 Recently, approximate strength criteria have been published for intact and jointed rock masses. 77 The values summarized in Table 5 are qualified by their authors as being somewhat tentative, since they are based upon so little field information. Column 4 refers to rhyolite, which is one of the test media at NTS, such as for the MOLBO event. Line 3 of column 5 could apply to the climax granite of the past HARD HAT and PILFDRIVER events, but there is no direct reference to tuffs. They may fit in the lower half of column 4, depending upon their degree of fracturing. 


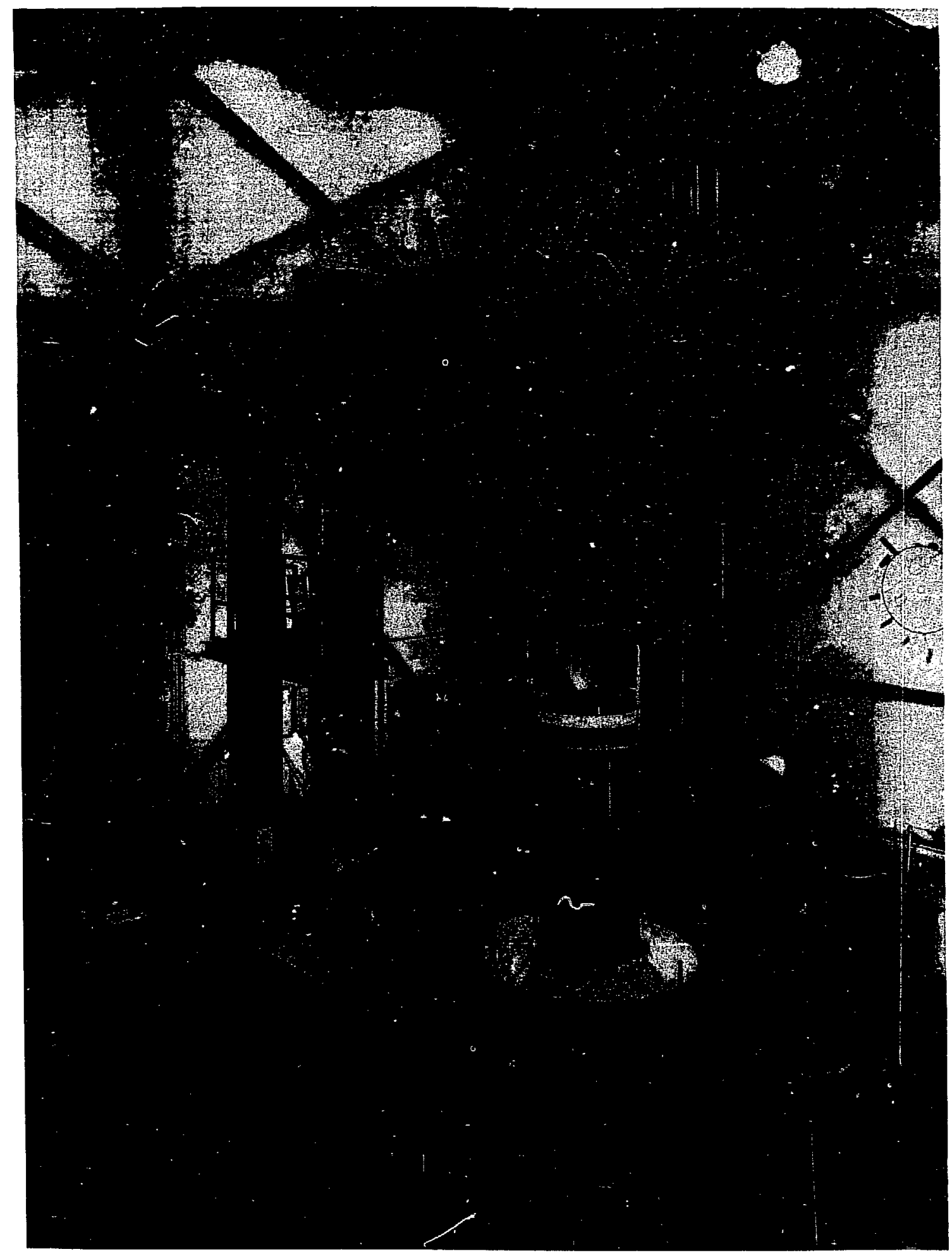

Figure 18. Large scale triaxial system at U.C. Richmond Field Station (LBL photograph ). 


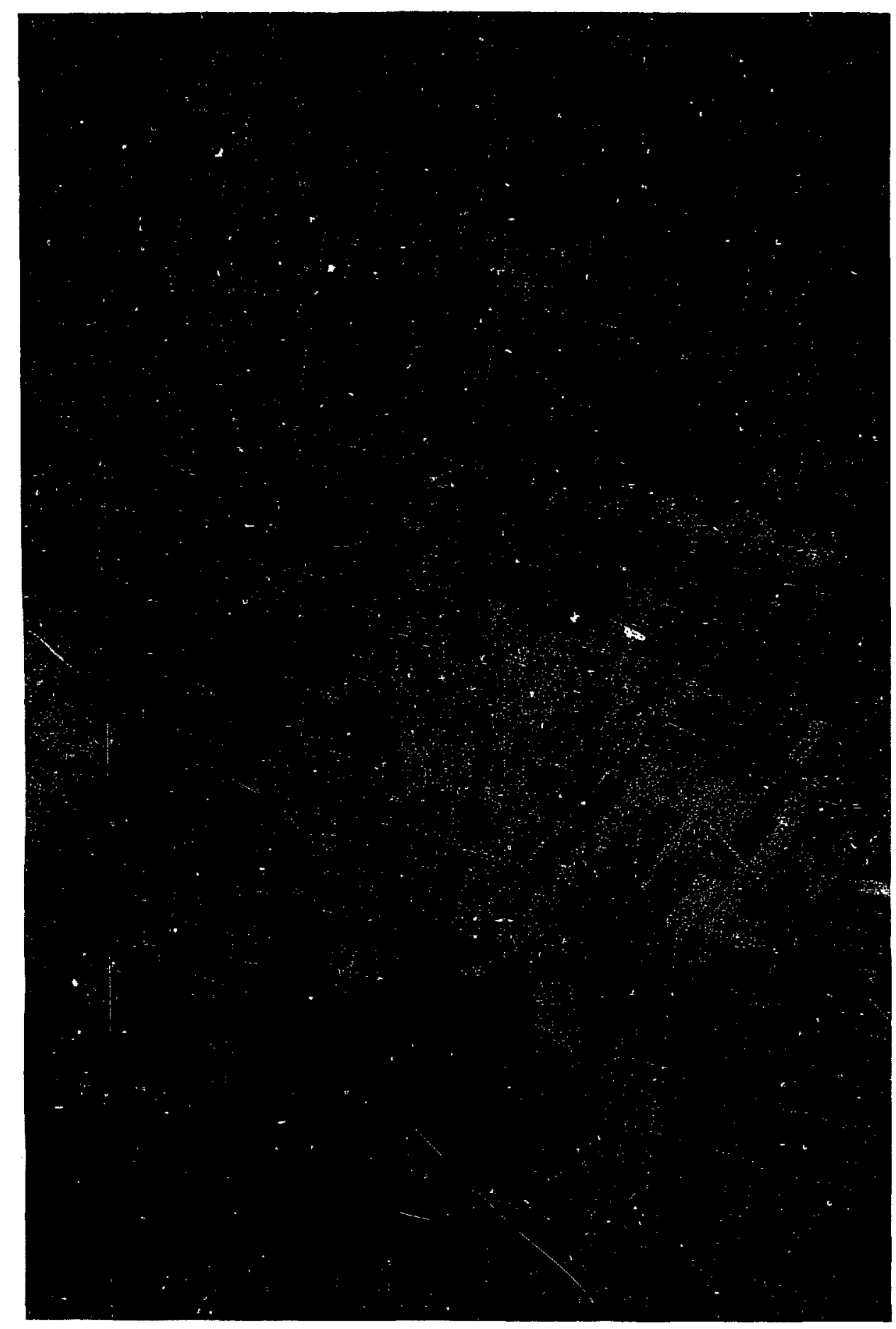

Figure 19. Large scale direct shear machine of U.C. Berkeley's Rock Mechanics Laboratory. Maximum sample area is $30 \times 45 \mathrm{~cm} .69$ 


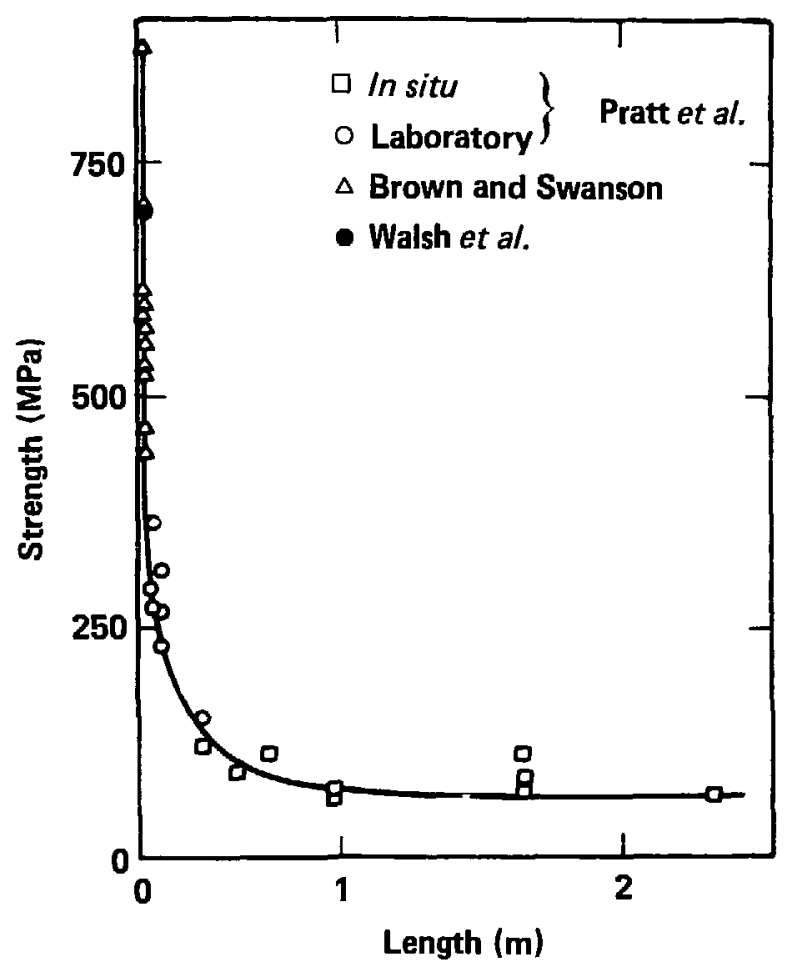

Figure 20. Scale effect on unconfined compressive strength of diorite. 70

\subsection{AN OUTLINE OF SUGGESTED COMPLEMENTARY STUDIES}

Based on the above discussion, several suggestions for new and modified procedures are grouped under the headings of field testing, laboratory testing, and numerical modeling. Table 6 outlines the types of activities which are involved, and the purpose of each activity. An attempt also is made to establish priority needs regarding these activities. The following comments are in order:

- The recommendations entail some redundancy in the testing. In particular, it is proposed that short-term deformability and strength properties be measured both in the field and in the laboratory. This is related to the effect of scale on the one hand and to the imperfections of both laboratory and field tests on the other. The exact volume of rock involved in a borehole test is not precisely defined, as it would be in a laboratory test. 13 on the 
Table 5. Approximate strength criteria for intact rock and jointed rock masses. 72

\begin{tabular}{|c|c|c|c|c|c|}
\hline \multicolumn{6}{|c|}{ APPROXIMATE RELATIONSHIP BETWEEN ROCK MASS QUALITY NND CONSTANTS } \\
\hline 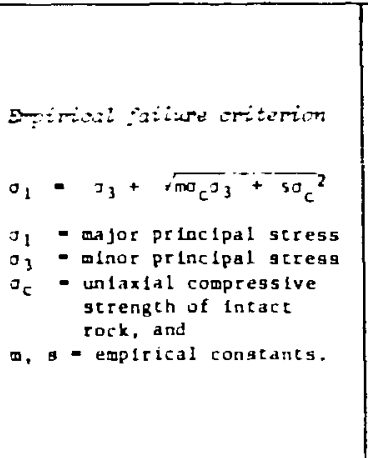 & 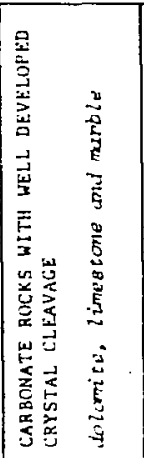 & 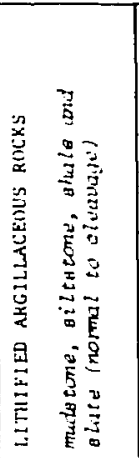 & 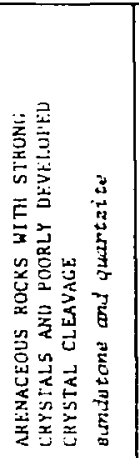 & 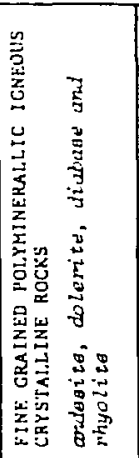 & 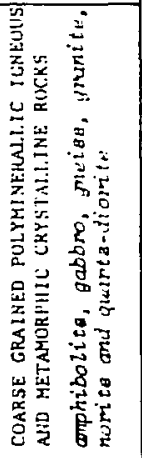 \\
\hline 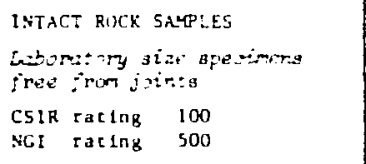 & $\begin{array}{l}=7.0 \\
s=1.0\end{array}$ & $\begin{array}{l}w=10.0 \\
s=1.0\end{array}$ & $\begin{array}{l}w=15.0 \\
s=1.0\end{array}$ & $\begin{array}{l}x=17.0 \\
g=1.0\end{array}$ & $\begin{array}{l}x=25.0 \\
3=1.0\end{array}$ \\
\hline 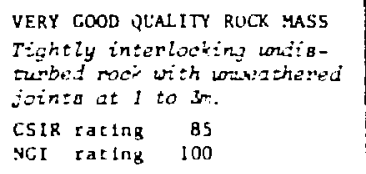 & $\begin{array}{l}a=3.5 \\
x=0.1\end{array}$ & $\begin{array}{l}m=5.0 \\
s=0.1\end{array}$ & $\begin{array}{l}m=7.5 \\
s=0.1\end{array}$ & $\begin{array}{l}m=8.5 \\
s=0.1\end{array}$ & $\begin{array}{l}m=12.5 \\
8=0.1\end{array}$ \\
\hline 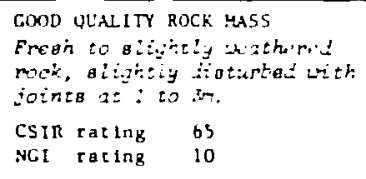 & $\begin{array}{l}\mathrm{s}=0.7 \\
\mathrm{~s}=0.004\end{array}$ & $\begin{array}{l}\sigma=1.0 \\
s=0.004\end{array}$ & $\begin{array}{l}m=1.5 \\
g=0.004\end{array}$ & $\begin{array}{l}m=1.7 \\
B=0.004\end{array}$ & $\begin{array}{l}\mathrm{m}=2.5 \\
\mathrm{~s}=0.004\end{array}$ \\
\hline $\begin{array}{l}\text { FAIR QLinLITY ROCK MASS } \\
\text { Several sets of moderateiy } \\
\text { weachered joints spaced af } \\
0.3 \text { to Im. } \\
\text { CSIR racing } 44 \\
\text { NGI rating i }\end{array}$ & $\begin{array}{l}m=0.14 \\
g=0.0001\end{array}$ & $\begin{array}{l}x=0.20 \\
=-0.0001\end{array}$ & $\begin{array}{l}a=0.30 \\
B=0.0001\end{array}$ & $\begin{array}{l}m=0.34 \\
\mathrm{~g}=0.0001\end{array}$ & $\begin{array}{l}u=0.50 \\
s=0.0001\end{array}$ \\
\hline 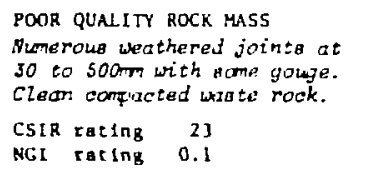 & $\begin{array}{l}=0.04 \\
s=0.00001\end{array}$ & $\begin{array}{l}=0.05 \\
s=0.00001\end{array}$ & $\begin{array}{l}=0.08 \\
=0.00001\end{array}$ & $\begin{array}{l}\mathrm{s}=0.09 \\
\mathrm{~s}=0.00001\end{array}$ & $\begin{array}{l}x=0.13 \\
s=0.00001\end{array}$ \\
\hline $\begin{array}{l}\text { VERY POOR QUALITY ROCK MASS } \\
\text { Mhenerous hequi iy weathered } \\
\text { jointe sprised \& som with } \\
\text { gouge. Hrate rock with fines. } \\
\text { CStR rating } 3 \\
\text { NGI rating } 0.01\end{array}$ & $\begin{array}{l}\mathrm{m}=0.007 \\
\mathrm{a}=0\end{array}$ & $\begin{array}{l}=-0.010 \\
s=0\end{array}$ & $\begin{array}{l}m=0.015 \\
=0\end{array}$ & $\begin{array}{l}a=0.017 \\
s=0\end{array}$ & $\begin{array}{l}0.025 \\
0=0\end{array}$ \\
\hline
\end{tabular}


Table 6. Suggested geotechnical studies complementary to current containment practice.

$\begin{array}{llr}\text { Type of information } & \text { Type of activity } & \begin{array}{r}\text { Suggested } \\ \text { priority }\end{array}\end{array}$

In Situ Testing ${ }^{a}$

In situ stresses

Hydrofracturing $(P)^{b}$

In situ deformability

In situ tensile strength

In situ shear strength

Laboratory Tests

Very-short-term (dynamic)

deformability and strength

Short-term deformability

Short-term shear strength

Long-term deformability

Long-term strength

Numerical Modeling

Short-term effects (cavity growth, spall region, containment cage)

Long-term effects (cavity collapse, subsidence, and surface collapse)
In situ velocity and stress measurements $(P)^{c}$

Borehole jack fracturing (S)

Petite sismique ( $\mathrm{S}$ )

Rock mass classification (S)

Modified hydrofrac (P)

2

Borehole jack fracturing (S)

Borehole shear

1

Large-scale triaxial $\quad{ }_{2}^{d}$

Large-scale triaxial 1

Large-scale triaxial (P) 1

Large direct shear (S) 1

Large-scale triaxial creep 2

Short-term triaxial plus creep tests 1

Explicit calculations

1

using refined input of in situ

stresses and material properties

Implicit calculations

2

input from short-term calculations

a A11 short-term tests.

b P: primary method; $S$ : secondary method.

c Such instrumentation recently was fielded with the TILCI event. Results of the measurements are being analyzed. 78

d Although this is very desirable information, we do not know of equipment now suitable for such testing. 
other hand, the material in place certainly is less disturbed than when extracted and transported to a laboratory.

- The typical stresses involved in the proposed field and laboratory tests range from 1 bar to 1 kbar $(0.1$ to $100 \mathrm{MPa})$. This is the very range where the greatest need exists for refinement of material properties in containment calculations. 78

- The recommendations offered in the section on physical properties do not affect the current practice for measuring these properties.

- The suggested priority for the various activities involve an attempt to weigh various potentially conflicting factors such as the desirability of having the information, the practicality of obtaining the information, and the possibility of using this information when it is generated. For example, it is desirable to know whether the principal stresses in the horizontal direction are unequal, because the more unequal they are the higher the horizontal shear stress. It is practical but not trivial to obtain a measurement of such stresses by hydraulic fracturing, for example. However, this information cannot be used directly in a two-dimensional calculation because it requires the horizontal principal stresses to be equal. Then, one may choose to adopt the smaller principal stress as the most conservative value.

Table 6 shows that first priority is given to the short-term effects and to the large scale determination of deformability and shear strength in the field or, when possible in the laboratory. Of less urgency are the long-term effects and the determination of tensile strength. This latter parameter, however, can be obtained as a by-product of hydrofracturing stress measurements, which rank as a very desirable task.

Definitions and details for the new in situ tests, laboratory tests, and computer models are given in the following chapter. 
4.1. IN SITU TESTING

\subsubsection{In Situ Stresses}

The recommended method to obtain in situ stresses at depths up to several hundred metres in the alluvium and tuffs is the hydraulic fracturing technique. $63,79,80$ Hydrofracturing results obtained in the tuffs of $N, E$, and $T$ tunnels at NTS, did correlate well with results obtained by the overcoring method. ${ }^{81-83}$ However, overcoring at great depth still is an experimental technique, ${ }^{84}$ whereas deep hydrofracturing is a proven procedure. In the Mesas, it has been shown that one of the principal stresses is near vertical. 81 Such an assumption is reasonable as well for the weakly consolidated materials of Yucca Flat. Thus, the two remaining principal stresses are in horizontal directions, and hydrofracturing in vertical holes is a suitable approach. These horizontal stresses are not necessarily equal to each other. This was confirmed by recent hydrofracturing in soils, 85 as well as in the tuffs of Area 12, where major and minor horizontal stresses were measured as 88 and $35 \mathrm{MPa}$, respectively. 81 The symbols used in this discussion are illustrated in Figs. 21 and 22 for a dry medium:

$\sigma_{h M}$ is the maximum horizontal stress.

$\sigma_{h m}$ is the minimum horizontal stress.

$\sigma_{t}$ is the tensile strength of the formation.

$P_{c l}$ is the initial breakdown pressure (hydraulic pressure when the first pressurization overcomes the tensile strength and the in situ stress concentrations).

$\mathrm{p}_{\mathrm{s}} \quad$ is the shut-in pressure or steady pressure achieved when pumping continues beyond $\mathrm{Pcl}$.

$P_{c 2}$ is the new peak pressure obtained when repressurizing a hole after letting the hole pressure fall below $P_{s} \cdot P_{c 2}$ does not enter the equations in conventional hydraulic fracturing to measure stresses. When there is no pore pressure, two equations allow $\sigma_{h M}$ and $\sigma_{h m}$ to be calculated if the in situ tensile strength is known: 

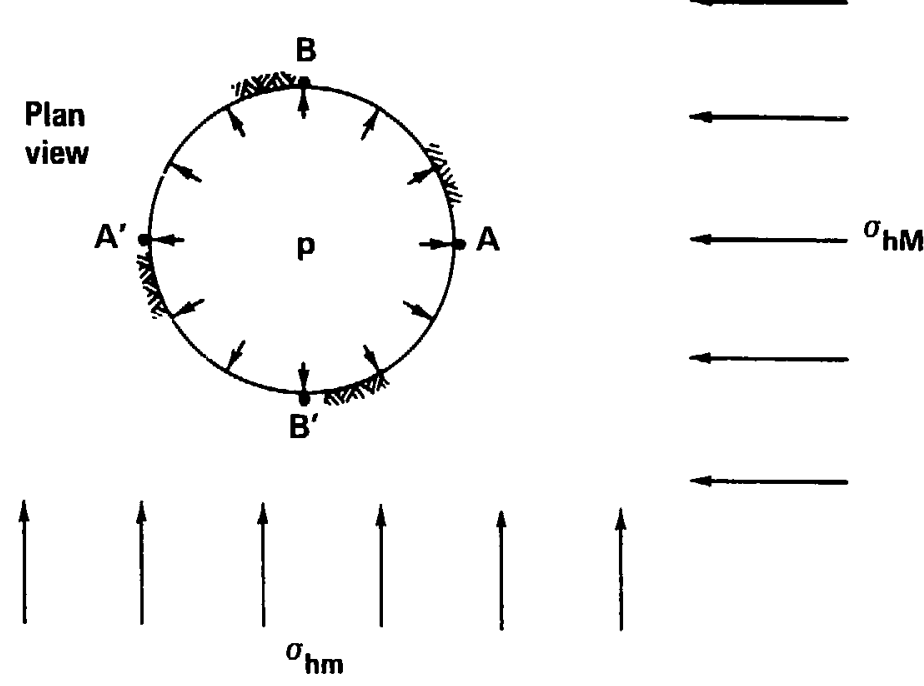

Figure 21. Internal pressure and in situ stresses in hydraulic fracturing.63

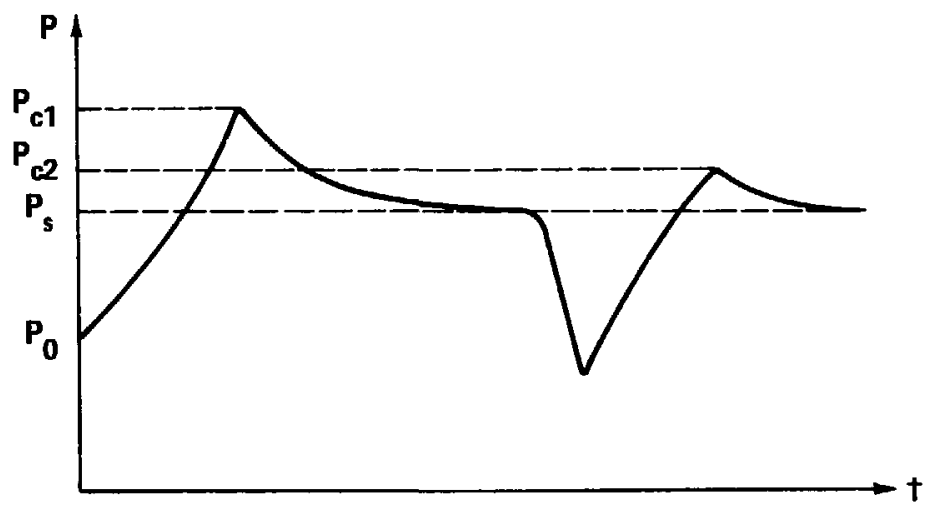

Figure 22. Pressure-time curve in hydraulic fracturing. 63 


$$
\begin{aligned}
& 3 \sigma_{h m}-\sigma_{h M}=p_{c 1}-\sigma_{t}, \\
& \sigma_{h m}=p_{s} .
\end{aligned}
$$

When there is a pore pressure, $P_{0}$, in the formation, $P_{0}$ is subtracted from the total stresses in Eqs. (1) and (2). The above equations also assume that the hydrofracturing fluid does not percolate in the geological medium. A previous attempt to measure stresses in the NTS alluvium by hydrofracturing did not provide reliable values. 86 Improvements in the technique, such as the use of highly viscous gels and of loss additives should enhance the prospect of obtaining better results today. 85 standard equipment available in the geotechnical community permits hydrofracturing in $\mathrm{NX}(7.5 \mathrm{~cm}$ diam) boreholes.

An alternate method is to use the modified NX borehole-jack method which is described elsewhere. ${ }^{87,88}$ The technique is still somewhat experimental but should work well in nonfractured formations. A recent application at NTS in the Climax granite was only partially successful because of the existing fractures in the rock. ${ }^{89}$ Such fractures would affect the quality of hydrofrac measurements as well.

\subsubsection{In Situ Deformability}

The preferred method consists of direct measurements with the NX borehole jack, which is particularly wel1 suited for soft rock formations. 90,91 The jack can apply wall pressure up to $70 \mathrm{MPa}$. A large number of measurements can be made at different orientations in a single hole. The volume of rock involved in the test is estimated to be about $4.6 \mathrm{ft}^{3}$, or $0.13 \mathrm{~m}^{3} .13$ This is the same volume as that of a 44-cm-diam cylinder with a length/diameter ratio of 2. Based on an earlier discussion, this means that the jack certainly is adequate when the fracture spacing or the maximum particle size are less than about $3 \mathrm{in.}(7.5 \mathrm{~cm})$. In fact, experience in rocks $16,90,92$ has shown the jack to be applicable in cases when the spacing was up to $10 \mathrm{in}$. $(25 \mathrm{~cm})$. Additional estimates of rock mass deformability can be obtained with indirect methods such as the empirical correlations based on the petite sismique method and rock mass classifications. ${ }^{89}$ A recent application of these methods in the Climax granite at NTS demonstrates the value of obtaining redundant estimates of rock mass properties. 92 


\subsubsection{In situ Tensile Strength}

There is no proven method to determine the tensile strength of geologic materials in situ. However, two methods have been proposed which, in theory can provide the required information, i.e., an extended hydraulic fracturing procedure and the use of borehole jack fracturing.

If, in hydrofracturing, the borehole pressure is dropped after reaching the shut-in pressure, $p_{s}$, and raised again, the hydraulic fracture will close and reopen. ${ }^{63}$ Let the new peak pressure be $p_{c 2}$ (see Fig. 21). It is smaller than $P_{c l}$, because the tensile strength of the materiai is now zero. Thus, replacing $\sigma_{t}$ by 0 and $p_{c 1}$ by $p_{c 2}$, Eq. (1) becomes

$$
3 \sigma_{h \mathrm{~m}}-\sigma_{\mathrm{hM}}=\mathrm{P}_{\mathrm{c} 2}
$$

Subtracting Eq. (1) from Eq. (3) gives:

$$
\sigma_{t}=p_{c 1}-p_{c 2}
$$

Turning around, one realizes that $\sigma_{h m}$ and $\sigma_{h M}$ can now be calculated without assuming $\sigma_{t^{*}}$. The extended hydrofracturing procedure is self-contained and provides $\sigma_{h m}, \sigma_{h M}$, and $\sigma_{t}$. A caveat is in order at this point. The hydraulic fracturing experiment does not yield the above results if the fracture is not vertical. ${ }^{63}$ Assuming that the tensile strengths for propagation of horizontal and vertical fractures are the same, the vertical fracture could form only at a depth below which the vertical stress is ${ }^{63}$ :

$$
\sigma_{v} \geq 3 \sigma_{h m}-\sigma_{h M}
$$

Let $\mathrm{K}$ be the ratio of the average horizontal stress to the vertical stress,

$$
k=\left(\sigma_{h m}+\sigma_{h M}\right) / 2 \sigma_{v},
$$

and $z$ be the depth in metres. A recent survey of numerous published in situ stress values 93 has led to the conclusion that most $K$ values are within the limits

$$
0.3+100 / \mathrm{z} \leq \mathrm{K} \leq 0.5+1500 / \mathrm{z}
$$


Table 7.

\begin{tabular}{ccc}
$\begin{array}{c}\text { Horizontal } \\
\text { stress ratio } \\
\sigma_{\mathrm{hm}} / \sigma_{\mathrm{hM}}\end{array}$ & $\begin{array}{c}\text { Minimum depth (m) for vertical } \\
\text { hydrofrac, assuming }\end{array}$ \\
\cline { 2 - 3 } 0.33 & 0 & $\mathrm{z}=1500 /(\mathrm{K}-0.5)$ \\
0.40 & 31 & 0 \\
0.50 & 83 & 500 \\
0.60 & 143 & 1,500 \\
0.667 & 188 & 3,000 \\
0.70 & 211 & 4,505 \\
0.80 & 292 & 5,495 \\
0.90 & 386 & 10,490 \\
1.00 & 500 & 25,424 \\
\hline
\end{tabular}

Equations (5) and (7) combine to give the range of the minimum depth to obtain a vertical hydraulic fracture corresponding to different values of $N$ (see Table 7). 63

The preceding discussion highlights the requirement for determining the orientation of the hydraulic fracture. This can be done either by using an impression packer, or by visual inspection of the borekole with a camera.

An independent estimate of in situ tensile strength can be obtained by borehole-jack fracturing. 94 The borehole-jack loading in a medium subjected to a biaxial stress field is illustrated in Fig. 23. In Fig. 24 the distribution of induced tangential stress, $\sigma_{\theta}$, shows a maximum at an angle, $\beta$, which is half the angular width of the jack plates. With the conventional NX borehole jack in which $\beta=45^{\circ}$, the tensile strength estimate was obtained as 94 :

$$
\sigma_{t}=\sigma_{h M}+\sigma_{h m}-2\left(\sigma_{h M}-\sigma_{h M}\right) \cos 2(45-\alpha)+2 \mathrm{P} / \mathrm{r},
$$




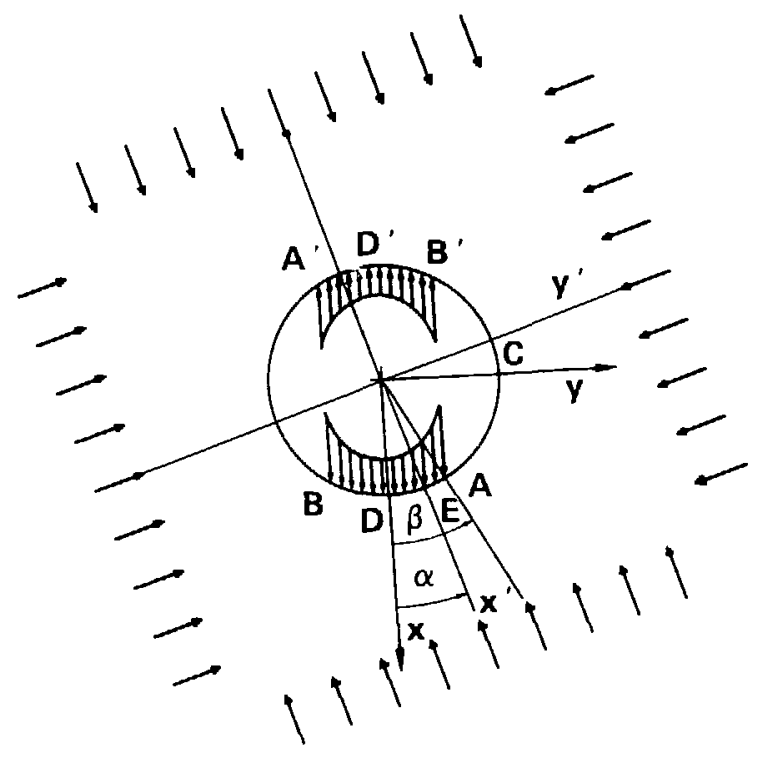

Figure 23. Borehole-jack loading in a biaxial stress field. ${ }^{83}$

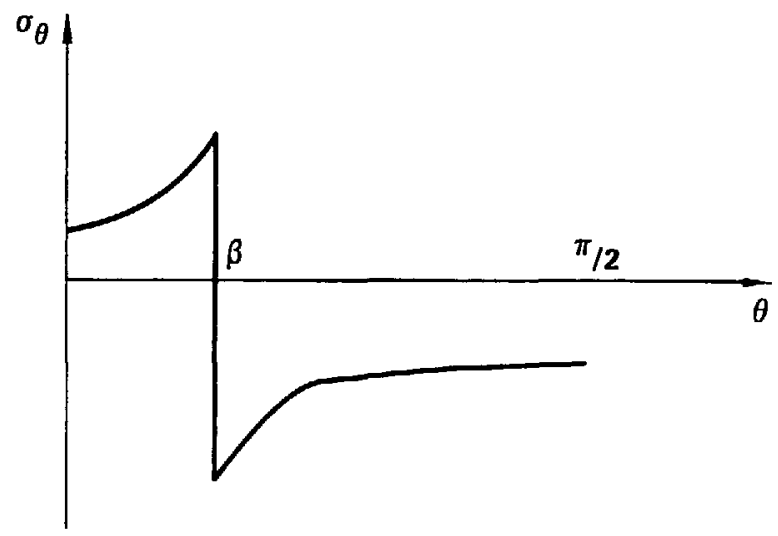

Figure 24. Tangential stress on borehole wall under jack loading. ${ }^{83}$ 
where

$\alpha \quad$ is the angle between the direction of borehole loading and $\sigma_{h M}$,

$P_{i}$ is the borehole jack pressure at initiation of tensile fracture around the hole, and

I is the borehole radius.

An estimate of $F_{i}$ can be obtained from a softening in the loaddisplacement curve of the jack record; $\sigma_{h M}, \sigma_{h m}$ and $\alpha$ can be gained in an independent hydrofracturing test. Thus, an additional estimate of $\sigma_{t}$ can be acquired to be compared with the value derived from the extended hydrofracturing procedure.

\subsubsection{In Situ Shear Strength}

The only instrument available today to measure rock shear strength at depth is the Rock Borehole Shear Tester (RBST), which has been developed for use in NX holes. 95,96 The principle is to expand a borehole jack with specially serrated loading plates and then to pull the shoes in contact with the rock, parallel to the axis of the borehole, under a constant normal force. The shear surface is in the material adjacent to the borehole wall. The normal stress range is 0.1 to $80 \mathrm{MPa}$, and the shear stress range is 0 to $50 \mathrm{MPa}$. From the measured pull force, a rock shear strength is derived which is expressed in terms of cohesion and friction angle. The instrument has been used in softer rocks (coal, marlstone, mudstone, trona,...) to the apparent satisfaction of the users. 96 A possible limitation of the method is that the material adjacent to the borehole wall would have been so disturbed in the drilling process that it would not be representative any longer.

\subsubsection{Suppliers and Costs}

The above tests can be done either by subcontracting or by having LLNL purchase and field the equipment, which would allow modifications and enhancement as desired. It is quite remarkable that a!l but one of the procedures can be performed in NX-size holes with off-the-shelf equipment. The exception is the petite sismique (shear-wave propagation) for which current down-the-hole equipment probably can be adapted to NX size at moderate cost. The cost of drilling a 1000-ft-deep hole with a diameter of 3 to 12 in. 
in alluvium currently is estimated at about $\$ 200,000 .^{97}$ This compares to about $\$ 600,000$ for a 1000-ft deep, 96-in.-diameter emplacement hole. 97 The cost of NX holes currently is not included in the budget for routine tests. Hydraulic fracturing in NX holes is routinely performed by Dr. B. C. Haimson of the University of Wisconsin at Madison. Costs incurred involve only time and expenses. No charge is made for equipment rental. The cost of LLNL acquiring this type of equipment is not known at present. Another man with considerable experience in hydrofracturing is $\mathrm{Dr}$. J. C. Roegiers who is presently with Dowell Company of Tulsa, Oklahoma, while on leave of absence from the University of Toronto, Canada.

The conventional NX borehole jack can be purchased from slope Indicator Company in Seattle (SINCO). A system to operate down to a few hundred metres would cost between $\$ 10,000$ and $\$ 15,000$. The equipment can also be rented from SINCO on a weekly or monthly basis, as was done for recent NTS work in the Climax granite. 92

The modified borehole jack for borehole fracturing is available on a service basis from $\mathrm{Dr}$. R. V. de la Cruz, also of the University of Wisconsin at Madison. Again, only personnel time and expenses are involved. Since this instrument is a prototype, there is no firm price on LLNL acquisition of such a system. Because of the still experimental nature of the procedure it would be advisable to consider purchase only after the method has been proven in the materials of interest.

The Rock Borehole Shear Tester is manufactured by Handy Geotechnical Instruments of Ames, Iowa. The service is also available for rent from Geotest in Chicago. Current depth limitation is about $100 \mathrm{~m}$. The cost of a system operating to a depth of about $100 \mathrm{~m}$, in connection with a wireline, would be about $\$ 10,000$. Rental costs can be obtained on request.

\subsection{Laboratory Testing}

The discussions of chapter 3 clearly pointed to the need for resolving time effects and scale effects on geological material properties. Laboratory testing seems attractive for two reasons. In terms of time, it would be most impractical to attempt performing the field tests previously described for extended periods of time; e.g., the days and, possibly, weeks required for investigation of creep. In terms of scale, the field tests in borehole do have a set size, whereas the sample size can be varied in the laboratory. 
It is not necessary to dwell on the well known triaxial test and the direct shear test. However, it is worth noting that large scale triaxial equipment is accessible within the University of California's own laboratories at Berkeley and Richmond. The large scale triaxial testing machine shown on Fig. 18 is currently on loan to the Earth Sciences Division of the Lawrence Berkeley Laboratory (LBL) by the Civil Engineering Department at U.C. Berkeley. The normal frame capacity is $4 \mathrm{Mlb}(17.8 \mathrm{MN})$; the system is servocontrolled and is equipped with an HP 9845 computer. Accessibility to this test equipment should increase now that the LBL/Stripa program, under the direction of Dr. P. A. Witherspoon, is being concluded. The large scale shear machine can be made available by Dr. R. E. Goodman of U.C. Berkeley on an ad hoc basis. Specific costs can be negotiated at a later date.

Even though the maximum confining pressure in the LBL machine is Iimited to about $1000 \mathrm{psi}(7 \mathrm{MPa})$, the independent testing of various sizes of samples in the U.C. 1 abs would indicate whether the test volumes involved in the field borehole measurements are representative. There is little doubt that the maximum volume that the Richmond triaxial system can accommodate would exceed the minimum representative volume for the great majority of the NTS alluvium. Testing of volumes up to $0.1 \mathrm{~m}^{3}$ was aleo proposed recently at LLNL, ${ }^{98}$ but this capability does not exist yet. As for the hard rocks, large granite cores have been tested on the recent LBL/Stripa program (see Fig. 25). The technology used to sample and transport these cores probably can be transferred to NTS materials such as welded tuff and rhyolite.

\subsection{Numerical Modeling}

For the analysis of short-term events (cavity growth, spall region, containment cage) a wave-propagation explicit finite difference code such as TENSOR provides a framework for computations. It contains algorithms which should accommodate the refined input of geology, in situ stresses, and mechanical properties of rocks and soils. The credibility of containment calculations can only benefit from a systematic effort to develop this refined input.

For the long-term aspects (cavity collapse, subsidence, and surface collapse) the numerical models should accommodate steady-state creep and failure mechanisms. Recent developments for calculations of subsidence over 


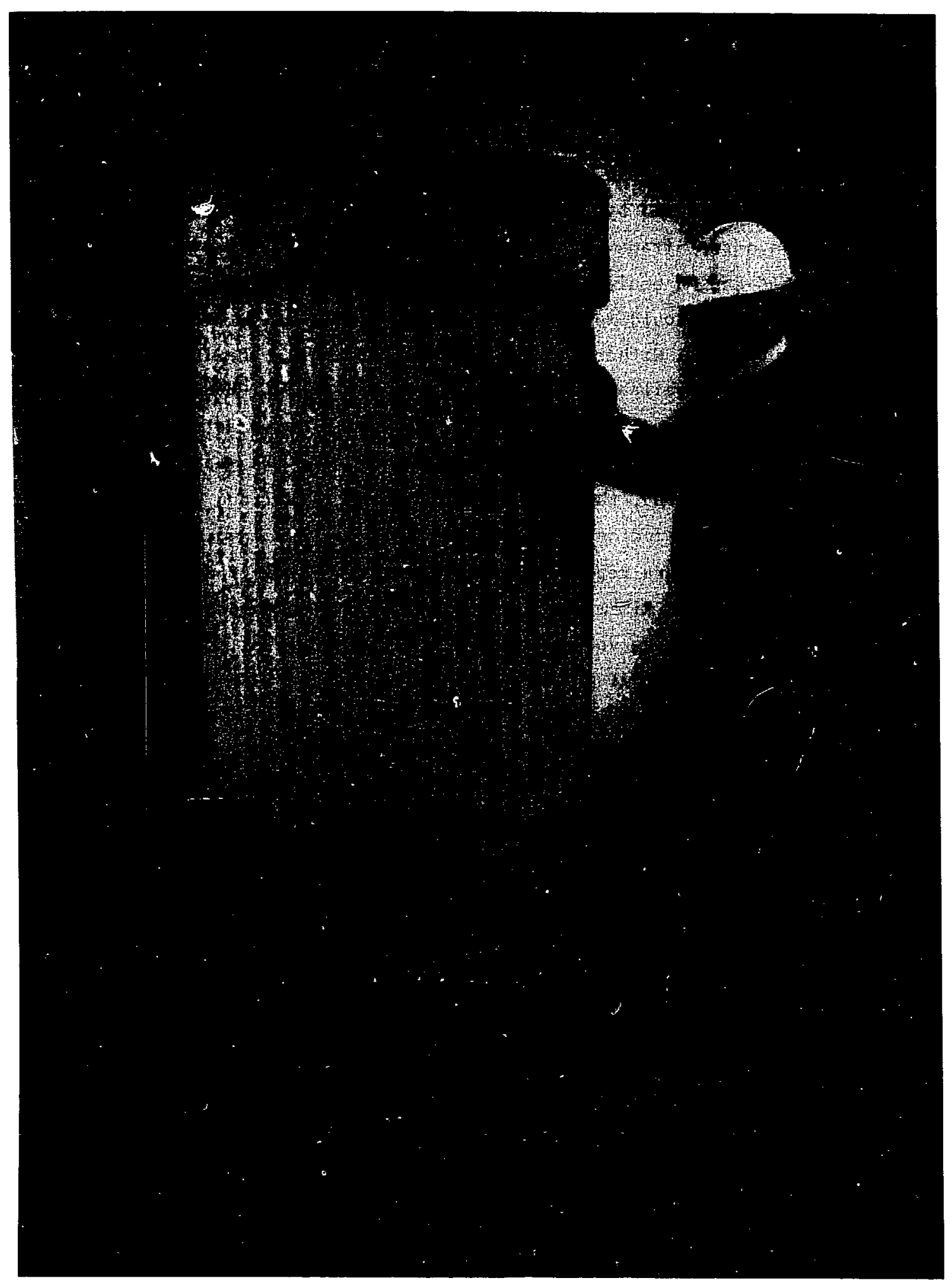

Figure 25. Large scale granite core for uniaxial test (LBL photograph). 
underground coal gasification areas $99-101$ and recent extensive surveys of the geotechnical computing field 102,103 indicate that implicit procedures are likely to be more efficient and versatile in performing the long-term calculations. It is suggested that development work be pursued on containment studies to couple the results of explicit short-term analysis to the input of implicit long-term calculations. TENSOR does have an implicit option but does not model transient or steady-state creep yet. Such creep models could be incorporated in the code. An alternative is to use a code already available at LLNL, such as the SANGRE finite element program developed at LANL, 104 and couple it to TENSOR. 


\section{SUMMARY}

Currently, estimation of containment of underground explosions at NTS is based mostly on empiricism derived from extensive experience and on a combination of physical/mechanical testing and numerical modeling. When measured directly, the mechanical material propertios are obtained from shortterm laboratory tests on small conventional samples. This practice does not determine the large effects of scale and time on measured stiffnesses and strength of geologic materials. Because of the limited data base of properties and in situ conditions, the input to otherwise fairly sophisticated computer programs is subject to several simplifying assumptions; some of them can have a nonconservative impact on the calculated results. As for the long-term, subsidence and collapse phenomena simply have not been studied to any significant degree.

This report has examined the geomechanical aspects of procedures currently used to estimate containment of underground explosions at NTS. Based on this examination, it was concluded that $s$ tate-of-the-art geological engineering practice in the areas of field testing, large scale laboratory measurements, and numerical modeling can be drawn upon to complement the current approach. Specific discussions were made with regard to:

- The time and scale effects in the measurement of mechanical properties of geological materials.

- Measurement of in situ stresses by hydraulic fracturing and borehole jack fracturing.

- Measurement of in situ deformability by NX-jack tests .

- Measurement of in situ tensile strength by hydraulic fracturing and borehole jack fracturing.

- Measurement of in situ shear strength by borehole shear tests.

- Large-scale laboratory triaxial tests.

- Large-scale laboratory direct shear tests.

- Implicit numerical modeling of subsidence and collapse processes, using the output from short-term explicit calculations of early ground response to explosions.

In cases where today's evaluations indicate marginal conditions or in cases where new test areas are contemplated for which there is no benefit of experience, it is reasonable to expect that a refined input to the calculations will provide more realistic containment estimates than current practice does. 


\section{ACKNOWLEDGMENTS}

This research was supported by the Containment Program funded by the Department of Energy at the Lawrence Livermore National Laboratory.

The author gratefully acknowledges the contributions of the following colleagues: A. E. Abey, D. E. Burton, M. S. Costantino, H. C. Heard, N. W. Howard, H. L. McKague, W. McKinnis, F. A. Morrison, Jr., C. W. Olsen, R. P. Swift, L. Thigpen, R. K. Thorpe, 0. R. Walton, and particularly J. T. Rambo and R. W. Terhune. Special thanks also are due to Mrs. L. Burrow for her fine typing of the manuscript. 
APPENDIX A

SUMMARY OF THE GEOLOGICAL, GEOTECHNICAL, AND GEOPHYSICAL INFORMATION PRESENTED TO THE CEP FOR EVENTS TILCI $^{8}$ and AKAVI ${ }^{9}$

TILCI: Figures A-1 to A-7; alluvium.

AKAVI: Figures A-8 to A-14; unsaturated tuff. 


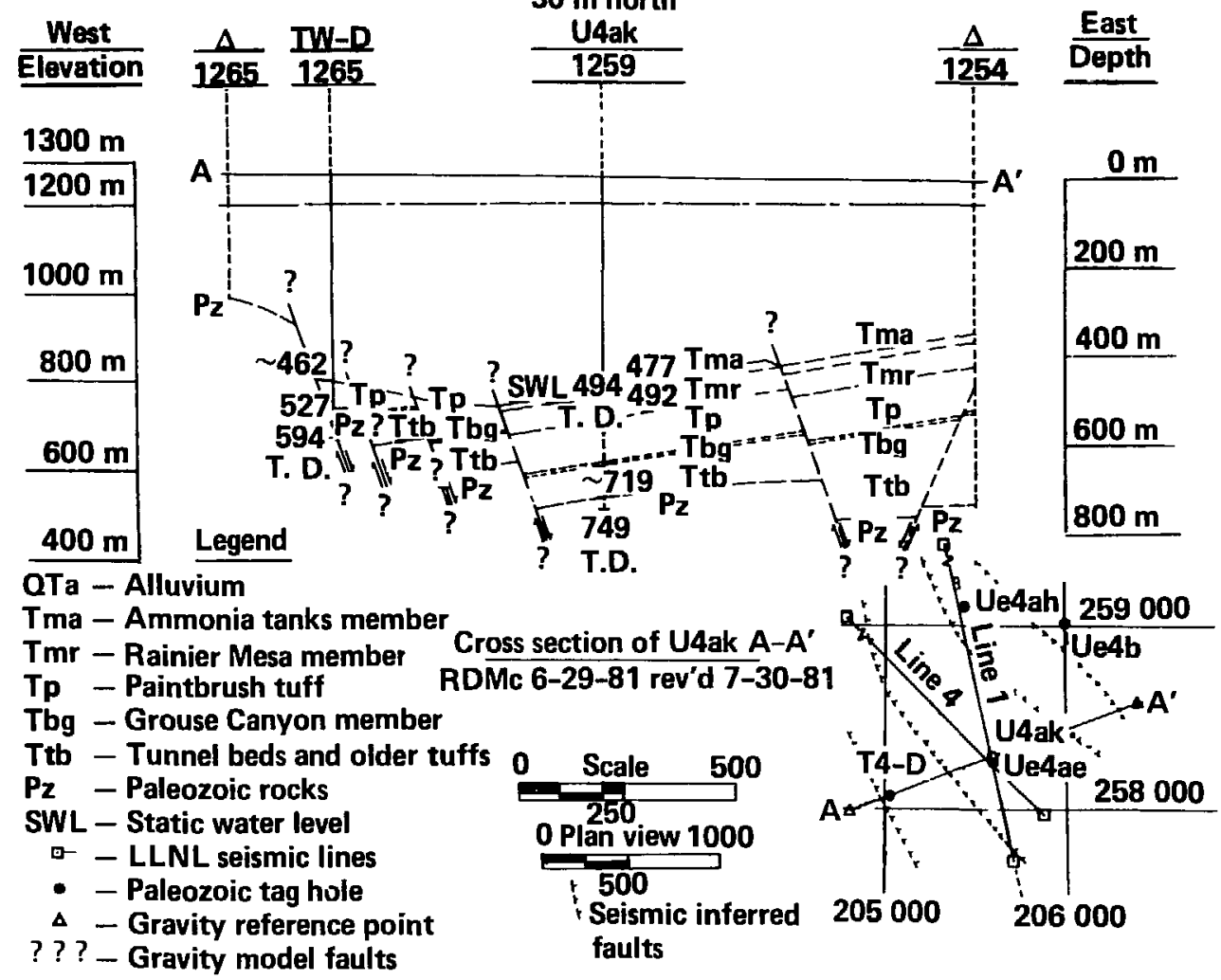

Figure A-1.

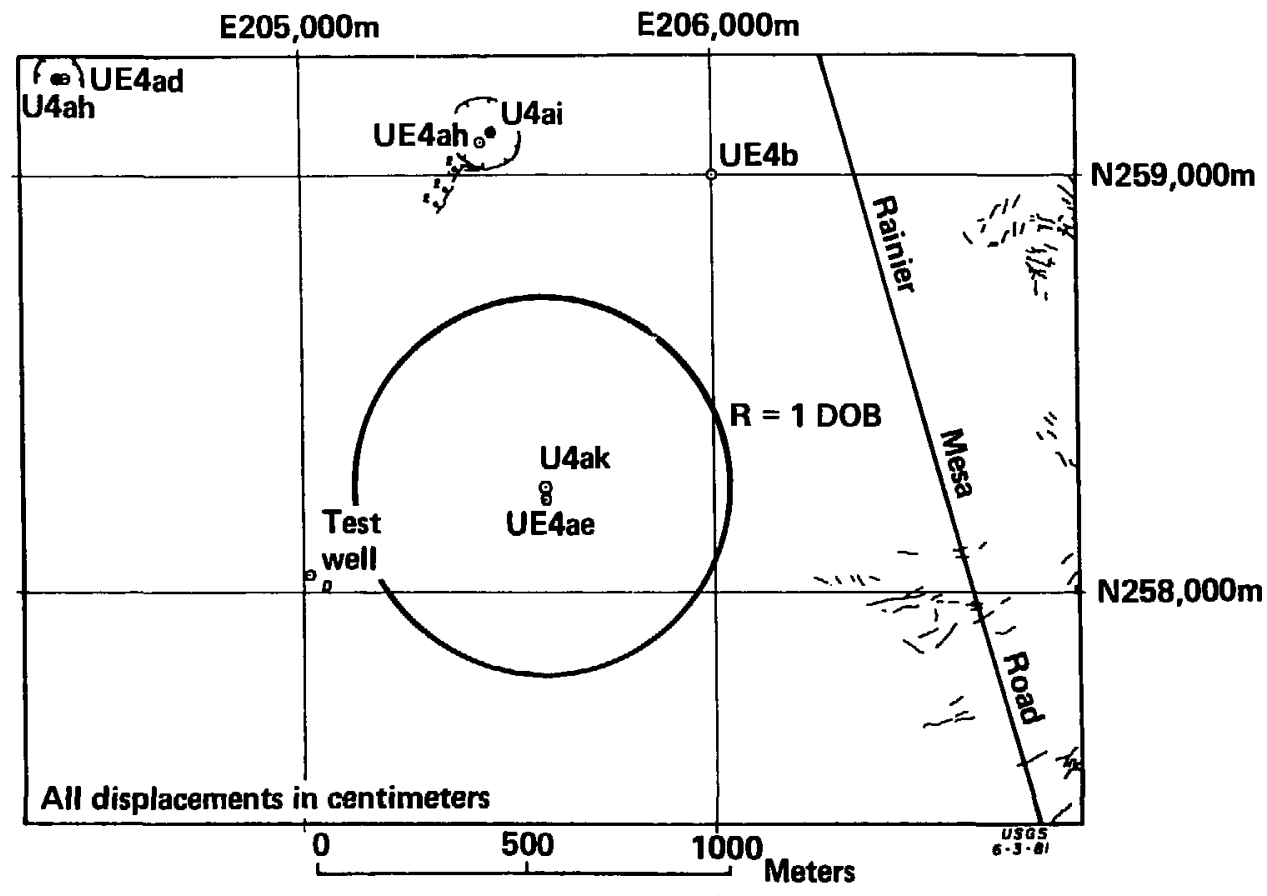

Pre-event location map of the U4ak site

Figure A-2. 


\section{ORILLIHG HISTORY}

Ue4ae was spudded 4-24-74 as part of the LLHL Area 4 exploration program. The hole, drilled with conventional air-foam was completed on 5-20-74 at a depth of $749 \mathrm{~m}$ in Paleozoic rocks. Logs were run 5-20- to 5-23-74, the hole was sidewall sampled on $6 \mathrm{~m}$ intervals 5-23 to 5-26-74, then plugged back to $698 \mathrm{~m}$ (above the Paleozoic surface). The hole was muddeo up; $3-0$, dipmeter and electric logs were run. In 1981, additional sidewall samples on $3 \mathrm{~m}$ intervals were taken on 5-10, and logs on 5-6 and 5-7-81.

U4ah was spudded on 4-13-81,30 m north of Ue4ae. It was completed using dual string reverse air and water circulation to a depth of $497 \mathrm{~m}$ by 5-6-81. No difficulties were encountered in drilling. Total cuttings samples were collected, and logs were run from May to July 1981 .

\section{MEDIUA ChARACTERISTICS}

Medium characteristics calculated for a $15.2 \mathrm{~m}$ radius averaging interval centered at $445 \mathrm{~m}$ in tuffaceous alluvium at U4ak are derived from Ue4ae and sunmarized in rable 1 . Between the two holes, magnetometer correlations indicate $2^{0}$ dip at the averaging interval, centered at $\mathbf{4 4 4} \mathrm{m}$ in Ue4ae wich corresponds to $\mathbf{4 4 5} \mathrm{m}$ in U4ak. The sources of information and assumptions made in this analysis are given in Table II. The previous experience for selecteo sites in alluvium in southern Area 2 and western Area 4 is shown in Table III, and graphically in the histograms Figs. 1 and 2.

All of the properties measured and calculated at U4ak are within the range of previous experience for these areas. Slightly high H.P. water content and porosity are simflar to those measured at the nearby U4ai (BURZET) site, whose H.P. was in tuffaceous alluvium at a similar depth $(450 \mathrm{~m})$. However, Burzet's averaging interval went into the Armonia Tanks unit, which has lower density and lower veloctity and of course, the averaging interval properties ref lect this.

\section{Figure A-3.}

OEAAE

GEIERATED ER/09/at

DATA GULARY TOR VP $.44 .6 \mathrm{n}=445 \mathrm{~m}$ U4ak

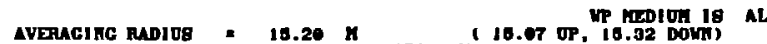
AVERACITC RADI08

\begin{tabular}{|c|c|c|c|c|c|c|c|c|c|c|c|c|}
\hline PANLLTER & vaLes & DN1Te & $\begin{array}{l}\text { no. } \\
\text { PoInte }\end{array}$ & $\underset{\text { DEV }}{\text { ETP }}$ & DETImatED & DATA & A-RAnC: & DEPTE-R & ARCE & $\begin{array}{c}\text { Averacino } \\
\text { IETE OD }\end{array}$ & LOG-TYPL & $\begin{array}{l}\text { RDT } \\
\text { no. }\end{array}$ \\
\hline 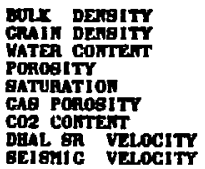 & $\begin{array}{l}1.84 \\
2.54 \\
16.1 \\
89.6 \\
74.3 \\
19.1 \\
1.6 \\
2181 . \\
189 .\end{array}$ & 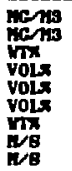 & $\begin{array}{l}181 \\
10 \\
\text { if } \\
\text { if } \\
\text { it } \\
\text { it }\end{array}$ & $\begin{array}{l}0.18 \\
0.04 \\
2.2 \\
\vdots: \\
\text { i.: } \\
\text { sis. }\end{array}$ & $\begin{array}{r}0.09 \\
6.1 \\
0.7 \\
3.1 \\
9.7 \\
4.6 \\
6.6 \\
290 .\end{array}$ & 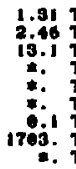 & 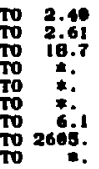 & $\begin{array}{l}428.9 \mathrm{T0} \\
431.9 \mathrm{T0} \\
491.9 \mathrm{T0} \\
428.9 \mathrm{~T} \\
428.9 \mathrm{T0} \\
428.9 \mathrm{T0} \\
481.6 \mathrm{T0} \\
429.6 \mathrm{T0} \\
411.5 \mathrm{TO}\end{array}$ & $\begin{array}{l}458.8 \\
457.2 \\
467.2 \\
459.3 \\
459.3 \\
459.3 \\
457.2 \\
497.2 \\
472.4\end{array}$ & $\begin{array}{l}\text { Int } \\
\text { nurt } \\
\text { nuth } \\
\text { cALc } \\
\text { CALE } \\
\text { CALC } \\
\text { nut } \\
\text { int } \\
\text { int }\end{array}$ & 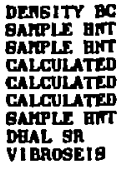 & 1,2 \\
\hline
\end{tabular}

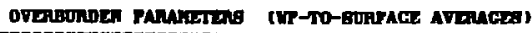

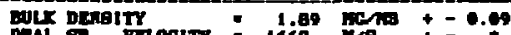

Dal on Vacits: 1668. WB $+=$ BeIsic vacity $=1640$ Ho $t-6$
Zones of swelling clay

greater than $20 x$

$381 \mathrm{~m}$. U4ak cuttings sample

BULT DENBITY IS YATER-COAREGTED

Figure A-4. 
PHYSICAL PROPERTIES DISTRIBUTION FOR SELECTED W.P. IN UNSATURATED ALLUVIUM, AREA 4 AND SOUTHERN AREA 2
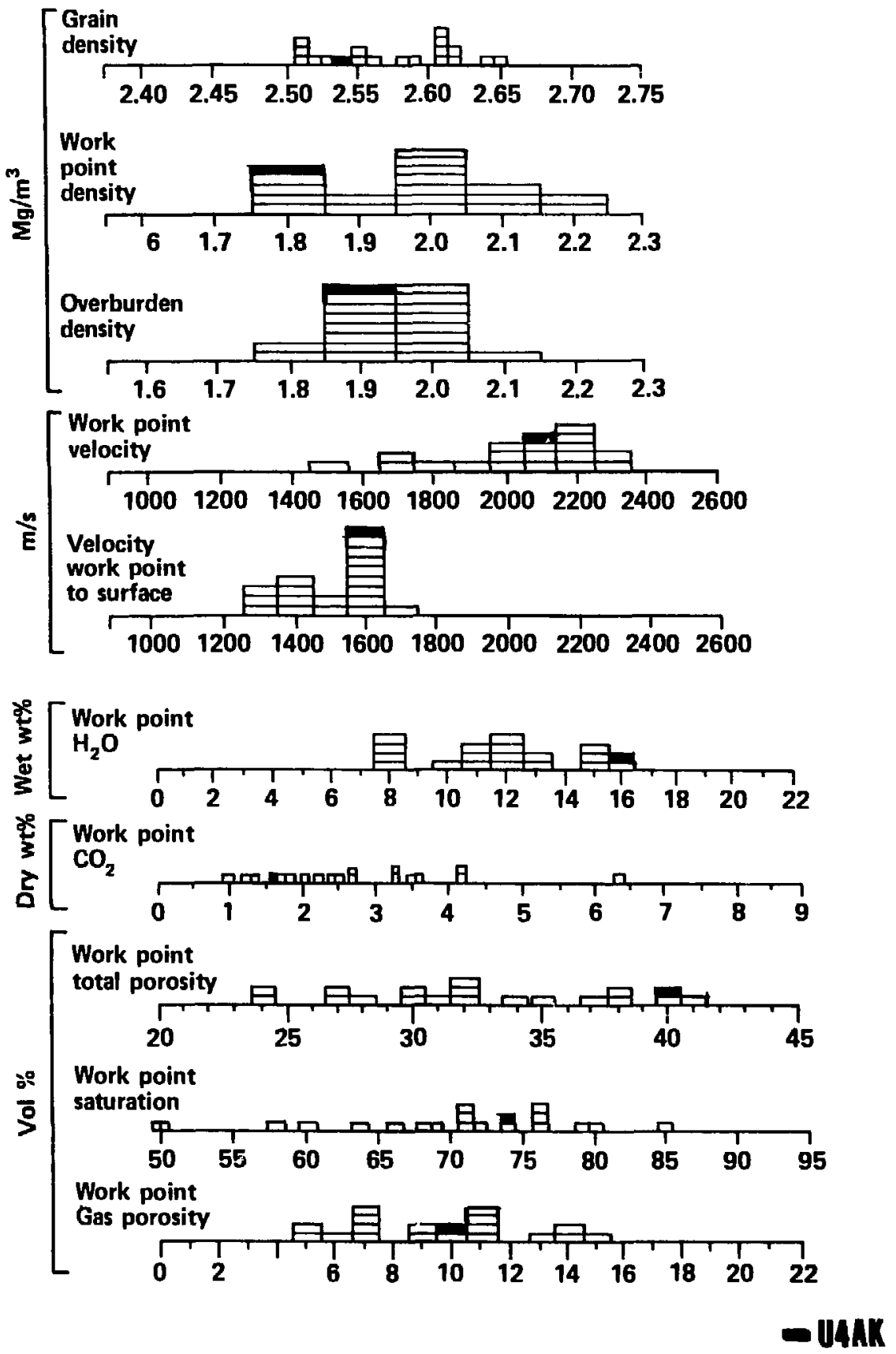

Figure A-5. 


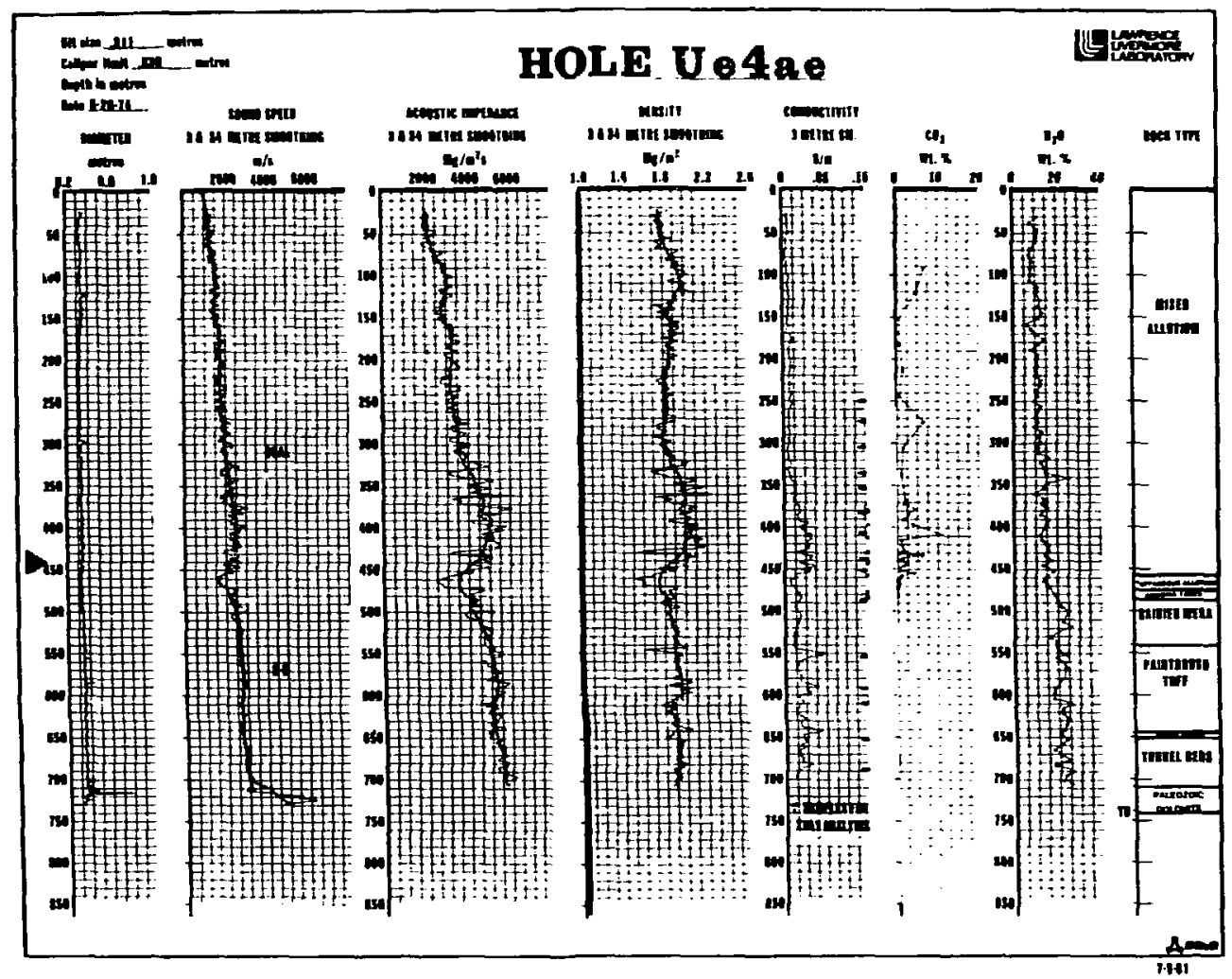

Figure $A-6$.

SOUTHWESTERN AREA 2 AND WESTERN AREA 4

ALLUVIUM CHARACTERISTICS SUMMARY

\begin{tabular}{|c|c|c|c|c|c|c|c|c|c|c|c|}
\hline Hole & H.P. & $\begin{array}{l}\text { Dens } \\
\text { Overburden }\end{array}$ & $\begin{array}{l}\text { ty. } M g / \\
\text { H.P. }\end{array}$ & $\begin{array}{l}n^{3} \\
\text { Grain }\end{array}$ & $\begin{array}{l}\text { Velocit } \\
\text { W.P. to Sur } \\
\end{array}$ & $\begin{array}{l}y \mathrm{~m} / \mathrm{s} \\
\mathrm{H.P}\end{array}$ & $\begin{array}{l}\mathrm{Ht} x \\
-\mathrm{H}_{2} \mathrm{O}\end{array}$ & 1 & $\begin{array}{c}\text { Yol } x \\
\text { Sat }\end{array}$ & Gas & $\begin{array}{l}\text { Ht } \mathrm{x} \\
\mathrm{CO}_{2}\end{array}$ \\
\hline U2dh-2 & 198 & 1.80 & 2.10 & 2.62 & 1280 & 1740 & 8 & 27 & 58 & 11 & 2.7 \\
\hline U2dh-3 & 259 & 1.90 & 2.10 & 2.61 & 1370 & 2260 & 10 & 27 & 76 & 7 & 6.3 \\
\hline U2di & 331 & 2.00 & 2.00 & 2.52 & 1646 & 2073 & 13 & 30 & 85 & 5 & 2.2 \\
\hline U2dk & 323 & 2.00 & 2.00 & 2.59 & 1585 & 2195 & 11 & 35 & 60 & 14 & 2.5 \\
\hline U2dI & 331 & 2.00 & 1.90 & 2.53 & 1645 & 2195 & 12 & 34 & 66 & 11 & 3.5 \\
\hline U2dm & 326 & 2.00 & 2.00 & 2.56 & 1615 & 1961 & 12 & 32 & 76 & 7 & 3.3 \\
\hline U2dn & 204 & 1.90 & 2.20 & 2.62 & 1280 & 1525 & 8 & 24 & 71 & 7 & 2.0 \\
\hline U2do & 326 & 1.90 & 2.00 & 2.58 & 1585 & 2350 & 12 & 32 & 72 & 9 & 3.3 \\
\hline U2dp & 296 & 2.00 & 2.10 & 2.61 & 1494 & 2134 & 11 & 28 & 80 & 5 & 4.2 \\
\hline U2du & 183 & 1.80 & 2.00 & $2.61 *$ & 1340 & 2070 & 8 & 30 & 50 & 15 & 1.2 \\
\hline U2 dv & 466 & 2.00 & 2.00 & $2.65^{\star}$ & 1615 & 1890 & 11 & 32 & 71 & 9 & 4.2 \\
\hline U2d & 374 & 2.00 & 2.00 & $2.61 *$ & 1554 & 2225 & 12 & 31 & 79 & 7 & 3.6 \\
\hline U2dn & 272 & 2.00 & 2.20 & $2.64 *$ & 1402 & 1951 & 8 & 24 & 76 & 6 & 2.4 \\
\hline U2dz & 536 & 2.08 & $1.88 *$ & $2.55 \star$ & 1747 & 2204 & 15 & 37 & 74 & 10 & 1.8 \\
\hline U4 ad & 263 & 1.90 & 1.80 & $2.51^{*}$ & 1500 & 2175 & 15 & 38 & 71 & 11 & 1.7 \\
\hline UAab & 263 & 1.90 & 1.80 & $2.51^{\star}$ & 1425 & 1975 & 13 & 38 & 64 & 14 & 1.0 \\
\hline U4 af & 208 & 1.87 & $1.80 *$ & $2.55^{\star}$ & 1388 & 1752 & 15 & 40 & 68 & 13 & 2.7 \\
\hline U4a 1 & 450 & 1.92 & $1.77 *$ & $2.51 *$ & 1589 & 1725 & 16 & 41 & 69 & 11 & 1.3 \\
\hline U4ak & 445 & 1.89 & $1.83^{*}$ & $2.54^{\star}$ & 1600 & 2141 & 16 & 40 & 74 & 10 & 1.6 \\
\hline
\end{tabular}

Figure A-7. 


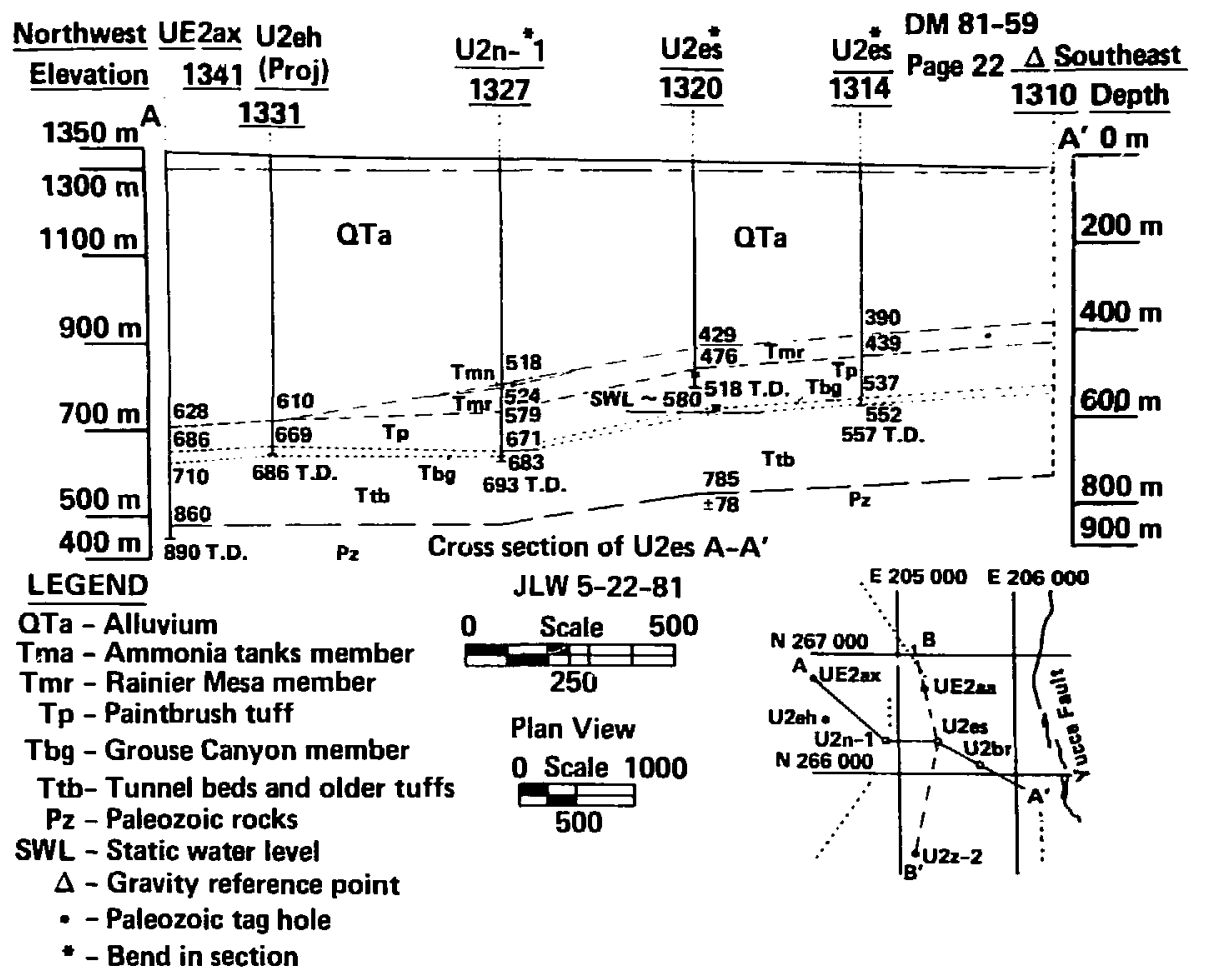

Figure A-8.

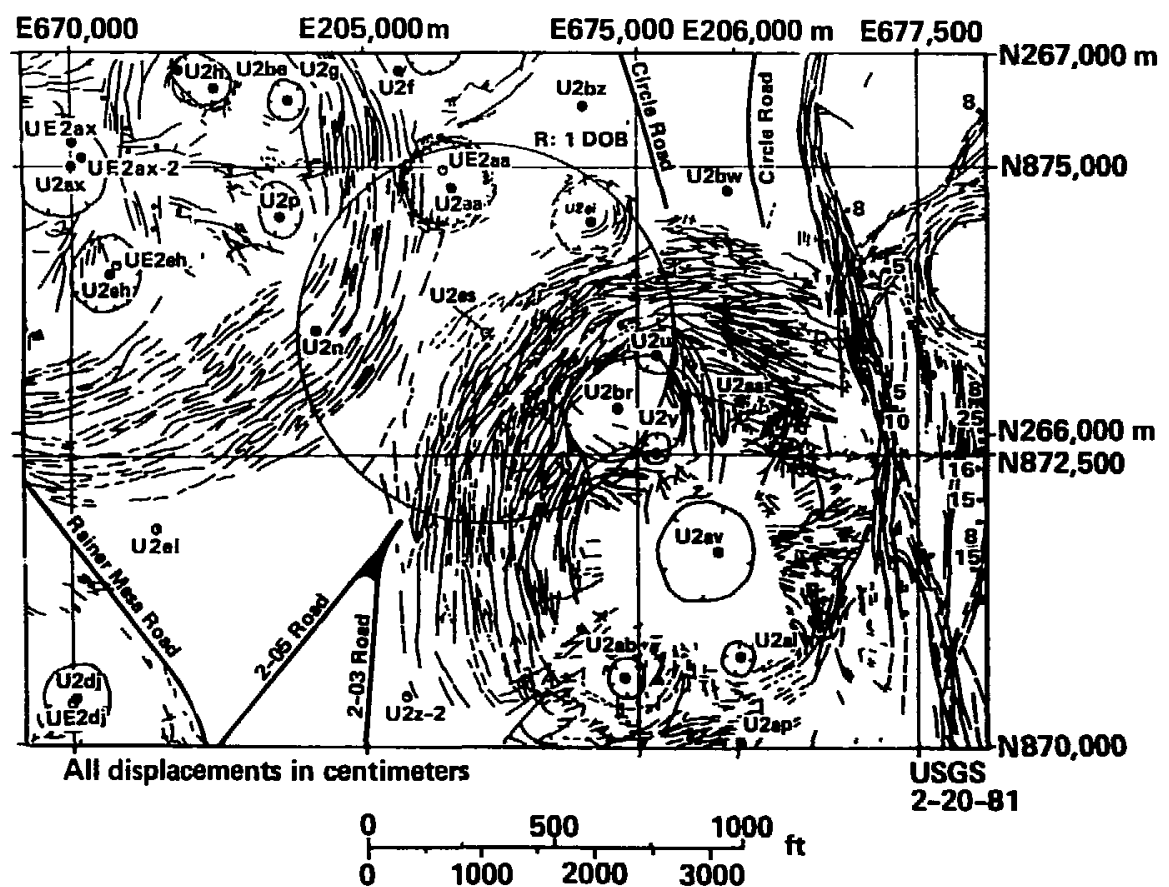

Pre-shot location map of the U2es site

Figure A-9. 
The emplacement hole, U2es, was spudded 1-5-81 and completed to a depth of $518 \mathrm{~m}$ on 1-29-81. Some sloughing has occurred, and there is $\mathrm{fill}$ in the hole whose depth is now $508 \mathrm{~m}$. The hole's condition has been monttored with monthly caliper logs. Kuutine Birdwell geophysical logs were taken 1-23-81, through 3-8-81, and LLL-N logs from 3-18-81 to 8-21-81. The hole was sidewall sampled $2-15 / 18-81$.

\section{MEDIUA CHARACTERISTICS}

Mediun characteristizs, tabulated in Table 1 , for a 19.1 radius averaging interval certered at $494 \mathrm{~m}$ in Paintbrush Tuff in U2es are derived from logs and samples from the emplacement hole. The sources of information and assumptions made in this analysis are shown in Table 11 .

Table Ill contains the previous experience for work points in unsaturated tuff of northern yucca Flat, and that experfence is graphically depicted in histograms on Figs. I and 2. All the properties are with in prevtous experience.

Figure $\mathrm{A}-10$.

0208

CEIBUTED cazo/ai

Duta ENTuRY ron yr. $494.0^{\circ}$ in

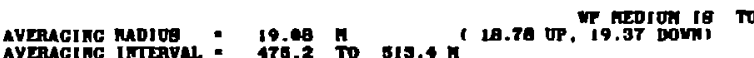

\begin{tabular}{|c|c|c|c|c|c|c|c|c|c|c|c|}
\hline Paruneton & value & OnITE & roints & $\underset{\text { DEY }}{\text { ETP }}$ & ETInaTED & DATA-maKGE & DExTg-n & Mas & $\begin{array}{l}\text { AVEMGIKE } \\
\text { FETEOD }\end{array}$ & 10E-TYRE & not \\
\hline 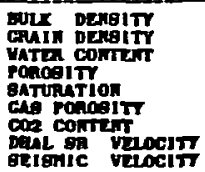 & 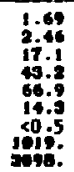 & 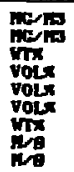 & $\begin{array}{r}101 \\
12 \\
12 \\
12 \\
12 \\
12 \\
\vdots \\
8\end{array}$ & 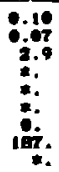 & $\begin{array}{c}6.08 \\
0.9 \\
2.9 \\
8.1 \\
4.4 \\
\vdots \\
0.1\end{array}$ & 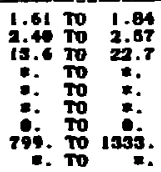 & 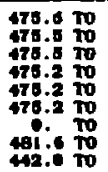 & 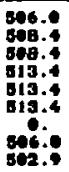 & 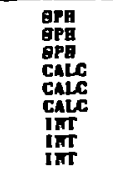 & 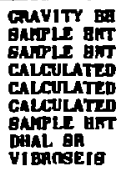 & $\begin{array}{l}2 \\
1\end{array}$ \\
\hline
\end{tabular}

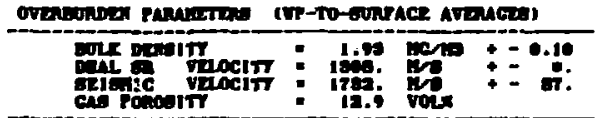

Zones of wellins clay greater then 208 : Ione detected

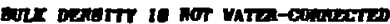

Figure A-11. 
PHYSICAL PROPERTIES DISTRIBUTION FOR SELECTED W.P. IN UNSATURATED TUFF
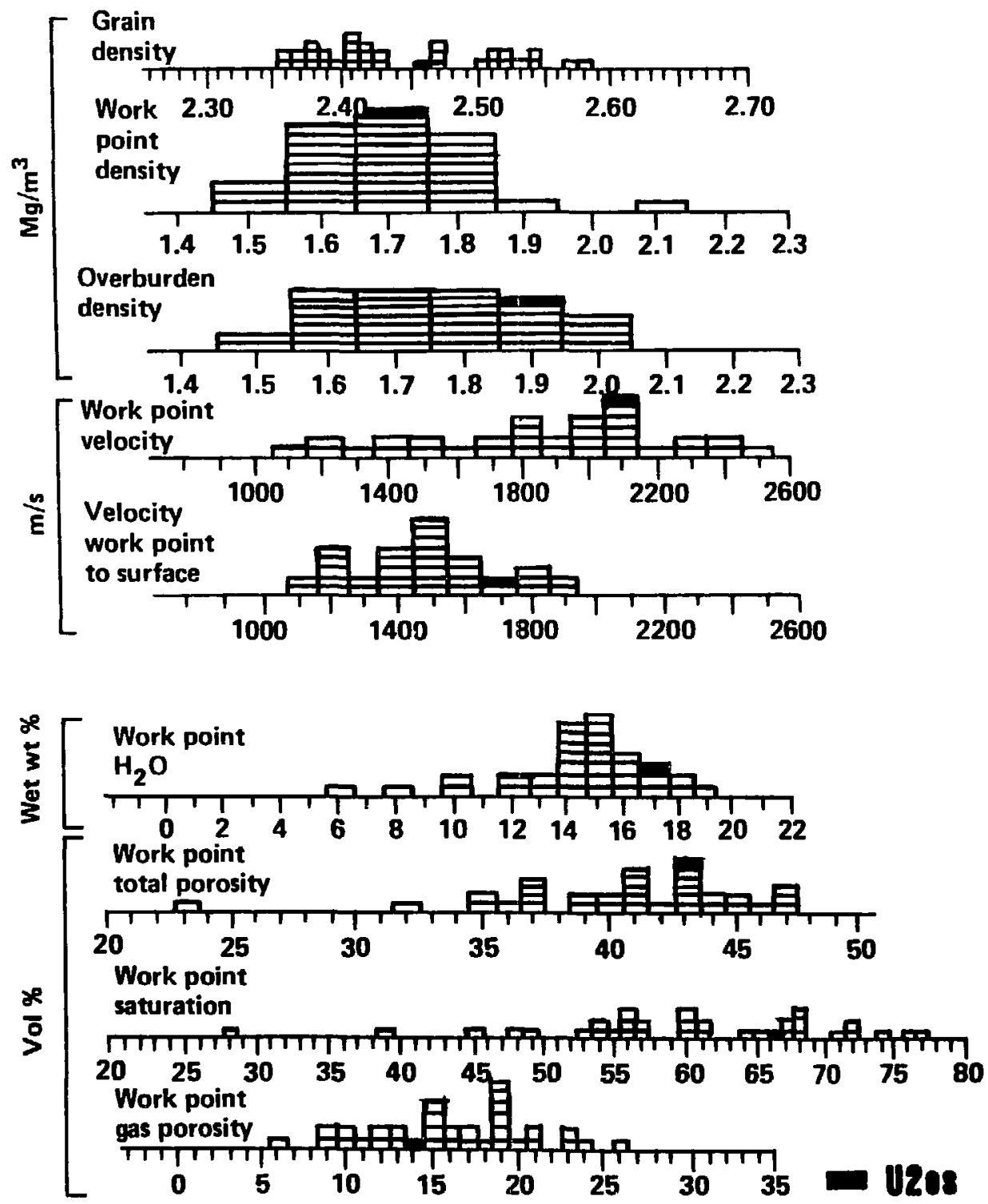

Figure A-12. 


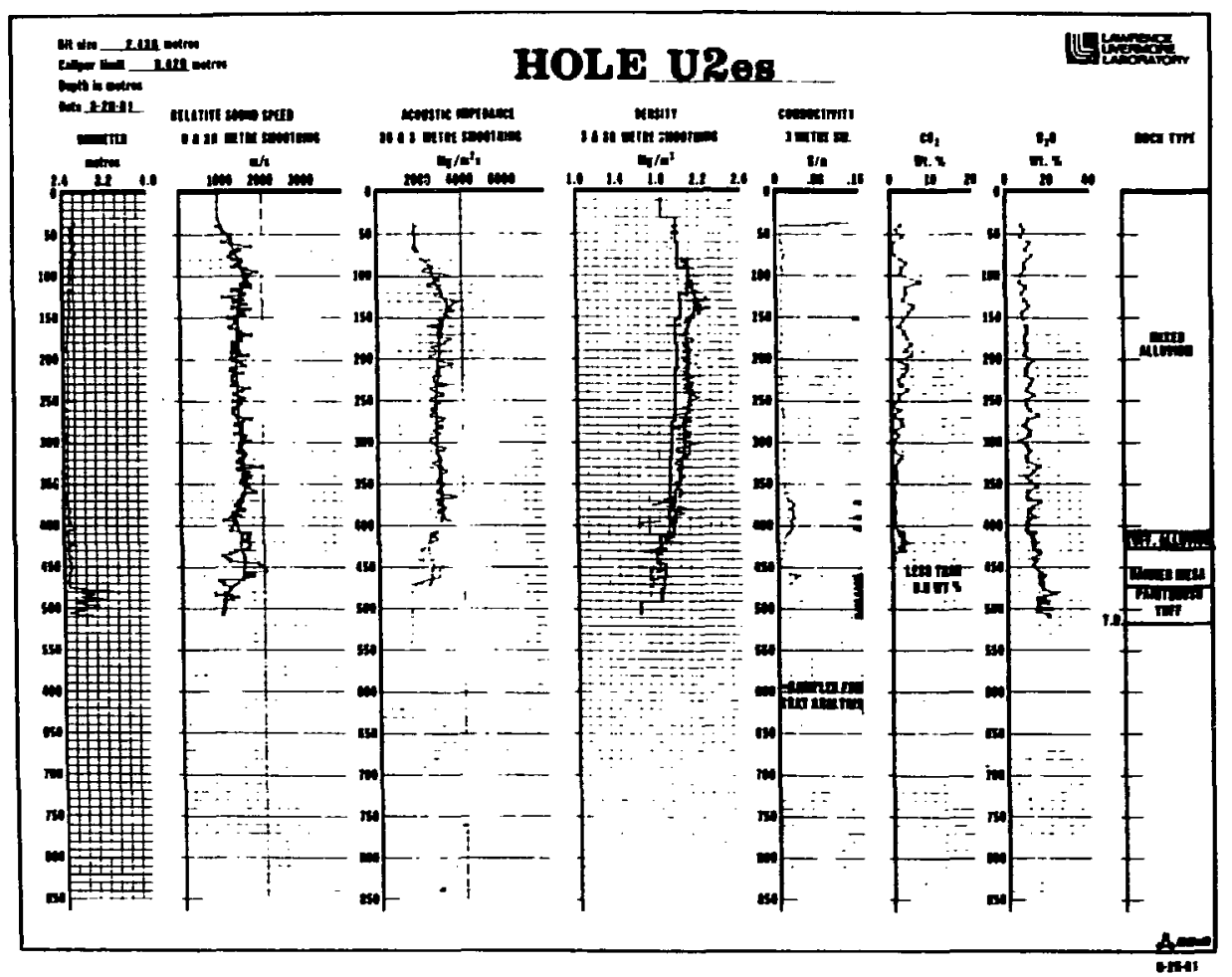

Figure A-13.

PREVIOUS GEOLOGIC EAPERIENCE UNSATURATED TUFF

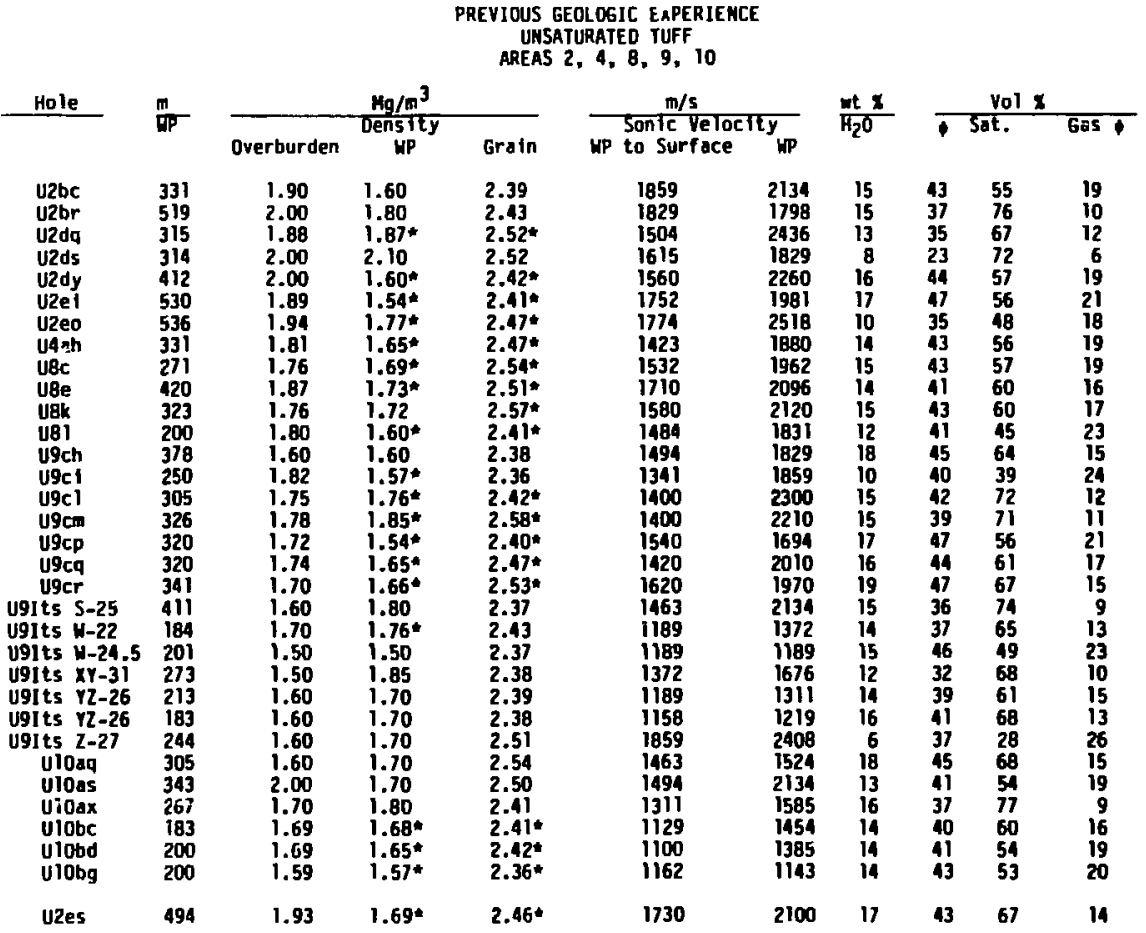

-water corrected density

NHH $7 / 31 / 81$

Figure A-14. 
APPENDIX B

SHEAR STRENGTH DATA FOR TUFFS AND ALLUVIUM

OF THE NEVADA TEST SITE AND ITS VICINITY

Figures B-1 to B-11: tuffs.

Figures B-12 \& B-13: alluviums. 


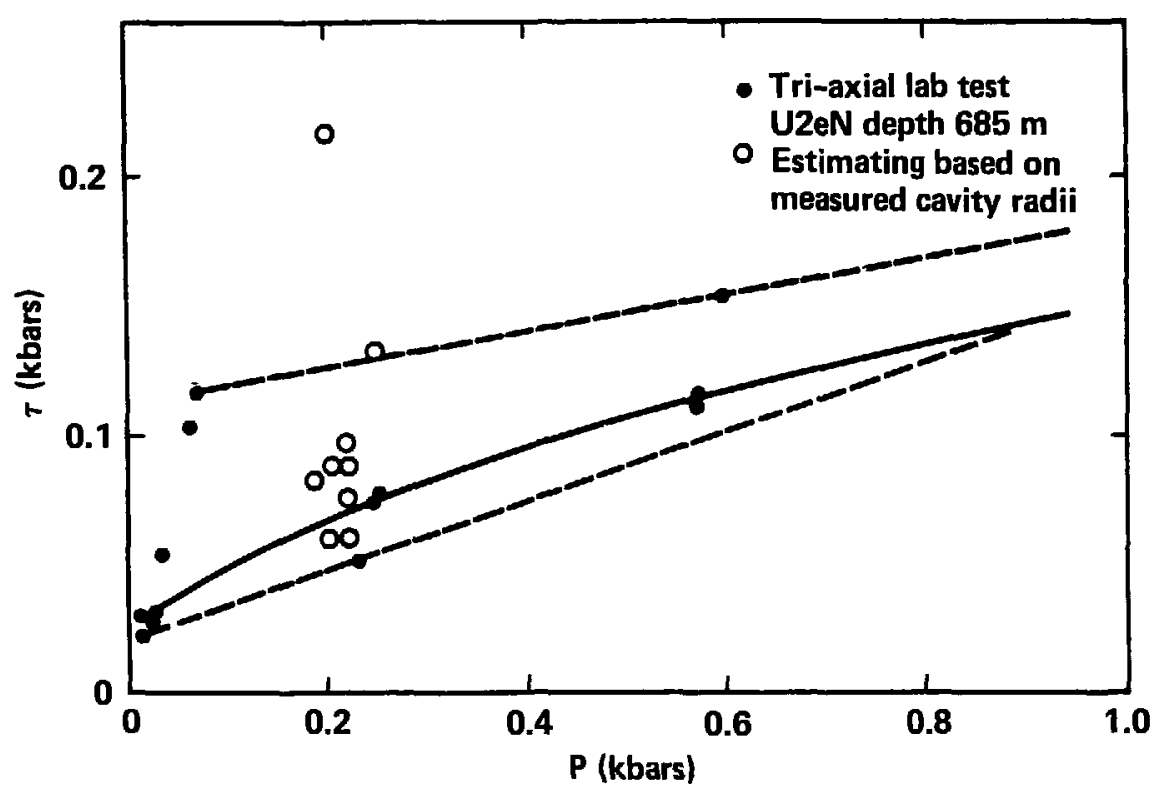

Figure B-1. Area 2.60

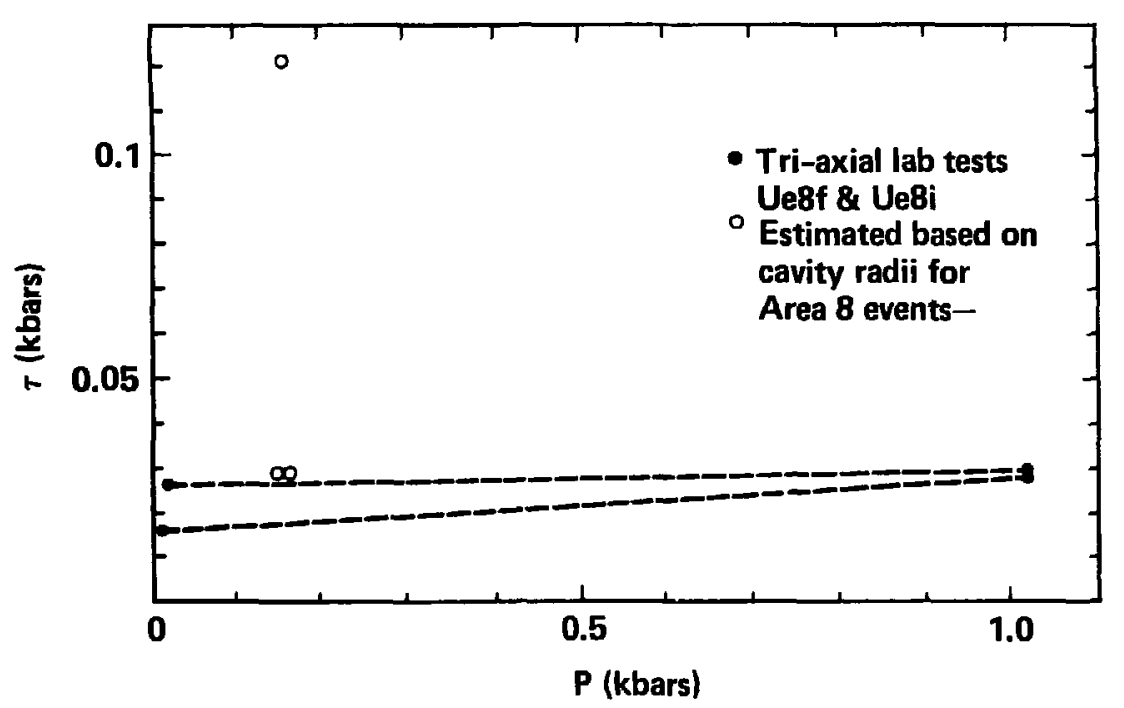

Figure B-2. Area 8. 60 


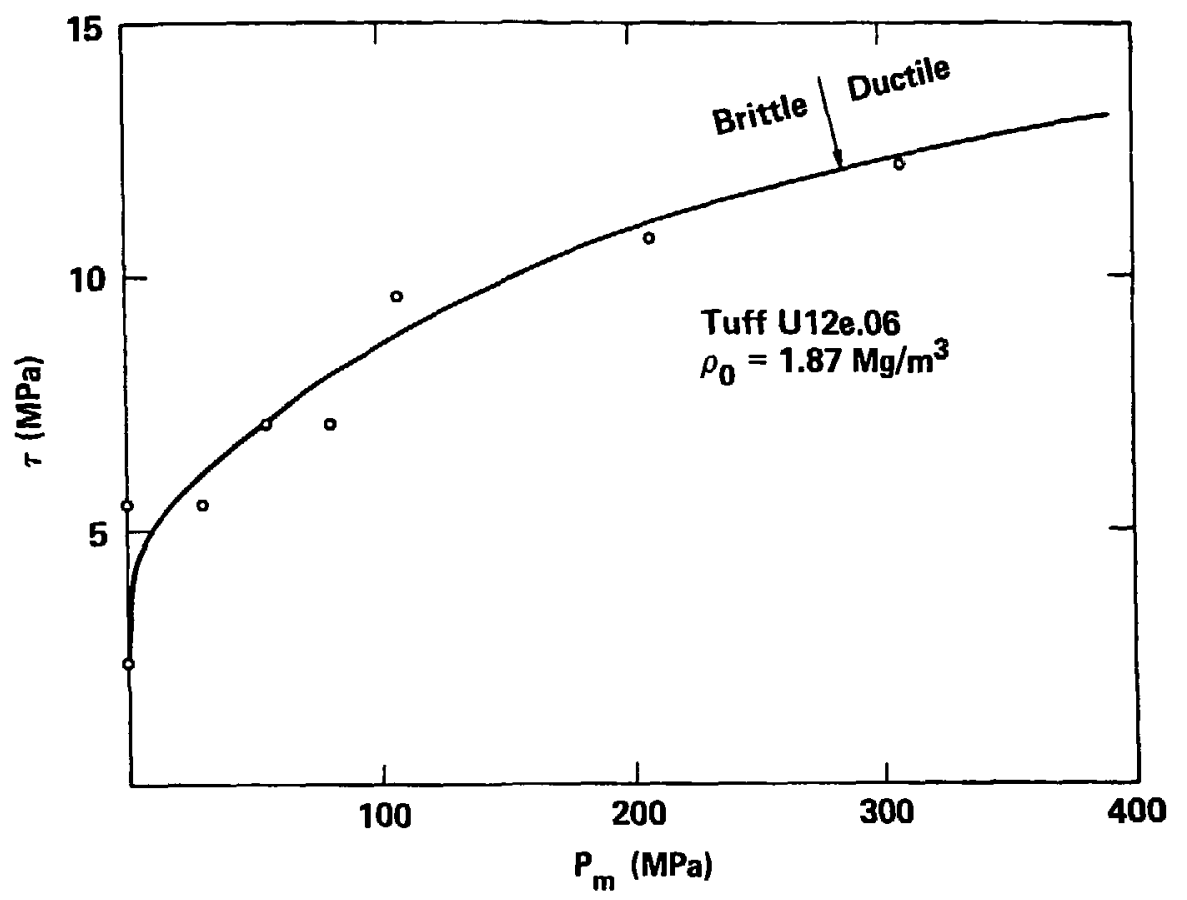

Figure B-3. Area 12.27

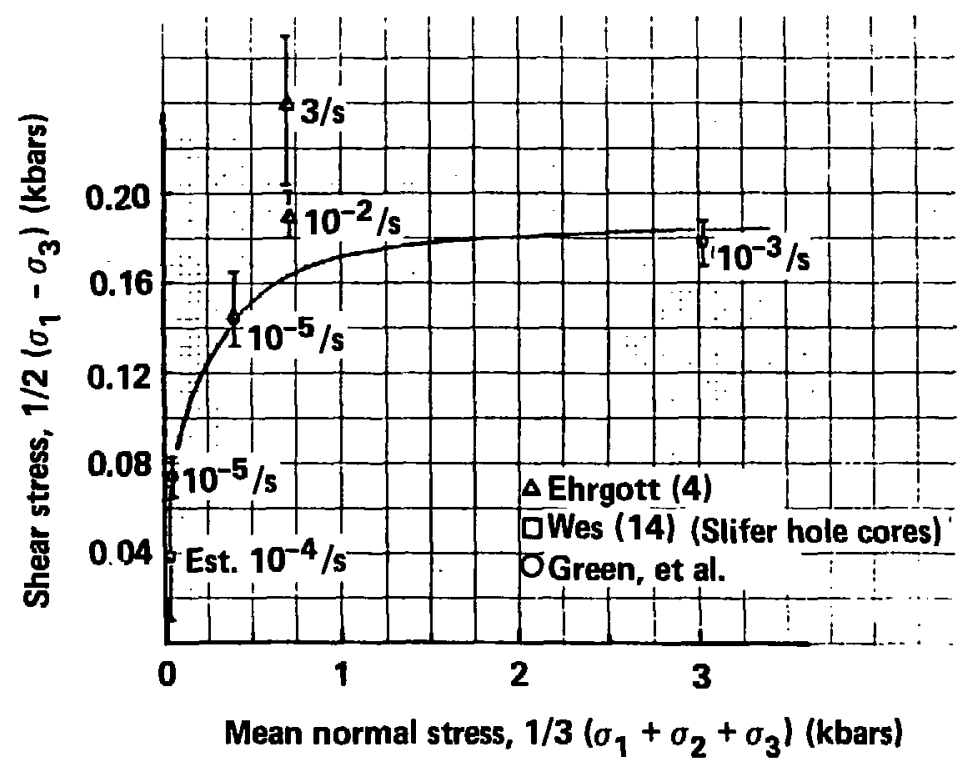

Figure B-4. Area 12.25 


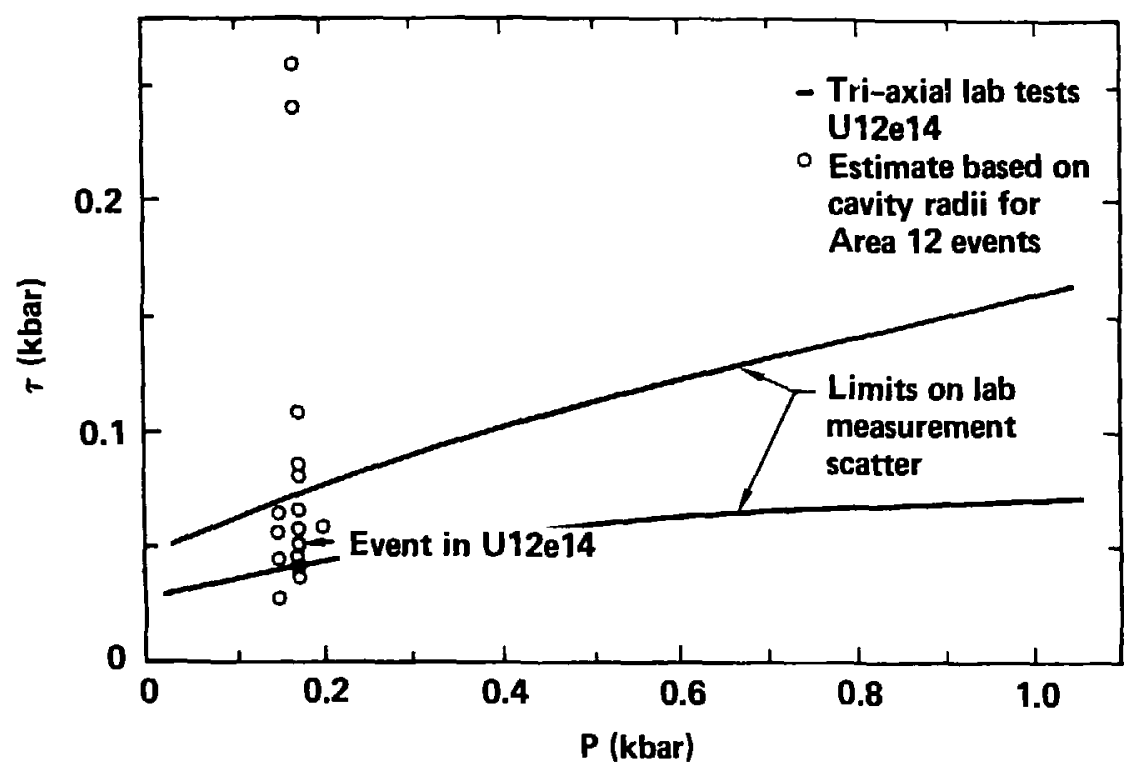

Figure B-5. Area 12.60

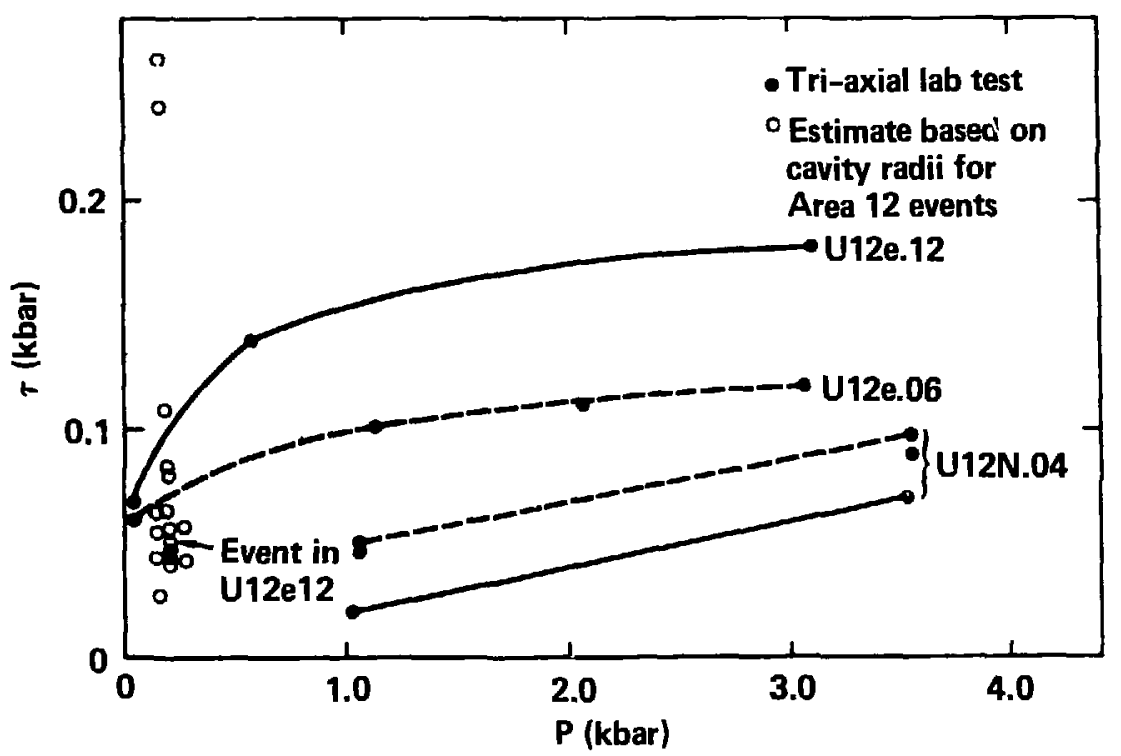

Figure B-6. Area 12.60 


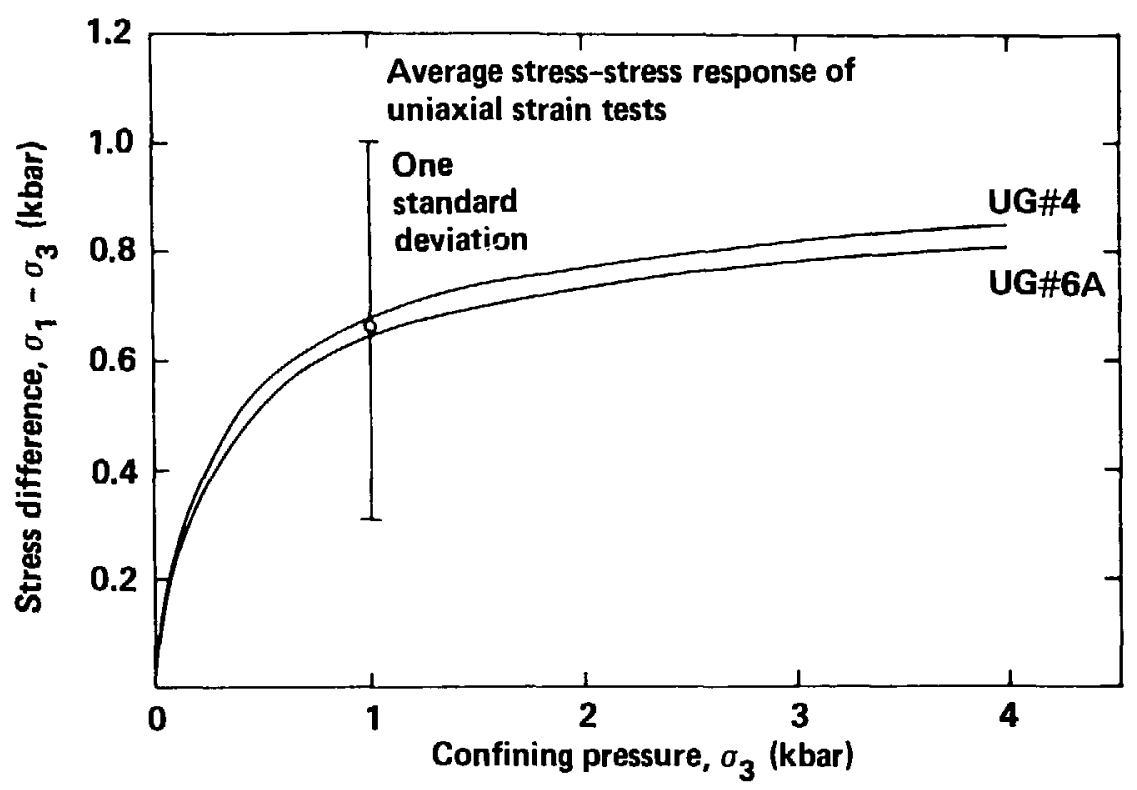

Figure B-7. Area $12 .{ }^{31}$

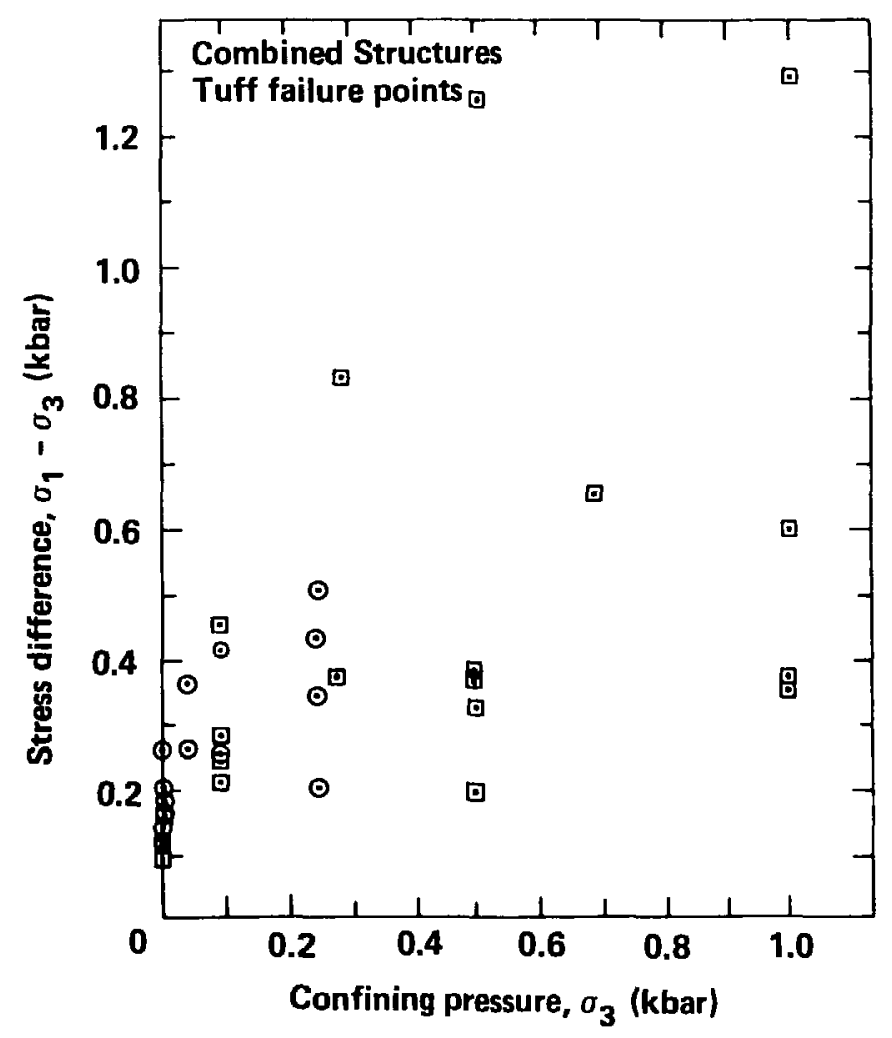

Figure B-8. Area 12. 31 

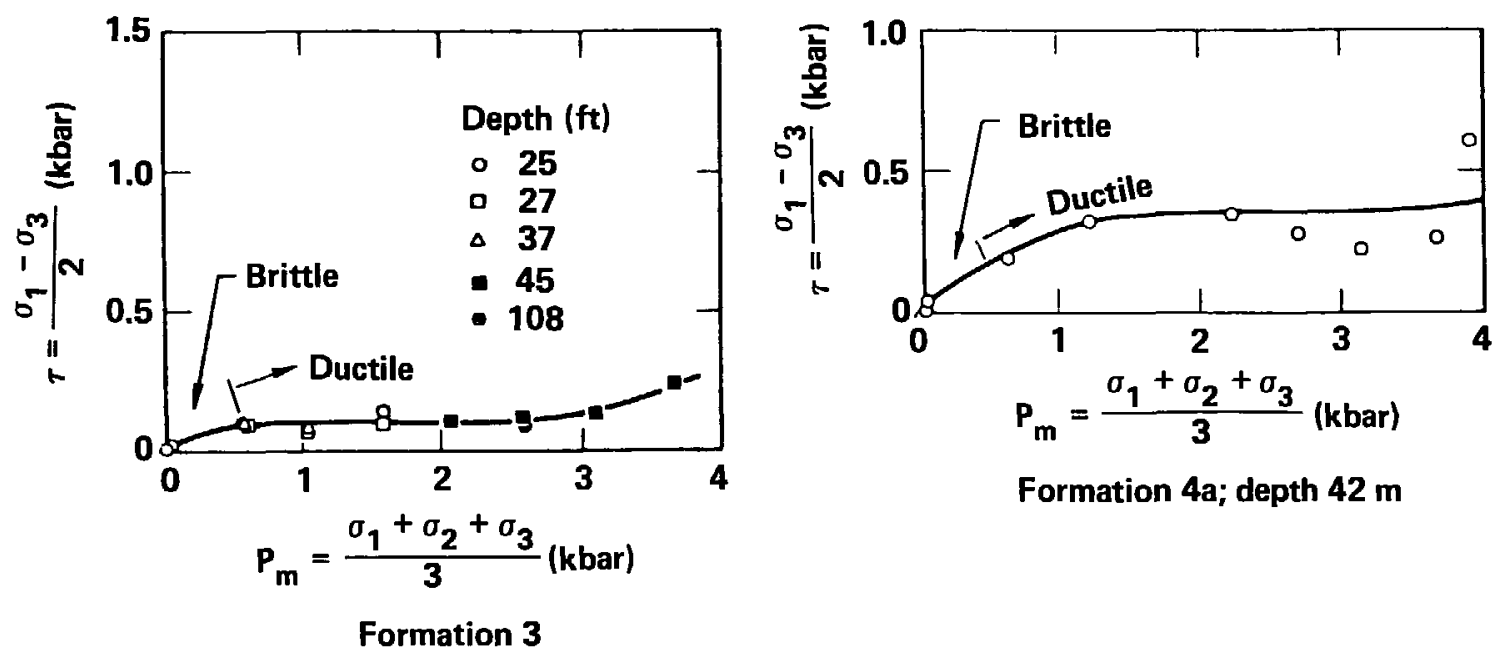

Formation 4a; depth $42 \mathrm{~m}$

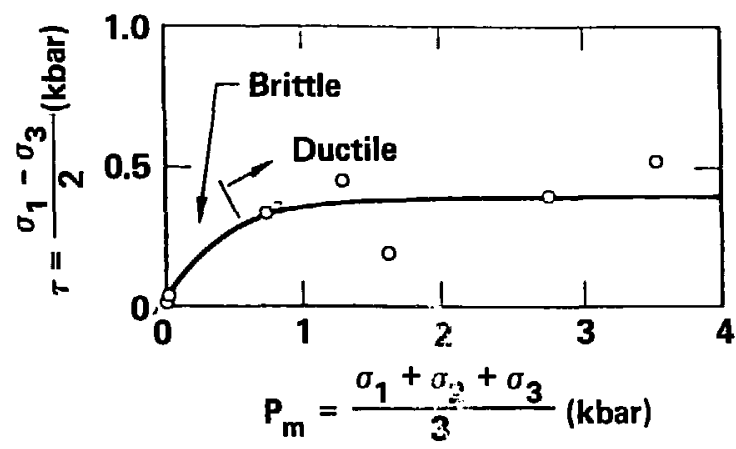

Formation 4a; repth $107 \mathrm{~m}$

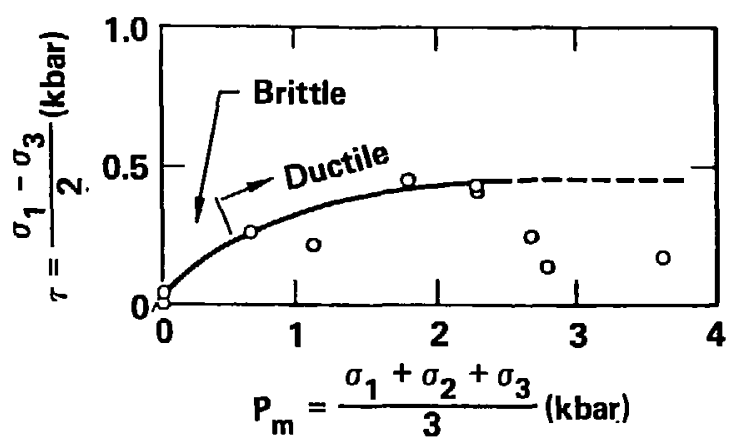

Formation 4a; depth $110 \mathrm{~m}$

Figure B-9. Area 16 - Diamond dust. ${ }^{22}$ 

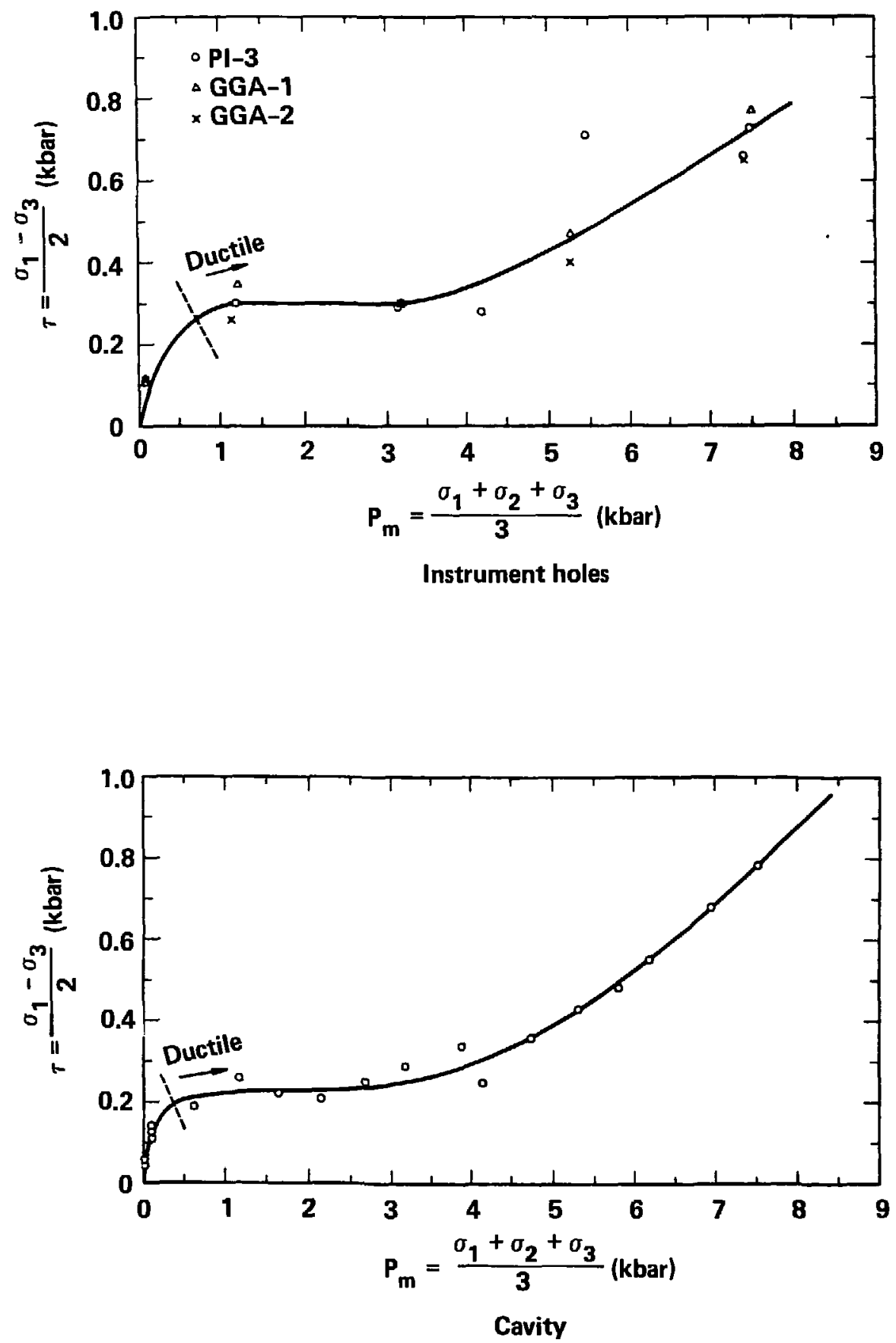

Figure B-10. Area 16 - Diamond Mine locations. ${ }^{24}$ 


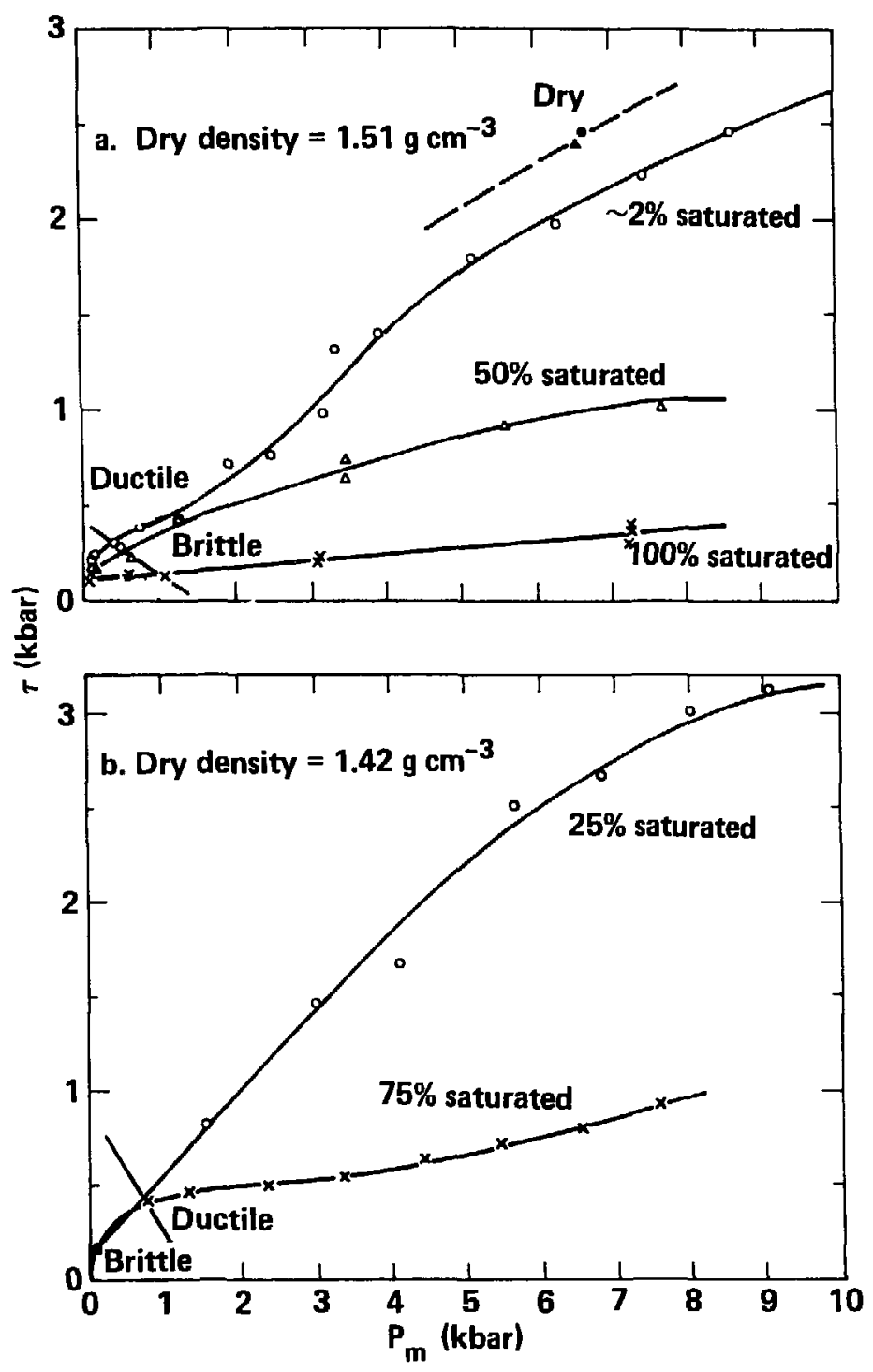

Figure B-11 Mt. He1en location. 29 

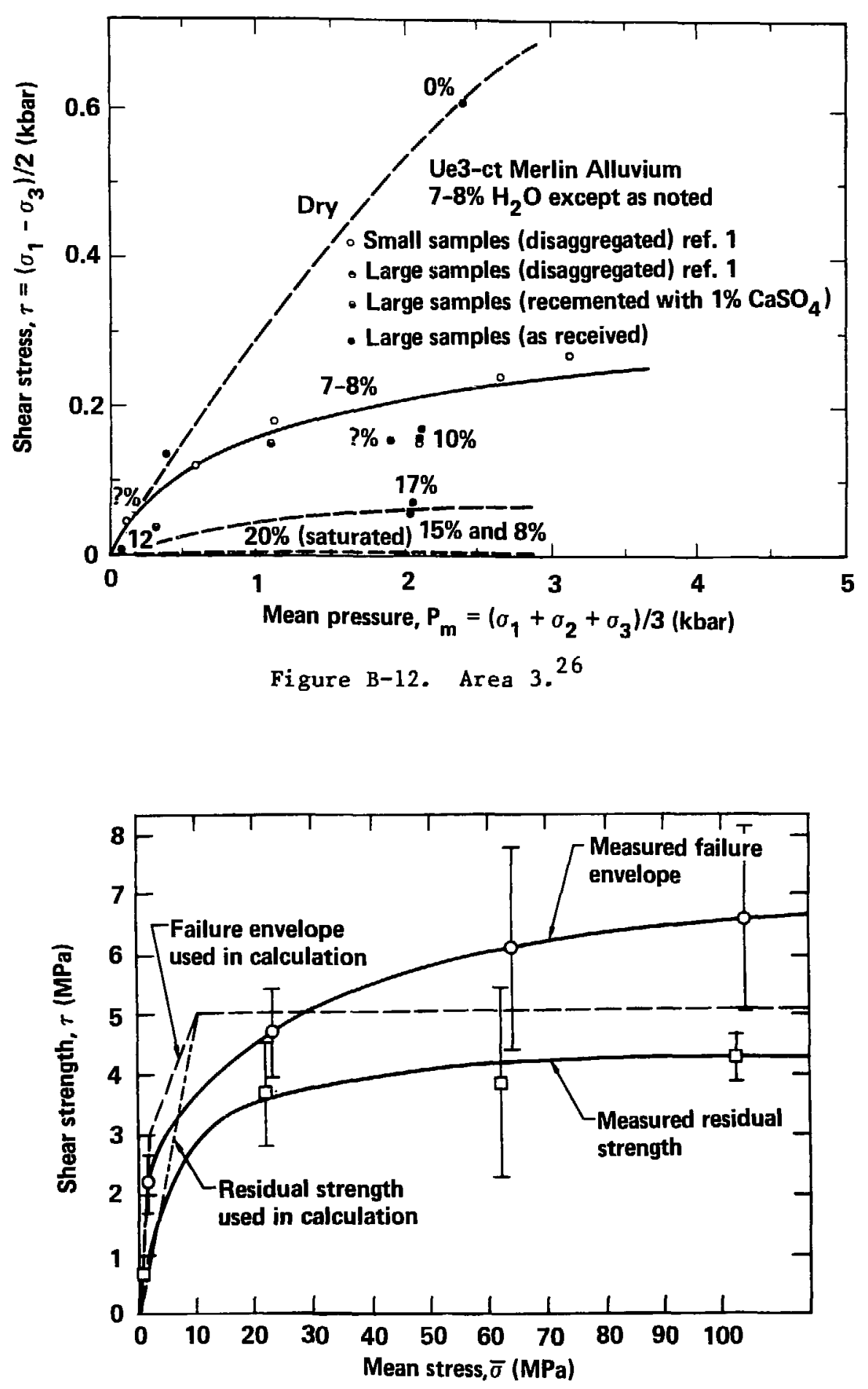

Figure B-13. Area 4.59 
1. R. W. Terhune, Analysis of Burial Depth Criteria for Containment, Lawrence Livermore National Laboratory, Livermore, CA, UCRL-52395 (1978).

2. R. W. Terhune, H. D. Glenn, D. E. Burton, H. L. Mckague, and J. T. Rambo, Calculational Examination of the Baneberry Event, Lawrence Livermort National Laboratory, Livermore, CA, UCRL-52365 (1977).

3. R. C. Carlson and J. R. Hearst, Physical Properties of (Mostly Northern) Yucca Flat Alluvium and Tuff, Lawrence Livermore National Laboratory, Livermore, CA, UCID-15848 (1971).

4. L. D. Ramspott and N. W. Howard, Average Properties of Nuclear Test Areas and Media at the USERDA Nevada Test Site, Lawrence Livermore National Laboratory, Livermore, CA, UCRL-51948 (1975).

5. R. W. Terhune and R. C. Carlson, site Characterization Requirements for Nuclear-Cratering Design, Lawrence Livermore National Laboratory, Livermore, CA, UCRL-52253 (1977).

6. N. W. Howard, U20ad - Preliminary Site Characteristics Summary, Lawrence Livermore National Laboratory, Livermore, CA, Internal Memorandum DM 79-6 (February 5, 1979).

7. J. L. Wagoner and L. D. Rams pott, Results of Exploratory Drill Hole Ue7nS, East-Central Yucca Flat, Nevada Test Site, Lawrence Livermore National Laboratory, Livermore, CA, UCID-18979 (1981).

8. N. W. Howard, U4ak - Preliminary Site Characteristics Summary, Lawrence Livermore National Laboratory, Livermore, CA, Internal Memorandum DM 81-54 (July 9, 1981).

9. N. W. Howard, U2es - Preliminary Site Characteristics Sumnary, Lawrence Livermore National Laboratory, Livermore, CA, Internal Memorandum DM 81-59 (August 4, 1981).

10. H. H. Einstein, G. B. Baecher, and R. C. H’rschfeld, "The Effect of Size on Strength of a Brittle Rock," Proc. 2nd Congress Int. Soc. Rock Mech., Belgrade, 1970, vol. 2, paper 3-2.

11. R. L. Stowe and D. L. Ainsworth, "Effect of Rate of Loading on Strength and Young's Modulus of Elasticity of Rocks," Proc. 10th Symposium on Rock Mechanics Austin, Texas (Port City Press, Baltimore, MD, 1972), pp. 3-34. 
12. S. J. Green and R. D. Perkins, "Uniaxial Compression Tests at Varyirg Strain Rates on Three Geologic Materials," Proc. 10th Symposium on Rock Mechanics Austin, Texas (Port City Press, Baltimore, MD, 1972), Pp. 35-54.

13. F. E. Heuze, "Scale Effects in the Measurement of Rock Mass Strength and Deformability," Rock Mechanics 12, 167-192 (1980).

14. N. Barton and S. Bandis, "Some Effects of Scale cn the Shear Strength of Joints," Int. J. Rock Mechanics and Mining Science 17, 69-73 (1980).

15. D. U. Deere, A. J. Hendron, F. D. Patton, and E. J. Cording, "Design of Surface and Near-Surface Construction in Rock," Proc. 8 th Symposium on Rock Mechanics Minneapolis, Minn. (Port City Press, Baltimore, MD, 1966), Pp. 237-302.

16. F. E. Heuze, The Design of Room and Pillar Structures in Competent Jointed Rock. Example: The Crestmore Mine, California, D. Eng., Civil Engineering, dissertation, University of California, Berkeley, CA (1970).

17. J. M. Raphael and R. E. Goodman, "Strength and Deformability of Highly Fractured Rock," ASCE J. Geotech. Eng. Div., GT 11 (1979).

18. Y. Fujiwara and S. Hibino, "Evaluation of Dynamic Properties of Rock Foundation by Cyclic Loading Test," Proc. ISRM Symp. on Weak Rocks, Tokyo, Sept. 1981, vol. 5, pp. 49-54.

19. D. R. Stephens, E. M. Lilley, and H. Louis, Pressure-volume Equation of State of Consolidated and Fractured Rock to $40 \mathrm{kbars}$, Lawrence Livermore National Laboratory, Livermore, CA, UCRL-71238 (1969).

20. D. R. Stephens, H. Louis, and E. M. Lilley, Pressure-Volume Relationships for Tuffs and Rhyolites from the Nevada Test Site, Lawrence Livermore National Laboratory, Livermore, CA, UCRL-50578 (1969).

21. D. R. Stephens, H. Louis, and E. M. Lilley, Loading-Unloading P-V Curves for Tuffs from the Nevada Test Site, Lawrence Livermore National Laboratory, Livermore, CA, UCRL-50554 (1969).

22. D. R. Stephens, H. C. Heard, and R. N. Schock, High-Pressure Mechanical Properties of Tuff from the Diamond Dust Site, Lawrence Livermore National Laboratory, Livermore, CA, UCRL-50858 (1970).

23. D. R. Stephens, H. C. Heard, and R. N. Schock, Preliminary Equation-ofState Data for Baneberry Altered Tuff, Lawrence Livermore National Laboratory, Livermore, CA, UCID-15874 (1971).

24. H. C. Heard, R. N. Schock, and D. R. Stephens, High-Pressure Mechanical Properties of Tuff from the Diamond Mine Site, Lawrence Livermore National Laboratory, Livermore, CA, UCRL-51099 (1971). 
25. S. J. Green, R. M. Griffin, A. D. Black, S. W. Butters, S. W. Duncan, H. R. Pratt, and K. B. Watson, "High-Pressure Properties of Several Nevada Test Site Tuffs," Terratek, Salt Lake City, UT, Report to Defense Nuclear Agency, DNA-2814F (1971).

26. B. P. Bonner, A. E. Abey, H. C. Heard, and R. N. Schock, High-Pressure Mechanical Properties of Merlin Alluvium, Lawrence Livermore National Laboratory, Livermore, CA, UCRL-51252 (1972).

27. A. Duba, A. E. Abey, and H. C. Heard, High Pressure Mechanical Properties of an Area 12, Nevada Test Site Tuff, Lawrence Livermore National Laboratory, Livermore, CA, UCID-16377 (1973).

28. H. C. Heard, "Strength of Ue8i Altered Tuff, NTS," Lawrence Livermore National Laboratory, Livermore, CA, Internal Memorandum (1973).

29. H. Heard, B. P. Bonner, A. G. Duba, R. N. Schock, and D. R. Stephens, High Pressure Mechanical Properties of Mt. Helen, Nevada, Tuff, Lawrence Livermore National Laboratory, Livermore, CA, UCID-16261 (1973).

30. S. W. Butters, R. K. Droper, and A. H. Jones, Material Properties of Nevada Test Site Tuff and Grout, with Emphasis on the Mighty Epic Event, Terratek, Salt Lake City, UT, Report to Defense Nuclear Agency, DNA-4235F (1976).

31. S. W. Butters, R. L. Stowe, J. W. LaComb, and R. A. Bendinelli, Characterization of Tuff and Development of Grouts for Mighty Epic Structures Program, Terratek, Salt Lake City, UT, Report TR 76-21 (1976).

32. D. S. Gardiner, D. D. Ennis, S. W. Butters, and A. H. Jones, Material Properties of Nevada Test Site Tuff and Grout, with Emphas is on the Diablo Hawk and Hybla Gold Events, Terratek, Salt Lake City, UT, Report to Defense Nuclear Agency, LNA-4528F (1977).

33. S. W. Butters and J. W. LaComb, Effect of Shock Loading on Rock Properties and In-Situ States, Terratek, Salt Lake City, UT, Report TR 79-25 (1980).

34. M. S. Costantino and B. P. Bonner, Ultrasonic Velocities, and Strength of Frenchman's Flat Alluvium, Lawrence Livermore National Laboratory, Livermore, CA, UCID-18862 (1980).

35. F. N. App, Los Alamos National Laboratory, private communication (1981).

36. J. L. Drake, Mathematical Model for Describing Stress Wave Propagation in a Jointed Rock Mass, U.S. Waterways Experiment Station, Vicksburg, MS, Technical Report N-73-7, AD-769582 (1973). 
37. L. D. Bertholf and S.E. Benzley, TOODYII, A Computer Program for Two-Dimensional Wave Propagation, Sandia National Laboratories, Albuquerque, NM, SC-RR-68-41 (1968).

38. T. R. Butkovich and A. E. Lewis, Aids for Estimating Effects of Underground Nuclear Explosions, Lawrence Livermore National Laboratory, Livermore, CA, UCRL-50929, Rev. 1 (1973).

39. J. F. Schatz, S0C73, A One-Dimensional Wave Propagation Code for Rock Media, Lawrence Livermore National Laboratory, Livermore, CA, UCRL-51689 (1974).

40. R. C. Schroeder, A Comparison of Initial Conditions for Nuclear Explosion Calculations, Lawrence Livermore National Laboratory, Livermore, CA, UCRL-51671 (1974).

41. D. E. Rawson, The Problem of Induced Block Motion Related to Deep Underground Strategic Facilities - A Surmary, R\& D Associates, Marina del Rey, CA, Report to Defense Nuclear Agency, DNA 4078T (1977).

42. R. W. Terhune, H. D. Glenn, D. E. Burton, and J. T. Rambo, Containment Analysis for the Simultaneous Detonation of Two Nuclear Explosives, Lawrence Livermore National Laboratory, Livermore, CA, UCRL-52268 (1977).

43. J. E. Schoutens, Ed. Nuclear Geoplosics Sourcebook. Volume IV, Part I: Empirical Analysis of Ground Motion from Above and Underground Explosions, General Electric Company, TEMPO, Santa Barbara, CA, Report DNA 6501H-4-1, for Defense Nuclear Agency, p. 332 (1979).

44. R. W. Terhune, C. M. Sne11, and H. C. Rodean, Enhanced Coupling and Decoupling of Underground Nuclear Explosions, Lawrence Livermore National Laboratory, Livermore, CA, UCRL-52806 (1979).

45. S. Blouin, Block Motion from Detonations of Buried Near-Surface Explosive Arrays, U.S. Army Cold Regions Laboratory, CRREL 80-26 (1980).

46. S. Blouin, Prediction of Explosively-Driven Relative Displacements in Rocks, U.S. Army Cold Regions Laboratory, CRREL 81-11 (1981).

47. A. L. Bruce and L. A. Lettis, Jr., TENGEN User's Guide, Lawrence Livermore National Laboratory, Livermore, CA, Draft (1981).

48. D. E. Burton, TENSOR User's Guide, Lawrence Livermore National Laboratory, Livermore, CA, UCID in preparation (1981).

49. C. J. Costantino, "Two-Dimensional Wave Propagation Through Nonlinear Media," J. Comput. Physics 4, 147-170 (1969). 
50. R. V. Whitman, The Kesponse of Soils to Uynamic Loading, Massachusetts Institute of Technology Report to U.S. Army Waterways, Vicksburg, MS, Contract Report 3-26 (1970).

51. J. Isenberg, Nuclear Geoplosics, Part Two: Mechanical Properties of Earth Materials, Agbabian Associates, E1 Segundo, CA, Report for Defense Nuclear Agency, DNA 128H2 (1972).

52. T. R. Butkovich, A Technique for Generating Pressure-Volume Relationships and Failure Envelopes for Rocks, Lawrence Livermore National Laboratory, Livermore, CA, UCRL-51441 (1973).

53. T. D. Riney, G. A. Frazier, S. K. Garg, A. J. Good, R. G. Herrmann, L. W. Morland, J. W. Pritchett, M. H. Rice, and J. Sweet, Constitutive Models and Computer Techniques for Ground Motion Predictions, Systems, Science and Software, La Jo11a, CA, Report to Defense Nuclear Agency, DNA-3180F (1973).

54. I. S. Sandler, F. L. DiMaggio, and G. Y. Baladi, A Generalized Cap Model for Geological Materials, Weidlinger Associates, New York, NY, Report to Defense Nuclear Agency, DNA-3443T (1974).

55. J. B. Forrest, Soil Mechanics and the Advanced Computer Codes, Naval Civil Engineering Laboratory, Port Hueneme, CA, Report for Defense Nuclear Agency, NCEL Technical Note N-1324 (1974).

56. L. Whitman and J. P. Wright, Tensile Behavior of Geological Material in Ground Shock Calculations, Weidlinger Associates, New York, Report to Defense Nuclear Agency, DNA-3769T (1975).

57. D. E. Burton and J. F. Schatz, Rock Modeling in TENSOR74, A TwoDimensional Lagrangian Shock Propagation Code, Lawrence Livermore National Laboratory, Livermore, CA, UCID-16719 (1975).

58. D. E. Burton, L. A. Lettis, J. B. Bryan, T. R. Butkovich, and A. L. Bruce, Anisotropic Creation and Closure of Tension Induced Fractures, Lawrence Livermore National Laboratory, Livermore, CA, UCRL-79578 (1977).

59. R. W. Terhune and L. R. Moreno, Containment Calculations for Burzet, Lawrence Livermore National Laboratory, Livermore, CA, UCRL-52784 (1979).

60. R. W. Terhune and H. D. Glenn, Estimate of Earth Media Shear Strength at the Nevada Test Site, Lawrence Livermore National Laboratory, Livermore, CA, UCRL-52358 (1977).

61. Z. T. Bieniawski, "Mechanism of Brittle Fracture of Rock," Int. J. Rock Mech. and Mining Sci. 4 (4), 395-430 (1967). 
62. M. John, "Time-Dependence of Fracture Processes of Rock Materials," (in German), Proc. 3rd Congress Int. Soc. Rock Mech., Denver, Co, Nat. Acad. of Sci., vol. 2A, pp. 330-335, Washington, DC (1974).

63. R. E. Goodman, Introduction to Rock Mechanics, (John Wiley and Sons, Inc., New York, NY, 1980) Pp. 111-115.

64. E. Becker, C. K. Chan, and H. B. Seed, Strength and Deformation Characteristics of Rockfill Materials in Plane Strain and Triaxial Compression Tests, Department of Civil Engineering, University of California, Berkeley, CA, Report TE-72-3 (1972).

65. N. D. Marachi, C. K. Chan, and H. B. Seed, "Evaluation of Properties of. Rockfill Material," ASCE, J. Soil Mech. and Found. Div., SM1, 95-114 (1972).

66. R. J. Marsal, discussion, Proc. 6th Int. Conf. on Soil Mech. and Found. Eng. (1965) vol. 3, pp. 310-316.

67. R. J. Marsal, "Large Scale Testing of Rockfill Materials," ASCE J. Soil Mech. and Found. Div. 93 (SM2), 27-43 (1967).

68. R. J. Marsal, "Plane Strain Testing of Rockfill Materials," Proc. 3rd Panam. Conf. on Soil Mech. and Found. Eng. (1967) vol. 1, pp. 249-271.

69. R. E. Goodman, F. E. Heuze, R. K. Thorpe, and J. M. Chatoian, The Design of Highway Cuts in Intermediate Quality Rocks: Rock Testing Techniques Related to the Performance of Highway Cuts in Shales and Sands tones, Department of Civil Engineering, University of California, Berkeley, CA, Report to California Department of Transportation, TE-75-1 (1974).

70. H. R. Pratt, A. D. Black, W. S. Brown, and W. F. Brace, "The Effect of Specimen Size on the Mechanical Properties of Unjointed Diorite," Int. J. Rock Mechanics and Mining Science 9, 513-529 (1972).

71. M. M. Singh and P. J. Huck, "Large Scale Triaxial Tests on Rock," Proc. 14th Symposium on Rock Mechanics, Penn State University (American Society of Civil Engineers, New York, 1973) pp. 35-60.

72. 2. T. Bieniawski and W. I. Van Herdeen, "The Significance of In-Situ Tests on Large Rock Specimens," Int. J. Rock Mechanics and Mining Science 12, 101-113 (1975).

73. R. Thorpe, D. J. Watkins, W. E. Ralph, R. Hsu, and S. Flexser, Strength and Permeability Tests on Ultra-Large Stripa Granite Cores, Lawrence Berkeley Laboratory, Berkeley, CA, LBL-11203 (1980).

74. P. A. Witherspoon, "Effects of Size on Fluid Movement in Rock Fractures," Geophysical Research Letters 8 (7), 659-661 (1981). 
75. N. G. W. Cook and H. C. Heard, "Executive Summary, NSF/UCB Workshop on Large Scale Laboratory Testing in Geomechanics," Geophysical Research Letters 8 (7), 645-646 (1981).

76. Z. T. Bieniawski, "Determining Rock Mass Deformability: Experience From Case Histories," Int. J. Rock Mech. and Mining Sci. 15 (5), 237-247 (1978).

77. E. Hoek and E. T. Brown, "Empirical Strength Criterion for Rock Masses," ASCE J. Geotech. Eng. Div., GT9, 1013-1035 (1980).

78. R. W. Terhune, Lawrence Livermore National Laboratory, Livermore, CA, private communication (1981).

79. J. D. Bredehoeft, et al., "Hydraulic Fracturing to Determine the Regional In-Situ Stress Field, Piceance Basin, Colorado," Geological Society of America Bulletin 87, 250-258 (1976).

80. B. C. Haimson, "The Hydrofracturing Stress Measurement Technique, Method and Recent Field Results," Int. J. Rock Mech. and Mining Sci. 15 (4), 167-178 (1978).

81. B. C. Haimson, J. LaComb, A. H. Jones, and S. J. Green, "Deep Stress Measurements in Tuff at the Nevada Test Site," Proc. 4th Congress Int. Soc. Rock Mechanics, Denver, Colorado (National Academy Press, Washington, DC, 1974) vol. IIA, PP. 557-562.

82. C. H. Miller, A Method for Stress Determination in $N, E$, and $T$ Tunnels, Nevada Test Site, By Hydraulic Fracturing, with a Comparison of Overcoring Methods, Report for Defense Nuclear Agency, U.S. Geological Survey, Denver, CO, Report USGS-474-222 (1976).

83. B. C. Haimson, "Confirmation of Hydrofracturing Results Through Comparison with Other Stress Measurements," Proc. 22nd Symposium on Rock Mechanics, Cambridge, MA, (Massachusetts Institute of Technology, Cambridge, MA, 1981), PP. 379-385.

84. T. Doe, K. Ingevald, L. Strindell, B. Haimson, and H. Carlsson, "Hydraulic Fracturing and Overcoring Stress Measurements in a Deep Borehole at the Stripa Test Mine, Sweden," Proc. 22nd Symposium on Rock Mechanics, Cambridge, MA, (Massachusetts Institute of Technology, Cambridge, MA, 1981), pp. 373-378.

85. J. C. Roegiers, University of Toronto, Ontario, CANADA, private communication (1981).

86. A. A. Daneshy, "Hydraulic Fracturing Experiment in Well Ul0am-5, Nevada Test Site," Halliburton Services, Duncan, OK, Report F05-F012-76 (1976). 
87. R. V. De la Cruz, "Jack Fracturing Technique of Stress Measurements," Rock Mechanics, 9, 27-42 (1977).

88. R. V. De la Cruz, "Modified Borehole Jack Method for Elastic Property Determination in Rocks," Rock Mechanics 10, 221-289 (1978).

89. F. E. Heuze, W. C. Patrick, R. V. De la Cruz, and C. F. Voss, In-Situ Geomechanics, Climax Granite, Nevada Test Site, Lawrence Livermore National Laboratory, Livermore, CA, UCRL-53076 (1981).

90. R. E. Goodman, T. K. Van, and F. E. Heuze, "The Measurement of Rock Deformability in Boreholes," Proc. 10th Symposium on Rock Mechanics, Austin, TX, (American Institute of Mechanical Engineers, New York, NY, 1972) PP. 523-555.

91. F. E. Heuze and A. Salem, "Rock Deformability Measured In-Situ, Problems and Solutions," Proc. Int. Symp. on Field Measurements in Rock Mechanics (FMRM '77), Zurich, Switzerland, Pp. 575-587, (A. A. Balkema, Rotterdam, The Netherlands, 1977).

92. F. E. Heuze, "Geomechanics of the Climax Mine-By, Nevada Test Site," Proc. 22nd Rock Mechanics Symposium, Massachusetts Institute of Technology, Cambridge, MA, PP. 428-434, Massachusetts Institute of Technology Publisher (1981).

93. E. T. Brown and R. Hoek, "Trends in Relationships Between Measured In Situ Stresses and Depth," Int. J. Rock Mech. and Mining Sci., 15 (4), 211-215 (1978).

94. K. Drozd, R. E. Goodman, F. E. Heuze, and T. K. Van, "On the Problem of Borehole Strength Testing," Proc. 2nd Congress Int. Soc. Rock Mech., Belgrade (1970) vol. 2, paper 3-46.

95. R. L. Handy, et al., "Rock Borehole Shear Test," Proc. 17th Rock Mechanics Symposium, Snowbird, UT, (Utah Engineering Experiment Station, Salt Lake City, UT, 1976), Paper 4B-6.

96. L. A. Panek, "Criterion of Failure for Design of Rock Mass Structures as Determined by Borehole Shear Tests," Proc. 4th Congress Int. Soc. Rock Mech., Montreux, Switzerland, (A. A. Balkema, Rotterdam, The Netherlands 1979) vol. 2, PP. 509-515.

97. M. Butler, Nevada Test Site, private communication (1981).

98. M. Costantino, Geomechanics Experiments on Large Volume Samples, Lawrencr. Livermore National Laboratory, Livermore, CA, UCID-19061 (1981). 
99. S. E. Benzley and R. D. Krieg, A Continuum Finite Element Approach for Rock Failure and Rubble Formation, Sandia National Laboratories, Albuquerque, NM, SAND 80-0227 (1980).

100. E. U. Jegbefume and T. W. Thompson, "The Use of the Finite Element Method to Predict Roof Collapse and Subsidence Resulting from the Underground Gasification of Coal," Proc. 7 th Underground Coal Conversion Symposium, (1981), CONF-810923, pp. 209-220.

101. R. T. Langland and B. C. Trent, "Computer Models to Support Investigations of Surface Subsidence and Associated Ground Motion Induced by Underground Coal Gasification," Proc. 7 th Underground Coal Conversion Symposium, (1981), CONF-810923 pp. 234-245.

102. M. S. Agbabian, M. P. Bieniek, F. E. Heuze, D. E. Munson, D. K. Parrish, and C. St. John, "Numerical Modeling", Ch. 9, Rock Mechanics Research Requirements for Resource Recovery, Construction, and Earthquake-Hazard Reduction, (National Academy Press, Washington, DC, 1981), pp. 172-196.

103. F. E. Heuze, On the Geotechnical Modeling of High-Level Nuclear Waste Disposal by Rock Melting, Lawrence Livermore National Laboratory, Livermore, CA, UCRL-53183 (1981).

104. C. A. Anderson and R. J. Bridwe11, "A Finite Element Method for Studying the Transient Non-Linear Thermal Creep of Geological Structures," Int. J. for Numerical and Analytical Methods in Geomechanics 4, 255-276 (1980). 